, Ferwerda, S.D. Jones, G.J. Fitzgerald, D. Rodriguez, and R. Belford. 2007 K., G.J. O'Leary, J.G. Ferwerda, S.D. Jones, G.at. Field Crop. Res - 104: 77-85.

hips of Tolk, J.A. and T.A. Howell. 2008. Field water supply: Yield 1303-1313.

southern Great Plains soils. Agric. Water Manag. Turral, H., M. Svendsen, and J.M. Faures. 2009.

future. Agric. Water Manag. 97. 551-560. UNESCO. 2009. Water in a changing world. Report Ned September 30, 2010 \.

unesco.org/water/wwap/wwdr/wwdr3/ (accessed Schafer, W.R. Gill, aned G.E. Vandenberg. 1994. Advances Upadhyaya, S.K., W.J.Chancellor, J.V. Peeh, MI.

in Soil Dynamies. ASAE, S. J 198 . Irrigation system having serUpchurch, D.R., D.F. Wanjura, J.R. Mahan, J.J. Burkication SN 09/153,652

sor arrays for field mapping. U.S. Patent Applicatorz. 2008. A real-t Vellidis, G., M. Tucker, C. Perry, C. Kvectron. Agric. 61: 44-50.

scheduling irrigation. Comput. Elenkinet, B. Hanquet, M. Destain, and J. Baerdemaeker. 2003. Analysis Vrindts, E., M. Reyniers, P. Darius, M. Fank winter wheat field. Paper presee nted at the annual American Sociel of spatial soil, crop and yies,

of Agricultural Engineers, Las Vent 1998 . Economic and environme ental feasibility of variable rate nitroWatkins, K.B., Y.C. Lu, and W.Y. Hearry-over effects. J. Agric. Resour. LEcon. West. Agric. Econ. Assoc. 2. gen fertilizer

. Watkins, K.B., Y.C. Lu, and W.Y.Huang. Agric. Eng. J. 11: 173-185.

rate nitrogen and water application. Ane, D. Moshou, and H.A. McCartney. 2003. The potential of optical West, J.S., C. Bravo, R. Oberti, D. Len control of field crop diseases. An $\sim$ nu. Rev. Phytopathol. 41: 593-614 canopy measuremente achievable, but direct costs and entWichelns, D. and J.D. Oster. 2006. Sustail.Agric. Water Manag. 86: 11-127.

ronmental impacts can be s. Workneh, F., D.C. Jones, and C.M. Jones. 20 approach. Ecol. Epidemiol. S9: 432-440.

streak mosaic intensity. A sta S.D. Kindler, and T.W. Popham. 208009. Differentiating stress induced by Yang, Z., M.N. Rao, N.C. Ello greenbugs and Russian whea aphes from Syria, the North Chim

Zhang, H. 2003. Improving water productivituctivity in Agriculture: Limėieits and Opportunities for Improvementhe Plain and Oregon, USA. In Wijne, R. Barker, and D. Molden, pp. 301-309. Interm national Water Management lsints. Colombo.

Zhang, N., M. Wang, and
Agric. 36: 113-132.

\section{Sustainable Soil Water Management Systems}

G. Basch, A. Kassam, T. Friedrich, F.L. Santos, P.I. Gubiani,

A. Calegari, J.M. Reichert, and D.R. dos Santos

CONTENTS

10.1 Introduction

Processes Affecting Soil Water Dynamics .230

10.2.1 Infiltration

10.2.2 Runoff

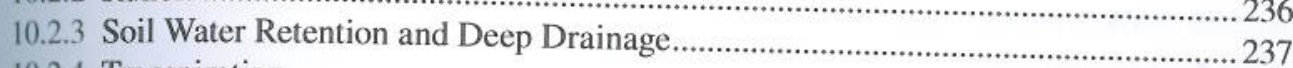

10.2.4 Transpiration

10.2.5 Evaporation

Management Practices That Affect Soil Water Availability

0.3.1 Soil Tillage.

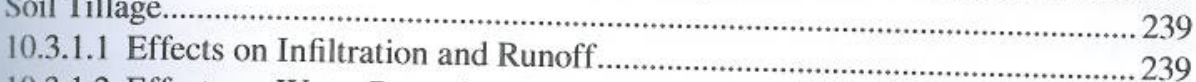

10.3.1.2 Effects on Water Retention Capacity and Deep Drainage................................2.243

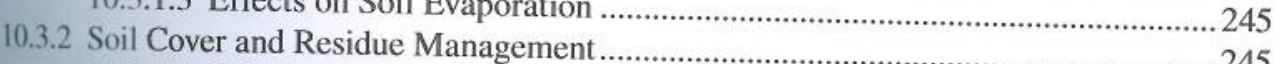

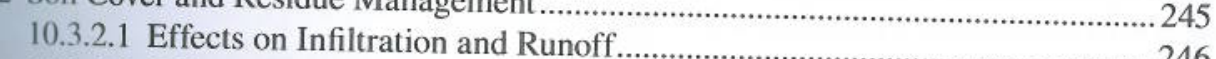

10.3.2.1 Effects on Infiltration and Runoff...

248

10.3.2.3 Effects on Soil Water through the Increase in Soil Organic Matter and Macrofauna Activity

10.3.2.4 Influence of Type of Soil Cover and Residues and Their

Management on Soil Water and Crop Productivity...

10.4 Production System Managemer

10.4.1 Crop Managent.

10.4.1.1 Crop and Cultivar Choice

10.1.2 Crop Establishment and Yield Response to Water ........................................2. 255

0.4.1.3 Crop Genetic Improvement

0.4.1.4 Pest (Weeds, Insects, and Pathogens) Managect.............25

10.4.1.5 Fertilization and Nutrient Management.............................................2.

10.4.1.6 Agronomic Manipulation for Best Phenotypic Expression ........................2.

10.4.2 Irrigation Crop Rotation and Intensification ............................................................2. 261

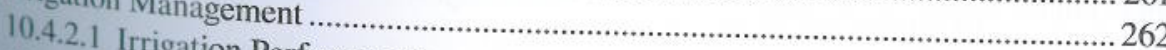

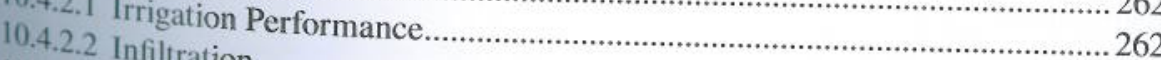

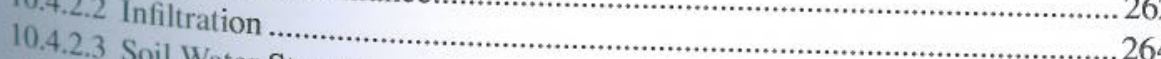

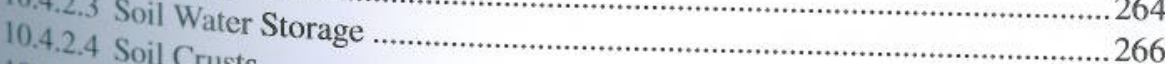

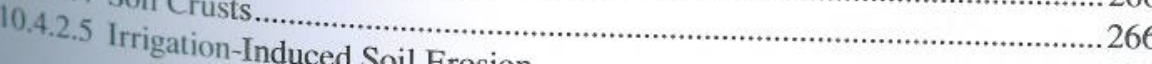




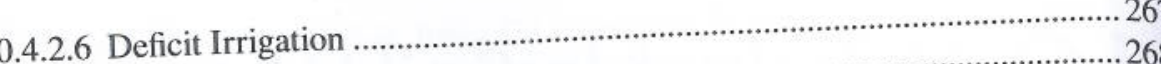
10.4.2.7 Evaporation.....

10.4.3 Case Studies on Improved Production System Managen..............................268 10.4.3.1 Soil Tillage Systems in the Central Great Plains...................................22

10.4.3.2 The System of Rice Intensification .......................................................2

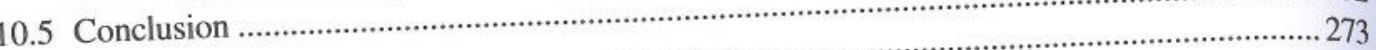
References.

\subsection{INTRODUCTION}

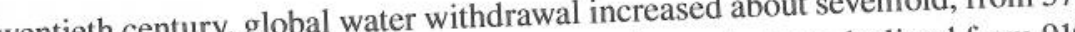
During the $\mathrm{km}^{3}$ year. In the same period, the share of total was and it is supposed to decrease to around $61 \%$ by 2025 (Ghor consumption (nonrecoverable withdecades, there was a considerable decline in the ratio of water consumption (n $66 \%$ in 1940 to $60 \%$ drawn water, i.e., lost by evapotranspiration [ET]) to wacr withdrawal, from and 2003), meaning that water was used mode effic in 2000 (Shiklomanov and

in the agricultural sector. Whereas irrigation water use represents almost and aquifers) (Rockstrom et al. 2009a), global withdrawn from water bodies such as river, lakes, and aquifers) (Rater that transpires productively agricultural blue water consumption, that is, the amount of wodies, and vegetation canopies, through crops or evaporates unproductively from soils, water bodies, an is estimated to be even higher (Rost et al. 2008). In addition, nonquantifable anio is estimater resources, or nonlocal water resources from distant regions are used nonrenewable groundwater resources, Table 10.1 summarizes the global freshwater pools based for irrigation (Vörösmarty et al. 2005). Table 10.1 sous . Although $30 \%$ of the global freshwate on the data compiled by Shiklomanov and Rodda $0.3 \%$ in rivers and lakes, the latter are the main resources are stored as groundwater, and less than $0.3 \%$ in rivers and lakes, sources of fresh water for human use as they represent the dynam withdrawals amount to aroun water resources (Shiklomanov 1993). Whereas global groundwater withas; Rosegrant et al. 2002 $20 \%-25 \%$ of the total water withdrawals (Shiklomanov and Rodda 2003; Rof in many countries relies heavily on groundwater, with $53 \%$ and $46 \%$ of irrigation wate irrigation in being pumped from aquifers in cornes are already overexploited, with the rate of water with et al. 2007). Locally, groundwater resources water tables to fall (Gleick et al. 2002). Globally, abou drawal being faster than recharge, causing water tables to fall (Ginable; many of these withdrawal $15 \%-35 \%$ of irrigation withdrawals are estimated to9) are from groundwater sources (Rosegrant et al. 2009 .

TABLE $\mathbf{1 0 . 1}$

Global Distribution of Fresh Water

Global Pools of Freshwater

Fresh groundwater

Germanent snow and permafros

Lakes (fresh water)

Marshes and swamps

River water

Biological water

Water in the atmosphere

Soil moisture

Total

$\begin{array}{cc}\left(\mathbf{1 0}^{\mathbf{1 2}} \mathbf{~}^{\mathbf{3}}\right) & \text { (\%) } \\ 10530 & 30.06 \\ 24364 & 69.55 \\ 91 & 0.26 \\ 11.5 & 0.03 \\ 2.12 & 0.01 \\ 1.12 & 0.00 \\ 12.9 & 0.04 \\ 16.5 & 0.05 \\ 35029.14 & 100\end{array}$

In addition to the expected increase in agricultural water use to meet the demand for more food, he ongoing urbanization of the world's population will require an increased share of the fresh water vailable. Based on the estimation of a world population of 9.2 billion people by 2050 and a dietary change driven by higher incomes and urbanization, world food demand is supposed to increase by $70 \%$ (or by $100 \%$ in the developing world) within less than 50 years (Bruinsma 2009; Thompson 2007). There are only two ways to cope with this increased projected demand, not only for food and feed, but also for fiber and biofuel: by a substantial increase in cropland and/or a large improvement in productivity per unit of land cropped. Based on an optimistic scenario of water availability and management in which a theoretical maximum of $85 \%$ of the total ET from cropland and pasture was assumed to be available for plant transpiration and thus biomass production, Rockstrom et al. (2009a) suggested that without improvements in water productivity (WP), a horizontal cropland expansion by about 1000 Mha would be required to produce the food for $>10$ billion people, which is two-thirds of today's cropland (Ramankutty et al. 2008). In fact, regarding this option, Thompson (2007) considers the possibility of the area of land in farm production being doubled, but only with the massive destruction of forests and the loss of wildlife habitat, biodiversity, and carbon sequestration capacity.

Several authors consider a potential increase in cropland of around $9 \%-12 \%$ as realistic and feasible (Bruinsma 2009; Molden 2007; Thompson 2007), not taking into account that around $10 \mathrm{Mha}$ may be lost every year due to soil erosion, other forms of degradation, and conversion to nonfarm uses (Leach 1995; Pimentel et al. 1995), indicating that cropland expansion could be close to zero (Postel 1998) and that the increasing demand has to be satisfied by higher crop productivities. However, with the exception of sub-Saharan Africa, most of the productivity enhancement potential of the "Green Revolution" technologies has already been exploited (Molden 2007). This means that the gains in agricultural productivity must be achieved through advances in other areas, such as the improvement in soil fertility and water-use efficiency (WUE), and the use of biotechnological innovations to further enhance the efficiency of the already applied inputs and to improve crop performance under stress conditions.

Although water is considered a renewable resource because it depends on rainfall, its availability is finite in terms of the amount available per unit time in any one region (Pimentel et al. 2004). Considering an optimistic scenario, Molden (2007) estimates the agricultural water withdrawal to increase by only $13 \%$ by the year 2050 . Therefore, and bearing in mind the limited blue wate resources and the rapidly increasing competition of other sectors for this resource, the necessary gains in agricultural productivity will depend strongly on improvements in the use of "green" water (precipitation or water that is stored in the root zone) (Rockstrom 2009a). Rost et al. (2008) consider it a misconception to regard agricultural water consumption as dependent primarily on blue water withdrawals. In fact, around $80 \%$ of global cropland is rainfed, and 60\%-70\% of the world' food is produced on rainfed land, that is, by the consumption of precipitation water inflteded the soil (Falkenmark and Rockstrom 2004). Further, green water also plays an important role on irrigated land in situations where blue water is only used to supplement the crop water requirement or optimal growth and production. Based on the application of different models, Rost et al. (2008) entimated that a share of over $85 \%$ of green water was being consumed on the global cropland. This underpins the statement made by Hoff et al. (2010) that an integrated water resources management RM) relying on blue water only can no longer provide complete sustainable solutions. These "ir also refer to the increasing interest in the potential of the "invisible" green water resource Tor additional crop production.

Managing precipitaction.

green and blue precipitation as a key resource for production intensification, through integrating Falkend blue water, has been postulated as the basis of a new paradigm to help close the water gap those in the and Rockstrom 2004). From a hydrological perspective, in many regions, including

recourse semiarid areas, there is enough rainfall to increase crop yields considerably without

2000 ) to the development of large-scale irrigation schemes (Rockstrom et al 2007). Rockstrom

00 ) has recorded este 
runoff, deep percolation and interception losses of up to 70\%-85\%. Irrigation plays and will conrunoff, dhe still exist a need tinue to play an important role in feeding irrigated cropland. However, to avoid at least half of the and opportunities for an expansion of the irrigated crom et al. (2007) have suggested two possibiliadditional water requirements in agriculture, Rockstrom et al. (2007s in irrigated and rainfed agriculties: (i) reduction of green water losses, that is, $W P$ in

ture, and (ii) better use of the local rainfall water.

In this context, soil quality and its management must be consides tive management of water resources, given that the hydrological cycle and tive manaly linked (Bossio et al. 2007). Bossio et al. (2010) have described soil degradation as the intimately linke (Bestive, self-accelerating starting point of a negative cycle of soil-water relation cycling and WP. Therefore, sustainable soi feedback loop with important negative impacts on water cycling and Whe improvement of soil water management corr management.

The purpose of this chapter is to review the existing options of soil water management systems The purpose of the and their potential contribution to the improvement of seem to be the only solution to producing WUE, and WP. Ultimately, these water-related aspects seem to be the 1.5 times today's world populion, without competing enough food, feed, fiber, and biofuels for 1.5 times their services and the water resources allo-

excessively with the existing natural ecosyst
cated to them and to other human activities.

\subsection{PROCESSES AFFECTING SOIL WATER DYNAMICS}

10.2 Although the earth's land surface (29.2\% of total surace on earth (Pimentel et al. 2004). About tion, it receives around $20 \%$ of the precipitation falling on eare $115 \times 10^{12} \mathrm{~m}^{3}$ of precipitation corresponds to about $780 \mathrm{~mm}$ of the land surace, of (Table 10.2). The transfer of this significant portion of water from oceans to land surface is of importance not only to agriculture but also to human life and natural eully transferred from the land is the fact that soils are able to store around $20 \%$

surface to the atmosphere by evapotranspiration.

Globally, it is estimated that out of the total precipitation over the conin infilrate the soil, formblue water, that is, runoff into rivers and aquifer recharge, and two-thirds infiry blue water, thed "green water" that supports, productively or unproductively, biomass prodic ing the so-called "Hoff 2010). Numerous hydrological models can be tion and returns to the atmosphes partitioning at different scales, depending found in the literature that attempt to describe water partitioning at different scales, dec

\section{TABLE 10.2}

Global Fluxes of Fresh Water (Annual)

Water Flux Component

Total earth's evapotranspiration

Evapotranspiration from oceans $(86 \%)$

Evapotranspiration from land $(14 \%)$

Average rainfall on land surface (20\% of global ETP)

River runoff (into oceans)

$\begin{array}{cc}\text { Units } & \text { Amount } \\ 10^{12} \mathrm{~m}^{3} & 577 \\ 10^{12} \mathrm{~m}^{3} & 496.2 \\ 10^{12} \mathrm{~m}^{3} & 80.8 \\ \mathrm{~mm} & 780 \\ 10^{12} \mathrm{~m}^{3} & 42.8 \\ \end{array}$

Source: Shiklomanov, I.A. and Rodda, J.C., World Water Resources at the Beginning of the Twenty-First Century, Cambridge University Press, New York, 2003, SHorld's Freshwatec World freshwater resources. In Water in Crisis: A Guide to the World's 1993. Resources, edited by P. Gleick, pp. 13-24, Oxford University Press, New York, 1993. on the pretended objectives. Lal (2008b), for example, described the processes of water loss from agricultural watersheds using the equation:

$$
P=R+I+D+\Delta \theta+\int E d t+\int T d t,
$$

where $P$ is the precipitation, $I$ is the infiltration, $R$ is the runoff, $D$ is the deep drainage, $\Delta \theta$ is the change in soil water storage, $\mathrm{T}$ is the transpiration, $\mathrm{E}$ is the soil evaporation, and $\mathrm{t}$ is the time. ive transpiration water as green water. Ngigi et al deep drainage as blue water and the consumpcharacterize the avas artioning components locharacterize the available crop water over a season and to describe the aspects of in situ rainwater harvesting and management systems. Still other components are used in water balance rainwater For example, to model soil water storage, Makurira et al. (2010) used Equation 10.2, based on a
water balance model from Savenije (1997).

$$
\frac{d S_{s}}{d t}+\frac{d S_{u}}{d t}+\frac{d S_{g}}{d t}=P-E_{T}-E_{1}-E_{s}-Q_{g}-Q_{s},
$$

where (all terms in $\mathrm{mm} / \mathrm{day}$ ) $\mathrm{P}$ is the precipitation received in the system, $\mathrm{E}_{\mathrm{T}}$ is the transpiration,

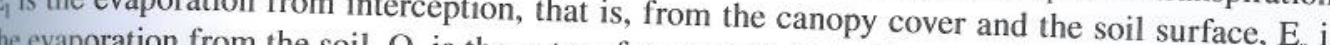
the evaporation from the soil, $\mathrm{Q}_{\mathrm{s}}$ is the net surface runoff, $\mathrm{Q}_{\mathrm{g}}$ is the groundwater run off, $\mathrm{dS} / \mathrm{dt}$ is the rate of change of surface water storage, $\mathrm{dS}_{\mathrm{u}} / \mathrm{dt}$ is the rate of change of water storage in the root zone, and $\mathrm{dS}_{\mathrm{g}} / \mathrm{dt}$ is the rate of change of groundwater storage.

Compared with Equation 10.1, Equation 10.2, in addition to introducing the component groundwater runoff, considers the evaporation of canopy-intercepted rainwater and the wet soil surface $\left(E_{1}\right)$. According to Savenije (2004), depending on the local conditions, the the soil surface $40 \%-50 \%$ of the total precipitation. Therefore, this author anditions, the latter can amount to "evapotranspiration" as it only reflects the incapacity to advocates the abandonment of the term that is, evaporation from interception, transpiration, to separate the different evaporative processes, evaporation, such as water retaine transpiration, soil evaporation, wet surface, and open-water waporation, such as water retained at the soil surface or flooded rice fields. Although open-water mproductive flux, evaporation through interception is not regarded as a loss to the classified as hecause it is responsible for the moisture recycling that sustainded as a loss to the water system On cropland, be included in the green or blue water fraction.

ance (runoff, soil and plant [interception] evation into the different components of the water baltremendously, depending [interception] evaporation, transpiration, deep percolation) may vary management, depending on the agroecological characteristics of the site, mainly the soil type and Laryea et of total (101) determined over a period of 4 years a blue water share (runoff and percol India, colation diffll of $37 \%$ and $59 \%$. Whereas runoff was similar at field scale fered considerably, reaching $9 \%$ and $33 \%$, respectively. fids scale based on onsite observations at two sites in nospectively. Modeling water partioning at the fived big differences in the water partiti. and forming practices, using the reditional and the innovaand the soil depth contribut the runoff diversion to crop plots. They found that the slope of the field unoff and that inteributed decisively to the partitioning of both the rainwater and the diverted siles, respectire a landscape or wively. Figure 10.1 gives an overview of the components of the watitation for the Considerin watershed. the growing

one of the world population, while water resources suitable to produce enough commodities for ofs betwe strategies by which agiculing other ecosystem services provided by agriculture, ween water uses is improving water management practices can deal with the large trade- 


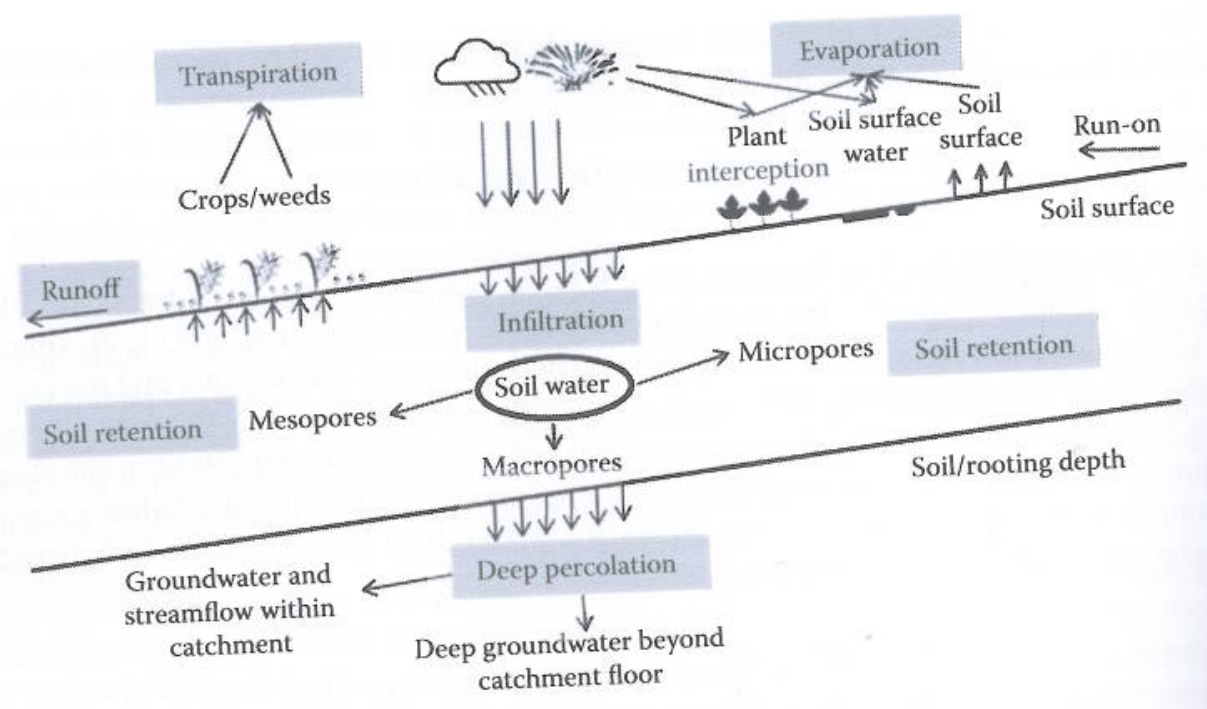

Water fluxes over a landscape or watershed and the destinations of rain and irrigation water

et al. 2010). This requires a careful look at the water fluxes described in Figure 10.1 and examining the processes affecting the soil water, which is ultimately the water source for plant growth and biomass production.

Although WP and WUE have been questioned as useful concepts in agricultural water managenent (Blum 2009; Zoebl 2006), they are the terms commonly used to evaluate the efficiency with which rain and/or irrigation water is transformed into grain yield or biomass production. Without which rain and same concept in mind (Ali and Talukder 2008), much has been written in recent always having the sassio et al. 2010; Fang et al. 2010b; Liu years about the ways to improve agricultural al. 2010; Alvaro-Fuentes et al. 2009; Kang et al. 2009, et al. 2010; Molden et al. 2010; Shaheen et al. 201. Ab; Evans and Sadler 2008; Khan et al. 2008; Katerji and Mastrorilli 2009; Rockstrom et al. 2009b; Evans and Molden et al. 2007; Rockstrom and Ritchie and Basso 2008; Bluemling et al. 2007; Bouman 2006; Singh et al. 2006; Zhang et al. 2005). Barron 2007; Steduto et al. 2007; Adekalu and Okunade 2006; Singh et al. 2006, Zuestion remains. Regardless of the discussion about terms and definitions, the fundamental quinfall and irrigaHow to produce more with the same or even less amount of water available from rast at field level, tion? This question is und unproductive water losses, name blue water resources cycle perspective, all these components are also inpes oses must occur, not only to achieve the goil from an agronomist viewpoint, a reduction of the (EWU), bu set above of a higher WP, WUE, or, as suggested by Blum (2009), A harmful consequences. Albel also because runoff losses, if uncontrolled, can have other severe and harmic consequet not expectel the shift from unproductive evaporation losses to an increase in crop transpiration is tool expect wate the shift for to alter significantly the retured runoff and deep percolation or water withdrawal for irrigation redirection, through either reduced stream flow (Falkenmark 2007). These trade-or could involve a corresponding depletion of the stream fow (Fal water resource management 5y. should be kept in mind when searching for improved agricultural water ment practices to achieve tems. They also point, in the first place, at soil and soil water management practice mizizing runo sustainable combination of maximizing transpiration and soil water storage and miement are a hig and evaporation. Technically feasible and cost-effective solutions for this achievenent ant systeml and evaporation et al. 2002) and form a basis for sustainable soil water managenten sigure 10. priority (Rockstrom et al. 20fferent processes that affect the soil water, as indicated in Fig These have to consider the differe processes (Figure 10.2).

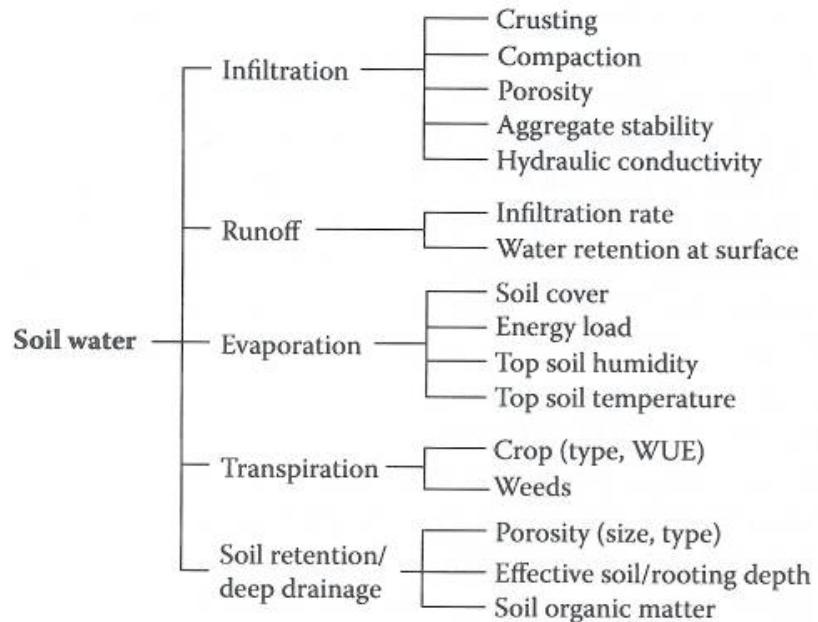

FIGURE 10.2 The processes and parameters affecting soil water

\subsubsection{INFILTRATION}

A first step in converting blue water to green water is to maximize water infiltration into the soil. This process and its variation with time are mainly governed by the initial wetness and suction of the soil, as well as its texture, structure, and the uniformity of its profile. While the soil texture and the initial moisture content can hardly be changed, an enhancement of the amount and the stability of the structural soil aggregates, total porosity and macroporosity, and thus hydraulic conductivity, and a decrease in the surface crusting and compaction are achievable through management practices.

Numerous attempts have been made to describe thoroughly the process of infiltration and many models and equations are used to express infiltrability as a function of time or of the total quantity of water infiltrated into the soil (Hillel 1980). However, beyond the understanding of the process itself, which has been subject to many studies, it is of crucial importance to identify the management practices that are able to enhance the infiltration flux, that is, to act on the factors that can be influenced in a technically feasible and cost-effective way. For that purpose, it is useful to distinguish whether infiltration is supply-, surface-, or profile-controlled. Whereas supply control (amount and intensity) is possible only under irrigated conditions, infiltrability of the soil surface layer (surface controlled) and the subsurface hydraulic conductivity (profile controlled) are manageable condiions, even under a rainfed situation.

Increasing the share of rainfall or irrigation water that infiltrates the soil can be achieved through cither an improved infiltrability or an extension of the time period during which water is capable infiltrating into the soil (surface retention or ponding). Whereas the former is strongly enhanced in the presence of continuous macroporosity (mainly biopores created by macrofauna activity and former root channels), the latter depends on the soil surface roughness and the overall slope of the land, which determine the so-called surface storage capacity. An increase in the surface roughness is often unintentionally attained through any form of soil tillage, or it is intentionally achieved through tillage operations along contour lines or by creating "pockets" or "basins" over the soil At the especilly with row crops.

Arone soil surface, the processes defined as particle detachment, sealing, and crusting are by the influenced by the vulnerability of the soil aggregates to breakdown, which is caused throughetic impact of raindrops or the surface irrigation water flow or the mechanical impact ally show tillage implements or wheeling ( $\mathrm{Li}$ et al. 2009). Soils prone to crusting and sealing usually show reduced infiltration rates (Ben-Hur and Lado 2008; Lal 2008b; Ramos et al. 2003). 


\subsubsection{Soll. Water Retention and Deep Drainage}

After water infiltrates the soil, its movement in or through the soil is mainly influenced by gravitational forces and suction gradients. Depending on whether these processes start from initially saturated conditions or an unsaturated state, they are called either internal drainages or redistributions (Hillel 1980), and the rate at which they occur are normally described by the saturated and unsaturated hydraulic conductivities of the respective soil. Internal drainage or the saturated and water flow beyond the effective rooting depth is referred to as deep drainage or even unsaturated The amount of water that is retained in depth is referred to as deep drainage or deep percolation. mines the soil water storage capacity. mines the soil water storage capacity.

Although deep drainage is an important process to allow excess water to drain and avoid waterlogging, and to recharge the groundwater, from an agronomic point of view and especially i regions with a low and erratic rainfall, but even in relatively humid regions, soil water storage is o vital importance for crops to overcome periods without insufficient precipitation. Effective plant valable soil water depends, in the first place, on the porosity (amount and pore size distribution) f a soil. While pore size distribution is strongly affected by the soil properties, such as texture, structure, and SOM, the total pore volume from which plants may extroperties, such as texture, he soil volume that the roots are able to explore. Thus, efforts to incract water depends also o available soil water involve the adoption of soil management practices that the amount of plantdepth and/or the volume of the pore size range from which practices that increase the rooting referred to as mesopores. Physical and chemical subsoil constraints may severely affect the rooting depth and restrict water
uptake from deeper soil layers (Dang et al. 2010; MacEwan et al. 2010; Passioura and Angs 2010; Rodriguez et al. 2006). Access to and uptake of water from the subsoil considerably (Kirkegaard et al. 2007), and improving subsoil y higher returns under Mediterranean conditions (Wng subsoil conditions was found to be justified have been suggested to overcome these conditions (Wong and Asseng 2007). Numerous approaches into three groups: (1) amelioration constraints, which were categorized by Adcock et al. (2007) application strategies including any type of deep soil loosening and the application soil amendments, (2) breeding efforts, and (3) avoidance strategies such as raised beds or crop management practices. However, they may be of only temporary effect and as raised beds Changes in the intervention (Lopez-Fando et al. 2007).

Changes in the soil porosity to increase the amount of plantavailabe wat

mprovement of the soil structure and aggregation (Horn and Smuvalable water will depend on the and Lal 2009; Hudson 1994). However, the relion (Horn and Smucker 2005) and the SOM (Abid arbon content is affected by proportion, the relationship of the soil water retention to the organic Inatric suctions (Rawls et by proportions of textural components and is more pronounced at lower carbon contents (Rawls et al. 2003). In particular, coarse-textured soils and soils with low organic a al. 2003).
a benefit in their water-holding capacity from increases in organic matter (Rawls

from the root zronentioned, deep drainage must not be considered as a permanent "loss" of wate soil's water-holding once the soil profile is replenished with water reaching the upper limit of the measures are used did capacity. The observation that higher infiltration rates where soil conservation bell et al. (2005), with result in a better crop performance in South East Queensland is explained (that may enhance unsaturated flow through and contribute to increased deep drainage "losses."

10.2.4 TRANSPIRATION

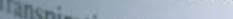

bomilation from the atmos crop canopies is inseparable from the processes of carbon dioxide bround transpiration efficiency (TE) biomass production. Its efficiency is generally referred to as growing season transpiration (Suyker the ratio of total plant biomass (above and below arable land to avoid prolonged waterlogging of the crops (Basch 1988) or to supply al. 200
ping areas with additional water, also designated as runoff diversion (Makurira et al. ping areas with additional since antiquit

deliberate inducement of runoff through mareas (Hillel 1980). 
from the terms WUE and WP. WUE is defined as water consumptively used in ET as a proportion from dofically (or economically) of the water applied by either irrigation or rain $u$ it of water consumptively used in ET (Ferere in terms of economic yield or total biomass per unit of wa con management to ensure that WUE and Kassam, 2003; Sadras and Angus 2006). It is the job of crop moning system and for the cropand Kassam, and WP are maintained as high as prevailing agroecological and socioeconomic constraints. Many ping system as a whole within the prevailing agroecological (Bluemling et al. 2007), mainly involving strategies have been identified to enhance WUE and WP 2008; Adekalu and Okunade 2006; Hatfiel appropriate tillage and soil management (Chiroma et al. 2008, Al. 2010a; Katerji et al. 2010; Liu et al. approprian), irrigation management (amount, timing) (Fang et al. 2010a, Kat management, includin et a10; Buttar et al. 2007; Adekalu and Okunade 2006), and weed and crop manas; Tennakoon and 2010; Buttar et al. 2007, Ad breeding efforts (Fang et al. 2010b; Passioura 2006; Tennakoon an the choice of cultivars and bred. 2005; Gregory et al. 2000). Although many authors continue usin Hulugalle 2006; Zhang et al. 2005; Gre efficiency with which water is used to produce biomass or the concept of WUE to characterize the efficiency with whoduced per unit of water used in ET, other yield and to characterize how much biomass or yield is producedive approaches such as the "effective authors question its usefulness (Zoebl 2006) or prefer alternative appited environments because high use of water" (EUW) as a target for yield improvement in water-limited en 2009). However, it would WUE, WP, or TE may be achieved at the expense of reduced EUW (Blum 2009). Howarticular index WUE, WP, or TE may be achieved air values, depending on the purpose for which a particular inder is being used.

To To improve biomass production especiall the TE (Bouman 2007). Whereas water available for the total amount of water transpired and/or and storage capacity, the increase in efficiency with transpiration depends on inflows, outflows, and storage cenetic improvements as the ratio of biowhich transpired water is exchanged for $\mathrm{CO}_{2}$ will require genetic inp for a given species in a given which ras been shown to be fairly con mass prost 2003; Steduto et al. 2007). Bennett (2003) has sumarized the breeding climate (Ehlers and Goss 20 ; efforts and bioengineering opporthities for differentiated TE have been found between cultivar isotope discrimination as an indicator for differeding efforts are directed toward the avoidance (Passioura 2006; Richards 2006), most of the breeding efre hydrological environment (Blu of dehydration, that is, adaptation of the crop cycle to the given hydroura 2006).

2009), and the genetic improvement of the harvest index (HI) (Passiour 2006).

The fact that $\mathrm{C}_{4}$ crops have a more efficient photosynthetic pathway, and $\mathrm{C}_{3}$ plants through geneli plants, has suggested the introduction of their photosynthetic pathway in rest (Furbank et al. engineering (Sheehy 2000), an approach that has been followed over the recent past (Furber 2009; Hibberd et al. 2008)

\subsubsection{Evaporation}

Evaporation is called the vaporization of a liquid that occurs at its surface. In a soil-platEvaporation is called the vaposize components. Although transpiration is atmosphere system, evaporation occurs from eachately or in combination (ET) as it is the producte specific form of evaporation, it is referred to separately or in combination (ET) as is is her from the tive consumption of water in crop production. All other origins of evaporation, wheler fare contive consun (we canopy, or from sprinkler droplemprehens soil surface (wet soil or free water storphere system. Burt et al. (2005) carried out a compros loso sidered losses to the soil-plant-atmosphere sud their contribution to the overall evaporat rirgati review of the different evaporative processes and their lonses of canopy-intercepted rain or inififich Although, as mentioned previously, the evaporation losses of canopy-intere 2004), they are difficle Although, as menter supply (Savenije 2004), the first opl water can reach consies through better timing of the overhead irrigation. Therefore, levaporatic to be influenced unless through bes losses is the understanding of the process of soil erter to reduce unproductive evaporation losses is the und practices.

order to minimize it through feasible management practices.

The most important factors that affect evaporation from the soil, apant, texture, structure

The evaporating body (evaporative demand), are its water content, textrit degree to which it is covered either by growing vegetation or any form of surface mulch. With regard to the soil water content, three evaporation stages are distinguished: the first stage is when the water supply at/to the surface is sufficient to allow a more or less constant evaporation rate as a function of the evaporative demand; the second stage, the falling-rate stage, depends on the soil properties that are responsible for the delivery of moisture to the evaporation zone; and the third stage depends nainly on the rate of vapor diffusion. Both the soil texture and the structure may affect evaporation due to their influence on the soil hydraulic properties (Ndiaye et al. 2007; Jalota and Araporation Inder similar soil structure conditions, finer-textured soils show higher Jalota and Arora 2002). coarse-textured soils (Jalota and Prihar 1986; Prihar et al. 1996). At low maportion water is held in coarse-textured soils between soil particles rather than moisture levels when the ration occurs mainly through the slower process of diffusion in than in continuous pores, evapoin the of conductance in water-filled The mard et al. 2009).

The most notable reduction of evaporation losses and the most easily attained through management pratices is through the cover of the soil by vegetation or any form of stubble and mulch, whether reanc (crop residus, waste products, cover crop, etc) or inorganic (stones, phsic Soil cover interferes with the evaporation process mainly by providin (s a to the removal of moisture over the soil, reducing the energy supply (heat flux) to the zarrier or resistance (boh lowering the evaporative demand), and decring over if superficilly in ayer if superficilly in the effectivenes of different mulching types and practices (Yuan et al. 2009; Ward et al. 2009; Monzon et al. 2006; B 2005 , sauc ctal. 196), and they generally agree that the soil cover is especially effective in reducing craporation losses at the first evaporation stage, thereby contributing to a However, under relatively dry soil conditions, a soil cover in the form of standing stubble may sor status. enhance evaporation, which is attributed to the hydroulic redituibus stems (Ward et al. 2009; Leffler et al. 2005).

\subsection{MANAGEMENT PRACTICES THAT AFFECT SOIL WATER AVAILABILITY}

The objectives and arguments for soil tillage are many, including weed control, soil decompaction, crop residue management, and adequate seedbed preparation. However, the results in the literion, and effects of tillage operations on the soil water and its use through crops are highly vaterate and contradictory. The inconsistency of the effects of different tilough crops are highly variable cal and hydraulic properties is attributed to the transitory nature of the soil structure soil's physithe site history, the initial and the final water contre structure after tillage, disturbances (Azooz and Arshad 1996) water contents, the time of sampling, and the extent of soil Based

effects of soil tilloge pres that affect soil water (outlined in Figure 10.2), this section reviews the and its use efficiency.

\subsubsection{SOIL TILLAGE}

10.3.1.1 Effects on Infiltration and Runoff

mosity, such as the stability of the structunoff components, basically by modifying the soil wil the hydraulic conductivity, the stuctural soil aggregates, the total porosity and macropothang gation improves with the soM. Generally, ansement. As a result, por conversion from conventional soil tillage to no-till (NT) soil In the lis properties. titerature, the

quantify the agricultural managementillage on infiltration is ambiguous. Reviewing the state-of-science 
The promote an increase in the macropore connectivity and the differences in soils, climates, and specific nectivity and the infittration rate, hithout a detailed knowledge of practices of tillage, it is not possible to gener ine the all the controlling factors. As related to water infiltration, seve (CT) practices. However, the sitereat advantages of the NT systems over conventional tillage (CT) pracices. Hower, the siegecific conditions could indicate the need for a surface, shallow soil disturbance to didney specific conditions could indicate the nich can occur as a consequence of little crop residue on th surface crust or compacted layers, which can occur as a con) or intense tillage and machinery traffic soil surface (Thierfelder and Wall 2009; Singh et al. Sasal et al. 2006; Hamza and Anderson 2005) (Reichert et al. 2009b; Mary and Changying 2008; Sasal come increase in water evaporation, Even considering that this surface disturbance may promote some will surpass the aforementioned Even considering thater infiltration due to the runoff reduction will probably the gain in water ins to have only a short-lasting effect on the improvement of the infiltraeffect. However, tillage seems

tion rate (Freese et al. 1993). Experiments performed in several regions of 2002) and water infiltration. One study carried out in gation (Stone and Schlegel 2010; Rhoton et al. 2002) and wed from $20 \mathrm{~mm} / \mathrm{h}$ under CT to $45 \mathrm{~mm} / \mathrm{h}$ southern Brazil showed that rainwater infiltration intion) (Calegari et al. 1998). In Kansas, Texas, under NT (which included cover crops and crop rotation) (Calegar itration rate under NT (30.56 under silt (mom soil, Stone and Schlegel (2010) observed that the int on a silt loa 29 $\mathrm{mm} / \mathrm{h}$ ) was 1.99 -fold and 2.67 fold grelated with the mean weight diameter (MWD) of the waterThe infiltration rate was positively correlate was also positively correlated with the total soil organic stable aggregates (WSA), which, in turn, was also posidy-state infiltration rate in the NT system to carbon (SOC). The authors attributed this greater steacropores, the greater concentration of larger, the presence and stability of the surface-connected macropores, the sealing due to the protection water-stable aggregates in the surface layer, and the reduced surface sealing water staindrop impact promoted by the residues. In their review of the effects of tillage systems from raindrop in soil and the water content in the Argentine Pampas, Alvarez and on the physical properties of the soil an her infiltration rates under NT when compared with limSteinbach (2009) clearly document the higher infilla

ited tillage, especially plow tillage (Figure 10.3). Soil disturbance caused by many tillage practices increases the surfeclines with time as a conseporosity, and the initial infiltrability, although the infiltration rapid dal. (2004) also observed a high quence of aggregate collapse (Guzha 2004). On a silt loam, Wahl et al. (2007) quence of aggendence on macroporosity. Their results showed that the infiltration rates measure infiltration de soil surface layer in CT than in conservation til with a tension infiltrometer were higher in the so

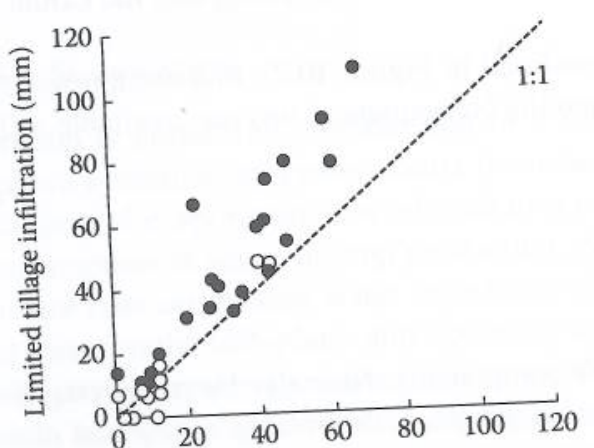

(a)

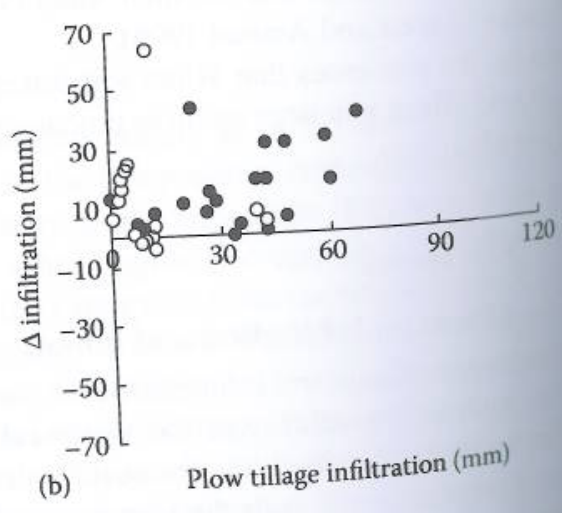

Plow tillage infiltration (mm)

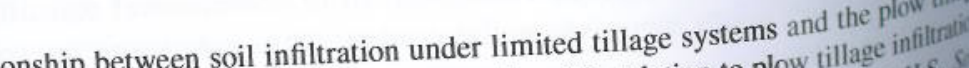
systems (a). The change in soil infiltration (limited tillage-plow tillage) in relation to plow tillage i. $\mathrm{H} S$. systems (a). The change in soil infiltration (limited tillage tillage. (From Alvarez, R. and Steinbact, Hs. Till. Res., 104, 1, 2009.
At depths greater than $50 \mathrm{~cm}$, the water intake in conservation tillage was higher than in CT and even higher than in the topsoil for both tillage types. The authors attribute these findings to a higher macroporosity under conservation tillage at $20 \mathrm{~cm}$ and below and to a much better macropore continuity promoted by the soil fauna activity in the soil profile.

In addition to the importance of macroporosity and its geometry for infiltration and redistribution of the soil water in depth, Sasal et al. (2006) emphasized the importance of the stability of the soil structure and the need for a complete characterization of the soil porosity as essential information to assess the effect of the structural conditions on the soil water dynamics. At two of three study sites, these authors observed a more horizontal orientation of the macropores under zero tillage when compared with the chisel plough, which they ascribe mainly to the pressures generated by repeated traffic and a low volume of crop residues in the soybean-dominated crop rotations. At the same time the infiltration rate, an observation frequently shared by other authors (Imhoff et al. 2010; Buczko et al, 2003; Tebrugge and Abelsova 1999)

An enhanced soil bioporosity through macrofauna, mainly earthworm activity, or created by roots after their decomposition, could compensate for the effect of reduced total porosity or even soil compaction on the water flux within the soil. Although Abreu et al. (2004) could not find an increase in the water infiltration under minimum tillage (MT), they were able to show that saturated hydraulic conductivity measured in the field increased in the soil cultivated with showy crotalaria (Crotalaria spectabilis Roth) under MT (Crotalaria), even when the soil mechanical resistance was greater than in other tillage-based systems (Figure 10.4). This result was due to the bester pore congreater than in other tillage-based systems (Figure 10.4). This result was due to the better pore continuity promoted by the deep root growth of Crotalaria, since the total porosity, macroporosity, and bulk density were not different among the tillage systems. Thus, the tillage and cropping systems that enhance vertically oriented bioporosity are likely to increase the amount of water captured and redistributed in the soil. Hartge and Bohne (1983) reported that repacked soil with artificial vertical macropores was more stable than repacked soil with artificial horizontal macropores.

Runoff is the direct consequence of the precipitation intensity being higher than the infiltration rate and the soil surface water storage capacity. Especially in regions where rainfall is low and andic, runoff is always undesirable as it reduces the amount of soil water available for producthe transpiration (Guzha 2004). Soil tillage normally increases the soil surface roughness and residence time of the water on the soil surface, but the continuous producion of eartworm cass on untilled land has also been found to induce a matked surace roughtics
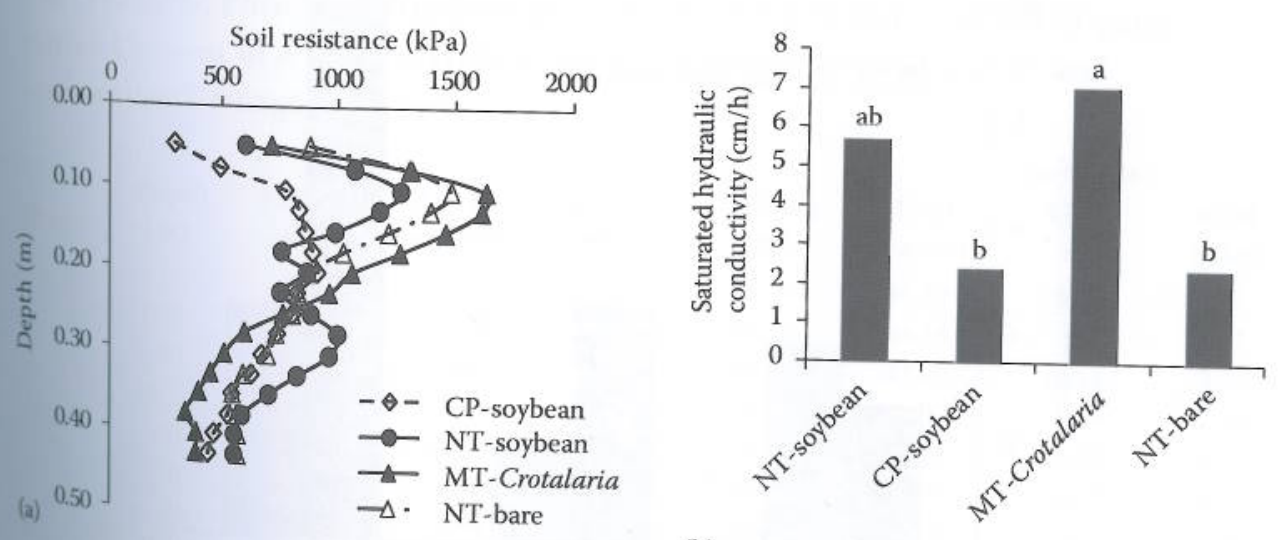

(b)

FIGURE 10.4

$2-0.12 \mathrm{~m}$ layer in soil penetration resistance (a) and the saturated hydraulic conductivity (b) measured at Alapted $(P=0.5)$, as deils under different management systems. Bars with the same letter are not significantly ed from Abreu, as determined by a DMS test. CP: chisel plow; NT: no-tillage; MT: minimum tillage. , S.L., et al., Rev. Bras. Cienc. Solo, 28, 519, 2004. 
(Podwojewski et al. 2008). Although soil roughness may play a key role in retaining precipitation (Podwoje soil surface sealing that follows tillin situ and retarding runoff, in warm and dry envirich age is critical, since the water that ponds on the soil sufal (Peterson and Westfall 2004).

thereby reducing the infiltration and the effective rainfall (Petson ance of the effects induced by Rhoton et al. (2002) have comprehensively described the importance ong-term studies of a silt tillage systems on the soil properties and the surface runoff. Based on long-term stu SOM, aggreloam in the southeast of the United States, they correlated the soil to surface runoff. From single, gate stability, total and dispersible clay content, and bulk depths of $0-1 \mathrm{~cm}$ and $1-3 \mathrm{~cm}$, the authors two-, and three-variable regression models performed for depths off was bulk density under NT and concluded that the most important soil property explaining rum concluded this ity under CT (chisel plough and disk harrow). Further, they cols aggregate stability sity is a measure of the surface por unimportant. This was not the same for the soil under CT, where ing other soil properties relatively unimportant. This was content were identified as the most importan the aggregate stability and the w

properties for controlling runoff.

A reduced aggregate stability and a less favorable sol the MT or NT sysfrequent arguments to explain a higher surface runoff when culions initially for infiltration and frequent argu tilloge temporarily creates more favorable condilions initly for int ems. Although tillo less runoff through higher macropos contributes to a rapid change in the infiltration conditions detachment of the disturbed soil surfaces contribut to the overall higher runoff and less infiltration (Teixeira et al. 2000, Azooz and Arshad 1996) and to the ov that NT reduced the runoff water losses of the tilled soil. For example, Castro et al. (1993) observed that Nes of 13.1, 35.7, and $93 \mathrm{~mm} / \mathrm{year}$ for by $88 \%$ when compared with heavy-disc harrowing, with losses of $13.1,35.7$, evaluated the effects bT the chisel plough, and the disc plough, respectively. Kosgei et al. (2007) evaluated the cilcerize NT, the chisel plough, anh) and NT on the water losses, infiltration, and rain use efficiency of mair of CT (moldboard plough) a in the $2005 / 2006$ season (Figure 10.5 ), $(37 \mathrm{~mm}$ ), corresponding to $6 \%$ and $8 \%$ of the seasonal raingenerated less runoff $(22 \mathrm{~mm})$ than $\mathrm{CT}(37 \mathrm{~mm})$, corrence in the cumulative water intake, the author fall $(463 \mathrm{~mm}$ ), respectively. Despite the small difference in the cuter availability under NT throughou ascribe the large di

the growing season.

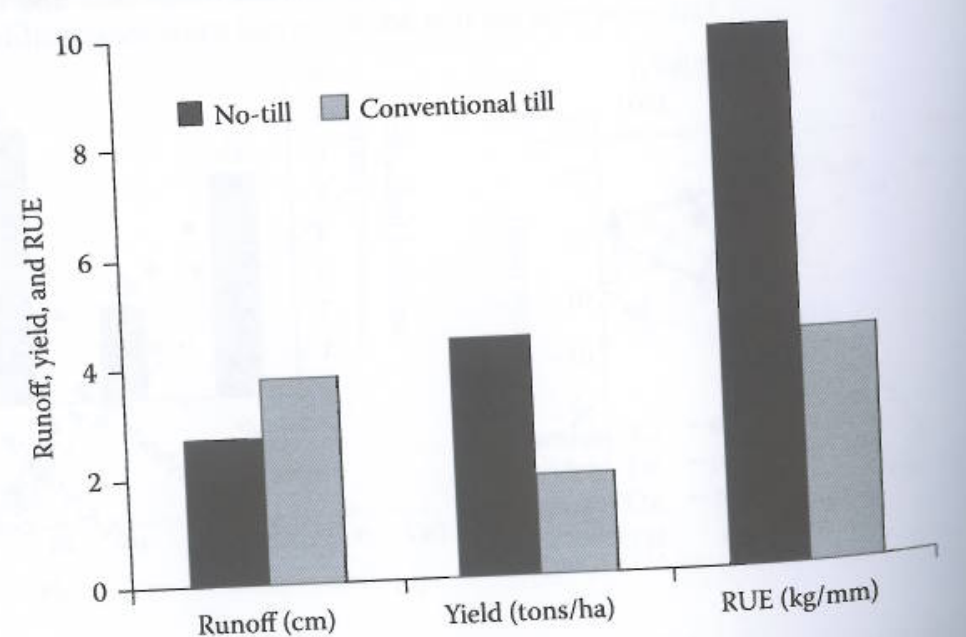

FIGURE 10.5 The seasonal average runoff depths $(\mathrm{cm})$, the maize yields (ton/ha), and the thent in th

rain use efficiency (RUE) $(\mathrm{kg} / \mathrm{mm})$ in no-tillage and conventional tillage plots in
10.3.1.2 Effects on Water Retention Capacity and Deep Drainage

As previously outlined in Section 10.2 plant-availe

the amount of mesopores that a he roots on demand. Second, to deliver it to is equally important as plat the total soil volume that the roots are able to explore (rooting depth) soil layers by increasing the water uptake fre for water stress in the upper, more densely rooted, management may directly or indirectly affect the deeper layers (Teuling et al. 2006). Thus, tillage hydraulic properties of the soil and hence, Today, it is widely recognized the the ate

and promotes SOM accumulat that the absence of soil disturbance improves aggregate stability and promotes SOM accumulation and stabilization. Through the buildup of SOM and the consequent promotion of soil aggregation and structure stabilization, the reduction of tillage intensity contributes to a higher percentage of intermediate pores in relation to the total porosity (FernandezUgalde et al. 2009; da Veiga et al. 2008; Bescansa et al. 2006). Many researchers have found a high correlation between the structural quality of the soil and the SOM content with have found a high (Imhoff et al. 2010; Abid and Lal 2009; So et al. 2009; Mrabet content with plant-available water observed reduction of the total porosity in the surface soil Mrabet et al. 2001). Despite a frequently pores is increased in the abence of moldboard plough), Carvalho and of differentiated tillage (NT and NT in the $0-0.1 \mathrm{~m}$ soil layer; howd Basch (1995) found a lower total and medium-size porosity under cially the pore space referring to plant-available water $0.3 \mathrm{~m}$ soil layers, the total porosity and espeThere was also a close correspondence to bulk density by other authors corroborate these finding (Fents obtained Bhattacharyya et al 2006; Rass servation (the porosity and SOM, Kay and VandenBygaat (2002) inter changes in mesoporosity did not occur. Accorting heir interpretation, only long-term studies are able to provide concistent infording to with regard to the changes in the SOM and the changes in the pore size frections.tion especially Chemical and physical subsoil constraints frequelly limit pore size fractions.

layers (Dang et al. 2010; MacEwan et 2010; Neper soil

\section{TABLE 10.3}

Total Porosity, Pore Size Distribution, Plant-Available Water, and Soil Organic Matter Content in a Vertic Cambisol after 6 Years under No-Till (NT) and Conventional Tillage (CT)

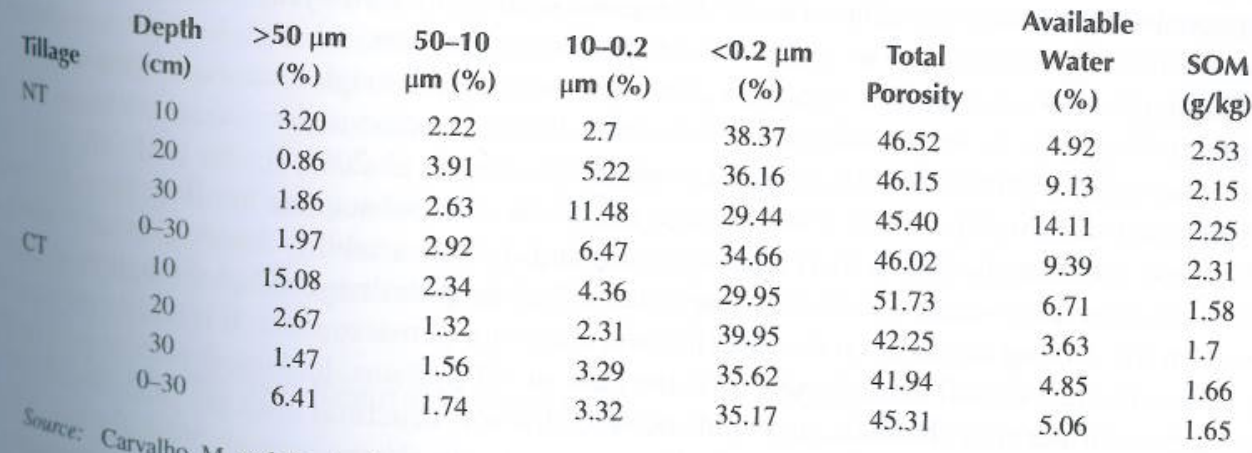


in the soil profile is considered especially valuable to crop yield because it becomes available during grain filling (Passioura and Angus 2010; Kirkegaard et al. 2007). With regard to the phans), deep soil grain filling (Passioura and Ang or anthropogenic origin (hard setting soils or hard pans), deep soil constraints, whether of natural or ant soil management practice where powerful tractors and subsoilloosening has become a widely used soil Anderson 2005). Deep ripping and slotting are frequently ing equipment are available (Hamza and Anderson 2and to improve the access of roots to additional proposed operations to overcome these constraints and to improve 2008; Adcock et al. 2007; Sadras et al. soil water and nutrients (MacEwan et al. 2010; Hartmann et al. 2008, Adove been variable and the ben2005; Hamza and Anderson 2003). However, the documented ray differ from one year to another and efits of deep soil loosening and the consequent crop response may differ from likely to benefit fron efits ofter locations and coarser-textured soils are more likely to benefit fron from one place to anotired soils and drier locations (Wong and Asseng 2007). Negative results fron subsoiling than fine-textured soils and drier locats or when deep drainage losses occurred (Wong and deep soil loosening were obtained in dry years or when deep drait duration, especially if not accomAsseng 2007). Further, the deep loosening effects are often of (i.e., gypsum), the installation of primer panied by additional measures, such as subsoil condito al. 2007; Hamza and Anderson 2003, 2005; crops, or reduced or controlled traffic (Lopez-Fando et al. 2007, Hued for a careful balance between Yunusa and Newton 2003). Adcock et al. (2007) also highlight the need for a ca colioration measure Yunusa and New in he expectable increase in eclationship between the soil physical constraints, the root growth, an In order to establish a relationship bictors such as growth-limiting bulk density (GLBD), leasthe soil-available water, the use of indicators such as growacity (IWC) has been proposed. The firs limiting water range (LLWR), and integrated water capacith (ITreshold bulk densities for a given soil one, based on the work of Pierce et al. (1983), provides thricted. LLWR serves as an index of the texture at which water availability becomes excessively restricted. LLWR seron, and the soil strengt soil structural quality, integrating values of the soil matrix potential, acrat an soil structur 1994). The concept of IWC has been proposed as a flexible method (Dasilva et al. 1he available water in nonswelling soils and then extended soil physical limitations when calcurden pressures (Groenevelt et al. 2001). Although considered as to swelling soils, introducing overburde prop et al. 2004 useful indicators of soil physical quality for crop production (Leas been questioned by several author the applicability of the most widely used LLWR indicator has 2009b; Benjamin et al. 2003), dis (Asgarzadeh et al. 2010; Kaufmann et al. 2010; Reichert et al. 200\%, Berjtics, based on bulk sol (Asgarza mainly on the critical values used for some of the soil characteristics, based on batr santry agreeing . Especially under NT, the critical bulk densities do not reveal the pore geomery a conditions. Especially unecessarily restrict root growth (Reichert et al. 2009b; Bolliger et al. 2006 continuity and may not necian rooting depth, occurs when

Deep drainage, defined as water passing belown front reaches the lower limit of the rooting zone the soil volume above is saturated and the wetting front is not saturated. It is an important process or through preferential pathways even if the soil profile is nom sail profile to the deeper soil layer. recharge the groundwater and to conduct excess water from the soll prity, however, deep drainage rech so tributing to reduced surface runoff. In regions with water scarcily, how for dry environment thus contriber correspond to a loss in the potential crop growth, although for dry (Passioura ant often considered to cor are usually much smaller than the losses through evaporation (Prasinge is at deep drainage losses are usually my soils (Passioura 2006). In some regions, deep drainacel. Angus 2010), except in very sandy socondary salinity (Asseng et al. 2001; Ridley et al. 2001). associated with the problems with secondary sal effects on soils subsequent to tillage have not thet According to Strudley (2008), the drainage effects on soils subsability. In addition to the about studied very extensively, due to their high temporal and spatial variability. Th a through its negate mentioned effects on water retention, tillage may affect deep drainage either it is widely recogn impact on the rooting depth or on the creation and longevity of macropores. It is macropores, ent impact on the rooting dept isturbance, as is the case in NT systems, biological macterved, the that in the absence of soil distubance and voids between the soil structural units are prescrillum 20" worm tubes, former root channels, and and deep percolation (Verhulst et al. 2010, Culmbrotact forming preferential pathways for rapid and deep percolation (Verag). Although Diaz-Ang hightle Strudley et al. 2008; Shipitalo et al. 2000; Tebrugge and Dufference to deep drainage, trainage to (2005) found that tillage treatments alone made little difference to ded to higher drainte (tilla

After 18 years of NT and CT on a Vertisol, McGarry et al. (2000) found that in addition to taking a longer time to ponding, final infiltration rate, total infiltration and deep drainage were also enhanced. Through a higher water intake, less evaporation losses in the case of residue maintenance, and better pore connectivity, deep drainage is more likely to occur under NT than under CT. However, the withdrawal of excess water from the saturated topsoil through deep drainage provides a basis for a positive trade-off between the consequent increase in infiltration and the reduction in a basis

\subsubsection{Effects on Soil Evaporation}

In arid and semiarid regions, the main unproductive water loss is caused by direct evaporation, especially if there are many low-intensity rainfall events (Lampurlanés and Cantero-Martínez 2006; Passioura 2006). Reducing the evaporation losses is a major challenge for farmers, especially in water-scarce regions where fallow periods are used to accumulate additional soil water. Under rainfed Mediterranean conditions in central Aragon (northeast Spain), based on field measurements and model simulations, Moret et al. (2007) obtained evaporation losses during the fallow period in the range of $55 \%-91 \%$, whereas deep drainage losses were in the range of $5 \%-28 \%$. Thus, comparing continuous barley and a barley-fallow crop rotation, Moret et al. (2006) measured only an additional $20 \mathrm{~mm}$ of soil water storage through the fallow period.

Evaporation reduction from a bare soil surface during the initial evaporation stage can be attained through a coarse or disturbed layer (or mulch) overlying the wet subsoil. In a conventional system, however, tillage operations with the purpose of reducing evaporation are carried out with the sit lavorable moisture conditions, which is almost at the end of the initial evaporation stage In addilon, soil loosening and exposure boosts water losses from the cultivated soil layer as tillage op. In addition, heating and the formation of air pockets in which evapor $24 \mathrm{~h}$ after the primary soil tillage, Moret et al (2006) mithi 24 2 measured up to $16 \mathrm{~mm}$ of evaporation losse aganst $2 \mathrm{~mm}$ under NT. After the secondary tillage, they still obtained differences of up to $3 \mathrm{~mm}$ of the the objective of reducing evaporation is the result of a balance between the short-term evaporation bes the soil layer disturbed by any form of tillage and the possible long trm gains through the breakup of a faster upward capillary movement in the undistura Tillage may also affect soil evaporation the surface to the overlying atmosphere and winds and and albedo. Despite a higher ploughed soil tent of the surf C., Oguntunde et al. (2006) found only small differences in the soil moisture conAccording surface layer. On swelling and shrinking soils, evaporation losses may be considerable frow. the soi scason was $0.6 \mathrm{~mm} /$ day and an additional $15 \mathrm{~mm}$ of soil water is lost by evaporiorghum forsil swells and cracks close from the rains. Mulching or superficia soit Armation of cracks or at least obliterate them aulching or superficial soil tillage could prevent the Although the absence of soil disturbate the after they have begun to form.

that reduces evaporation of soil disturbance through the practice of NT has been viewed as a method the tillage-ind al. 2007; Fowler and Rockstrom 2001), information on aly associated withects on water evaporation from bare soils is scarce, as NT treatments are usurasides on the some form of residues over the soil surface. The effects not, have been soil water and especially evaporation, whether in combination with NT prects of the following section.

10.3.2 Soll Cover and Residue Management

beclops sonesystems with some minimum rainf

the scil some form of orgath of vegetation, the soil surface thete, the controls the flux cover consisting of plants and their residues after senescence. hydrosphere, the bo onergy and water by interacting with components of the atmo- 
environments into agricultural areas leads to a significant change in the partitioning of the water enviro nutrient, carbon, and energy flow. During an it to recharge the groundwater, and some may run of soil to replenish the soil water or flow through it to recharge (directly from an unprotected soil surface as overland flow and evaporate back into the atmosphere (directly from an unprotected soil surface and from plant leaves) (Bot and Benites 2005). The soil cover and residues directly affect the runof and from and them representing unproductive and soil evaporation and indirect sustainable soil and soil water management are to redirect these water losses. The objectives of suster storage and availability to plants.

列

In this section, we address the infuence soil water, either through thei inorganic mulching material, cover crops, and content an direct impact on infiltration/runoff and evaporation or the macrofauna activity. Additionally, we present evidence on how the soll cover type (including cover macrofauna activit. Ad characteristics and their management affect the soil water conservation an the soil productivity.

10.3.2.1 Effects on Infiltration and Runoff

Soil macroaggregate breakdown is seen as the major factor leading to surface pore clogging by ( primary particles and microaggregates and thus to the for Shukla 2004). The soil cover prevents this breakdown by reducing the kinelic engy with which Shing soil surface (Ben-Hur and Lado 2008). In addition to the detachment of the sol raindrops reach the soil sur raindrop impact and the physicochemical dispersion of the clays, slakin aggregates through direct raindrop impact an the disintegration of the aggregates and the consequen is considered another important process in the disintegration of the dry soil, the higher are the slakseal formation (Lado et al. 2004). The faster the wetting rate of ing forces. As the aggregate breakdown due to slaking is invered soil reduces the slaking forces. content (Haynes 2000), the higher topsoil moisture of the covered soil in fitration, and the amont

The tendency of a soil to form a surface seal, the resulting decrease in infiltration, and the amount of the resulting runoff and soil loss depend on the aggregate stability (Ben-Hur and Lado 2008). of the resulting runoff and soilished on the effects of the soil properties, such as texture, organic Many reviews have been published on the elity and sodicity, on aggregate stability (e.g., Lado and matter content, soil mineralogy, and soil salinity and sof crop residues and their management, howBen-Hur 2004; Kay and Angers 1999). The amount of crop residues akdown. After applying differ ever, can have a decisive effect on the resilience of the aggregate breakdown. After applorer a period ent amounts of wheat straw on an untilled loamy Fluvisol in the southwest of Spain over a foriond a of 3 years, Jordan et al. (2010), using the water-drop test and ultrasonic disruption methods, fond a clearly improved aggregate stability with an increase in the amount of straw residues ranging from clearly ime two highest mulching rates provided a significant 0 to $15 \mathrm{Mg} / \mathrm{ha}$ (Figure 10.6 )

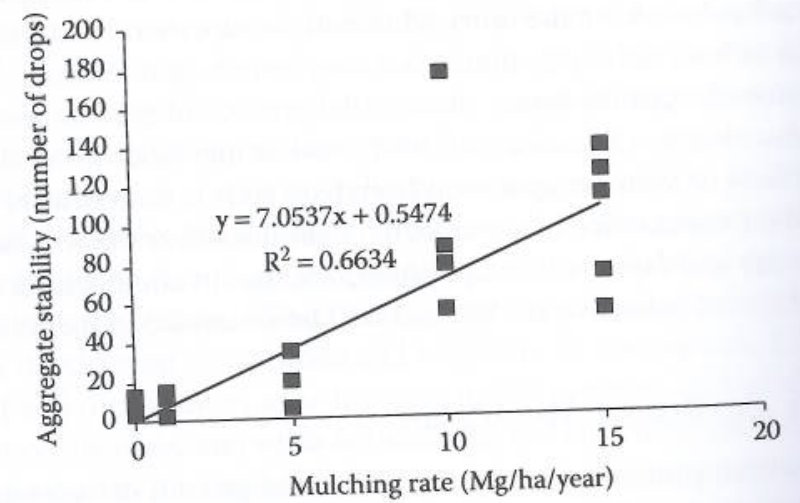

FIGURE 10.6 The relationship between the aggregate stability and the mulching rate. (From Jordan. Zavala, L.M., and Gil, J., Catena, $81,77,2010$.) better aggregate stability after 3 years. A more linear and positive correlation between the amount of wheat straw and the percentage of WSA and the MWD was found by Mulumba and Lal (2008) after 11 years on a stagnic Luvisol in central Ohio. Yet, it seems that crop residues alone are not effective in improving the soil aggregate stability. After 7 years of different residue management, which included NT with residues, residue incorporation through chisel/disk tillage, and residue removal before and replacement after tillage, Wuest (2007) found no differences in the MWD of the ggregates in the $0-5 \mathrm{~cm}$ layer between the straw mixed and surface-applied in the tilled treatments; however, under NT, the MWD was more than two times greater. This significant improvement of the aggregate stability under NT, when compared with the mixed treatment, was also expressed in the 5-10 cm soil layer. According to the author, an improved fungal activity might explain the observation of a better aggregate stability in the 5-10 cm layer when the straw was surface-applied after tillage instead of being incorporated into the surface soil. Under NT, this effect would also add other changes such as an increase in the SOM.

Soil cover with crop residue also promotes topsoil porosity, improving the water entry and transmission into the soil. The continuity of the pores left by decayed roots plays an important role in improving the infiltration rate, particularly in a very fine textured soil.

It is widely accepted that the random roughness of the soil surface created by tillage may contribute to the temporary retardation of the runoff, mainly through an increased depressional storage capacity. However, depending on several soil properties, there is a more or less sharp decline in the depressional storage with the progressive impact of the raindrops (Gomez and Nearing 2005; Guzha 2004). If crop residues are left on the soil surface, or are partially incorporated in the upper soil layer through mesofauna, not only is the impact of the raindrops reduced, but also the stream velocity, as the residues act as a succession of physical barriers (Verhulst et al. 2010; Jin et al. 2009). The residues play a role similar to that of surface roughness, that is, increasing the time for infiltration to take place (Blevins and Frye 1993), with the difference that their effect lasts longer. Therefore, the time lag for runoff generation is also greater when the crop residue is left on the soil surface (Jordan et al. 2010) and the transmission losses (turning small-scale runoff into large-scale runoff) decrease with the increasing vegetation or residue cover (Leys et al. 2010).

When incorporated into the surface soil, the amount of residues also seems to affect the infiltration and runoff. Gimenez and Govers (2008) measured an extra shear stress created by the freshly surface-incorporated residues and a reduced flow velocity, both of which were well correlated with the quantity of residues incorporated. However, at high runoff rates, their effect on reducing the flow hydraulics and erosivity is decreased. Studying the effect of shredded and spring-incorporated corn stalks of different plant populations $(0 \%, 50 \%$, and $100 \%)$ on runoff and erosion, Wilson et al. (2008) found a reduction in the average annual soil loss of around $50 \%$ for the $50 \%$ and $100 \%$ plant densities compared with the $0 \%$ population with no residues (bare soil), but a very small reduction in the surface runoff of $6.5 \%$ and $10.8 \%$, respectively. The $50 \%$ and $100 \%$ population did not differ in the yield or in the amount of residues left, which was around $7 \mathrm{Mg} / \mathrm{ha}$.

Thus, soil cover and crop residues left at the soil surface seem to be effective in improving infiltration and in reducing the surface runoff and soil loss. It also appears that the amount of residues is closely related to the degree to which the runoff is decreased. After 3 years under different mulching rates of wheat straw, rainfall simulation measurements at intensities of $65 \mathrm{~mm} / \mathrm{h}$ provided clear differences in the surface runoff between mulching rates (Jordan et al. 2010)
Figure pletely A hig did runoff.

found in difference between high and low standing, surface cut and removed stubbles has been Sharrat $(2002)$ where the retention of snow is crucial for supplying water to the following crop. tion, and (2002) reported that taller stubble trapped more snow, reduced the depth of frost penetraor residue remed thawing of the soil profile by at least 25 days, when compared with short stubble amount of snow cover. 


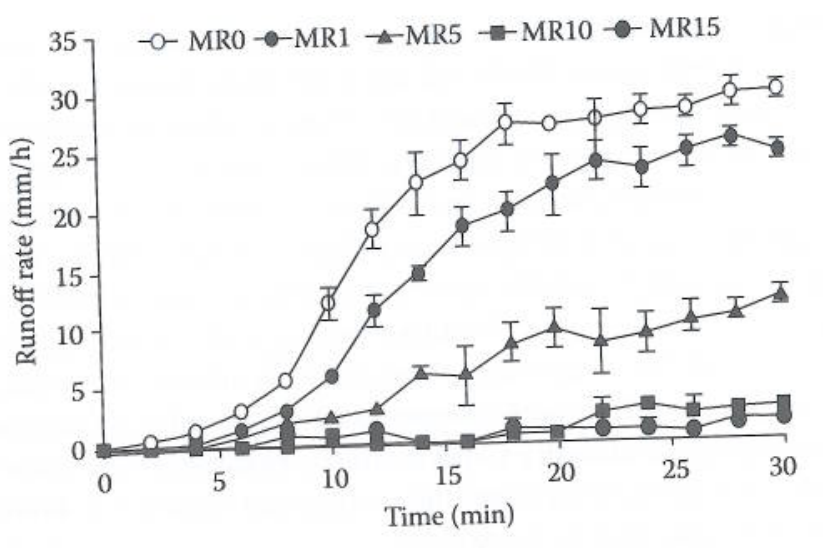

FIGURE 10.7 The variation of the mean runoff rates under different mulching rates. $\mathrm{MR} 0=$ contro $M R 1=1 \mathrm{Mg} /$ (ha year); $\mathrm{MR} 5=5 \mathrm{Mg} /$ (ha year); $\mathrm{MR} 10=10 \mathrm{Mg} /$ (ha year); $\mathrm{MR} 15=15 \mathrm{Mg} /$ (ha year). $\mathrm{N}=5$ fordan, A., Zavala, L.M. and Gil, J., Catena, $81,77,2010$.)

\subsubsection{Effects on Evaporation}

The transfer of water from the liquid phase to the vapor phase occurs at the expense of the absorbed heat energy and depends on the occurrence of the water vapor deficit in the air above the soil surface and the diffusion resistance along the pathway. The amount of heat energy and the water vapo face and the difusion resistance al due to the absorption of the incident radiant energy from the sul deficit are increased proportionally due to the absorperature. Furthermore, the evaporation vapor by the soil surface and the resulting increase in the temperature. Furh for reducing water evaporation flux from the soil is increased by the wind. Thus, the main approach for reducing water evaporation is by reflecting the incident energy to reduce the energy absorption by the surface, reducing the wind speed at the soil surface, and impeding or reducing the vapor flux from the soil into the atmosphere. The soil cover and residues act on all these processes, but it has been difficult to quantify their effects on the processes separately.

Soils much with crop residues or cover crops have a reduced maximum soil temperature an Soils mulched with crop residues or cover crops have a reduced Fabrizzi et al. 2005). The high sola a lower amplitude (Zhang et al. 2009; da Silva et al. 2006, Fabrezi an increase in temperature reflectivity and low thermal conductivity of the crop residues prevent an increase in (Shinners et al. 1994; Hillel 1980). On submitting a long-term NT area after a winter cover cren (black oats) to different tillage practices (NT, mouldboard plough, and chisel), da Silva et al. (2006 found that the cover crop residues on the soil surface under NT reduced both the maximum soil tict found that the cover temperature perature and the year, compared with sol amplitude down to $20 \mathrm{~cm}$ in depth with an oat straw wace energy balance will be used as latent heal without a straw cover. Thus, a lower portion of the surface energy

in the system, reducing the evaporation of water from the soil.

Both transpiration and soil evaporation depend on the evaporative demand of the environmenand order to study the interaction between the soil type, the residue cover, and the evaporative dempes and Freitas et al. (2006) treated a loamy sand and a heavy clay soil covered with different types add Freitas et al. (2006) treated a different evaporative demands of around 3, 5.2-6, and 7-8 mm/mon (Table 10.4)

Wheres the uncovered soil remained in the first evaporation stage only at the evaporati the 21-day tint demand of $3 \mathrm{~mm} / \mathrm{day}$, both residue-covered treatments maintained this stage both soil and residure period for the medium and highest evaporative demands. On average, over both soil $30 \%$ of this types, the highest amounts of residues resulted in total evaporation, which was around 30 r duction measured in the treatment without residues. Especially on the loamy sand, evaporationd. meas evaporive demand.

\section{TABLE 10.4}

Total Soil Evaporation during 21 Days (after Reaching Field Capacity) for Two Different Soils under Different Types and Amounts of Residues and Different Evaporative Demands

\begin{tabular}{|c|c|c|c|c|c|c|c|c|}
\hline \multirow{2}{*}{\multicolumn{3}{|c|}{ Residues (kg/ha) }} & \multicolumn{6}{|c|}{ Evaporative Demand $(\mathrm{mm} /$ day) } \\
\hline & & & \multicolumn{3}{|c|}{ Corn } & \multicolumn{3}{|c|}{ Wheat } \\
\hline & & Wheat & 8 & 6 & 3 & 7 & 5.2 & 3 \\
\hline $\begin{array}{l}\text { Loamy } \\
\text { sand }\end{array}$ & 0 & 0 & 74.2 & 82 & 57.2 & 59.2 & 68 & 47.9 \\
\hline Heavy clay & 0 & 0 & 56.4 & 74.2 & 56.4 & 54.7 & 59 & 46.9 \\
\hline $\begin{array}{l}\text { Loamy } \\
\text { sand }\end{array}$ & 5000 & 3500 & 40.2 & 28.9 & 19 & 38 & 28.4 & 18.5 \\
\hline Heavy clay & 5000 & 3500 & 35.7 & 30.1 & 22.2 & 35.2 & 32 & 22.8 \\
\hline $\begin{array}{c}\text { Loamy } \\
\text { sand }\end{array}$ & 10000 & 7000 & 20.4 & 19.8 & 18.6 & 20.6 & 20 & 16.5 \\
\hline Heavy clay & 10000 & 7000 & 21.1 & 18.1 & 13.6 & 20.3 & 17.1 & 13.1 \\
\hline
\end{tabular}

e: Adapted from Freitas, P.S.L., et al., Rev. Bras. Eng. Agr. Ambient. 10, 104, 2006.

The contribution of residues, whether alone or in combination with NT, to reducing the evaporation component of total ET has been confirmed by numerous studies and under many different conditions. In Punjab, India, Jalota and Arora (2002) observed that straw mulching $(6 \mathrm{Mg} / \mathrm{ha})$ substantially reduced the soil water evaporation under medium-textured and coarse-textured soils by 18.5 and $13.1 \mathrm{~cm}$ in maize, 23.8 and $16.6 \mathrm{~cm}$ in cotton, and 23.6 and $17.6 \mathrm{~cm}$ in sugarcane crops, respectively. They concluded that the irrigation requirements of summer crops can be reduced further by mulching with crop residues. Lamm et al. (2009) also suggest that strip tillage and NT, due to the maintenance of the crop residues, should be considered as improved alternatives to CT, particularly when the irrigation capacity is limited. In Texas, Lascano et al. (1994) found in cotton production that the total ET was similar between a conventional and a wheat straw residue-based strip-tillage system. However, they found large differences in the components of ET, with a share of the transpiration of 50\% with CT with no residue against $69 \%$ under straw mulch, which resulted in a $35 \%$ increase in the lint yidd. In a recent study using undisturbed mini-lysimeters, Klocke et ah. (2009) comped soil with the soil partially or complety coverd with wheat sube without the end stover and with and canopy and full of the corn canopy. On average over 3 years, the evaporation in the field study (with canopy and full residue cover) was reduced by almost a half through both types of residues. Even with a surface coverage between $91 \%$ and $100 \%$, the higher the amount of residues, the more pronounced was reduction in evaporation. In the trial without a canopy, evaporation compared with bare soil W

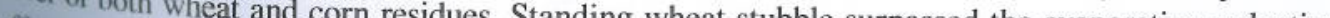
effect of the flat corn residue, an observation that the authors attribute to the possible aerodynamic
effects of standing straw. However, the straw.

ent climatic conditidue management effects on the evaporative water losses may vary with differof evaporations. For example, in contrast to a possible reduction of the convective componen under sandy through standing wheat stems, advanced by Aiken et al. (2003), Ward et al (2009), stubhe wy topsoil conditions, observed an increased evaporation in the presence of standing upward compared with cut and removed stems or slightly buried stems. A possible capiln also bovement of water through the senesced roots is provided as a poss. A possible capillary conteen concluded that residue the senesced roots is provided as a possible explanation. It has Controlling evaporation (Sesidue thickness (volume) is more important than mass per unit area for 
horosity and pore continuity are favorable characteristics for increasing the soil filtration, they also enhance the upward water movement from water storage capacity and deep infiltration, they also enhance the upward water compared with the the deeper soil layers (Lampurlanes and Cantero-Martnez to reduce evaporation effectively, some retention of a sufficient amount of residues at the soil surface to reduce evaporation of residues because this authors found better results with a very shallow surface incorporaton for Sillon et al. (2003), seems best at breaking the unsaturated hydraulic conductivity, a process that, in albedo and surface roughto be more important for evaporation reduction than the differences in alo the benefits of the residue management treatments followed ness. Prihar et al. (1996) found thatue-mulch $>$ residue-incorporated. According to Gill and Jalot the order of residue-undercut $>$ residue-mulch $>$ reside the top few centimeters can be as efficient or (1996), incorporating lower rates of straw mulch ing evaporation.

more efficient than higher mulch rates at reducing evaporation.

Other types of surface covers have been proposed to reduce Unan et al. 2009; Tao et al. 2006. such as plastic films or sand or gravel mulch (Liu et al. 2009, Yuan en Despite some positive results with regard to reduced evaporation and inproved waler storage and Despite some positive resultal investment are clearly the major constraints to the widespread use of productivity, labor and capital the objective of evaporation reduction.

these materials, at least with the strongly depend on the The process of evaporation and its control remain aver which treatments or practices are applied. soil and climate conditions and the length of the soil surface mulch can reduce the Nonetheless, it is widely agreed that an increase in the rate of the soils sul. 2010; Blanco-Canqui and amount of short-term and probably long-term soil evaporation (Vero Lamo Lal 2009, Sigh al al al. 2009; Burt et al. 2005). soils, surface mulch may not be effective for ef the soil evaporation and that of the soil water storage However, under these conditions, the response of the soil dirrespective of the soil cover (Monzon 2006). to rainfall are in a phase where all rainfall is evaporate, increase in Soil Organic

\subsubsection{Effects on Soil Water through the} Matter and Macrofauna Activity The removal of crop residues through burning or for fodder and bioferall sustainable development be a major threat to soil productivity, environmental quality, and overall sustainable developmention (Blanco-Canqui and Lal 2009; Hakala et al. 2009; Lal 2009). In addition to the physical protection of the surface soil layer and its impact on infiltration and evaporation, organic residues enhance the buildup of SOM and soil fauna activity, which contribute to improve 2009; Wuest et al. 2005). aggregation, soil moisture storage, and deep water infiltration (Lal 20 activities of earthworms and

The improved pore space is a consequence of the bioturbation activities of earting the effect Ther macroorganisms and the channels left in the soil by decayed plant roots. Studying the effect other macroorganisms and the chnst et al. (2009) found that the soil water was strongly affected by of earthworms in Germany, different earthworm species. The epigeic Lumbricus rubellus tended the activity of ecologically different earthworm spoil, and the endogeic Aporrectodea caliginosi to enhance the storage of soil moisture in the topsoil, and the endischarge through the soil. Although strongly improved the water infiltration and hastened the water discharge throge absence of soil dis the benefits of increased earthworm populations are mainly attributed to the abively less than the turbance (two to nine times more in NT than under CT [Chan 2001] and Blanco-Canqui and Lal turbant of residues retained at the soil surface [Eriksen-Hamel et al. 2009]), Blanco-Canqui and amount of (2007b) found a strong effect of corn stoval at rates above $25 \%$ drastically reduced the number On all three soils studied, stover wally anaerobic clayey soil, stover removal above $50 \%$ eliminater earthworms and, on the occasionally anaerobic 0,8 , and $16 \mathrm{Mg} / \mathrm{ha}$ year of wheat sir the earthworms. At a different site after 10 years of applying 0 , (2007a) found $158 \pm 52$ earthworm without crop and cultural operations, Blanco-Canqui and Lal (2007a) found in the highest mulching per square meter in the medium and $267 \pm 58$ earthworms per square me

per square meter no earthworms were present in the zero mulch level. Whereas the authors associate the higher water infiltration rates obtained with less or no grealc removal in the study under three different soils (Blanco-Canqui and Lal 2007b) to number of surface-connected earthworm burrows and other biopores, they found no difference in the infiltration rates between the residue levels at the other site (Blanco-Canqui and Lal 2007a). In both studies, however, they measured significantly higher soil water retention under the higher amount of residues, although this was confined to the surface soil layer. While some reports indicate that an abundance of earthworms has a strong influence on the soil porosity and the consequent water infiltration in mulched NT soils, Bottinelli et al. (2010), Kladivko et al. (1997), and BlancoCanqui and Lal (2007a) concluded that increases in the earthworm population by mulching does Catr always increase the water infiltration rate in all soils, depending on the dominating type of earthworms.

Increases in the surface mulch or the residues incorporated into the soil tend to increase the SOM (Wuest et al. 2005; Sharma and Acharya 2000). Even under NT, the amount, type, and managemen of the residues play an important role in the evolution of the SOM. Basch et al. (2010) compared the residues of chickpea and the different amounts and management of wheat straw with regard to the changes in the SOM under Mediterranean conditions. After 3 years, they had already foun (he $\mathrm{SOM}$ in the following order (letters indicate differences $\mathrm{P} \leq 0.05$ ): chickpea residues (c) $>$ stubble only (bc) $>$ in-field grazing of straw and stubble (b) $>>$ straw retained (a) $>2 \times$ straw retained (a).

SOM promotes soil biological activities and processes, resulting in more bacterial waste products, organic gels, fungal hyphae (polysaccharides), and worm secretions and casts (Wuest et al. 2005), which improve the aggregate stability and porosity. Directly or indirectly, these organic compounds are related to the water-holding capacity, although it is the total SOC or organic matter that is usually considered as an important aggregate indicator in a discussion on water retention pedofunctions (Rawls et al. 2003). Evaluating the efficiency of the pedotransfer functions to estimate water retention in 725 soil samples from the state of Rio Grande do Sul, Brazil, covering all types of soil textures, Reichert et al. (2009a) concluded that organic matter must be included as an independent variable, because it had an individual positive effect on the field capacity and the plantavailable water. Sharma and Acharya (2000) found that the application of fresh lantana (Lantana camara $\mathrm{L}$.) at a rate of $8 \mathrm{Mg} \mathrm{DM} / \mathrm{ha}$ either as a surface mulch or incorporated over 4 years significantly increased the SOM content in the layer $0-15 \mathrm{~cm}$. At the different sowing dates, the mulched Ireatments compared with the unmulched treatment showed a higher amount of stored soil water (between 15.1 and $22 \mathrm{~mm}$ ) in the $0-45 \mathrm{~cm}$ layer. From the third year onward, both mulch treatments yielded significantly higher than the unmulched treatment, and in the fourth year the yield in the surface-applied mulch surpassed those in the incorporated mulch.

Crop residue incorporation is not the best residue management practice because it implies soil disruption and eliminates the beneficial effects of the residues retained on the soil surface. Even so, in a long-term experiment, Singh et al. (2005) found that rice straw incorporation was less detrimental to the soil physical and hydraulic properties than the burned or removed rice straw. Whereas straw removal compared with the other residue management systems performed worst with regard $1050 \mathrm{M}$ and soil aggregation, straw burning led to reduced water retention due to an increased water repellency of the soil surfaces. Comparing the effect of rice straw incorporation plus $60 \%$ of the mineral fertilizer-only treatment over 8 years in a sweet potato-rapeseed rotation, Zhu et al. (2010) found a $13 \%$ increase in the SOM with the rice straw application and a significant increase in the -holding capacity. The correlation between these two parameters was highly significant.

10.3.2.4 Influence of Type of Soil Cover and Residues and Their Management on Soil Water and Crop Productivity

As shown in the previous sections, the soil cover has a decisive effect on the soil water dynamics the choice of to enhancing the green water component and promoting WP. The possibilities and clim se the soil cover and its impact depend, in addition to the main objective behind it, on the (Wilhelm et al. 2004), and (Wing system (Wilhelm et al. 2004), and the 
Whereas the use of cover crops is mainly restricted to humid or subhumid regions, in semiarid most commonly used option to improve the environments, soil cover through crop to crop productivity. On a very limited scale, other materuse efficiency of the main limiting factor to crop pro waste products are used for mulching to protec als such as plastic films, gravel or sand, or organic waste product the effectiveness of these material the soil and enhance the green water component. The use and the effectivenes or reducing the soi have been reported mainly from Asian countries and are considered an option for reducing the soil evaporation, thereby increasing the infiltration of rainwater and soil water retention (Liu et al. 2010; Ghosh et al. 2006; Ramakrishna et al. 2006). In studies using soil cover with plastic film, Wan (2009) found that transpiration was the main component of total ET. From a 2-year study, Li et al. (2009) found that transpiration of $19 \%-24 \%$ in maize yield and 23\%-25\% in WUE in soil covere et al. (2010) reported an increase or orian bare soil. Total and partial covers of plain soil or ridges and with plastic film compared with rainfed bare sil. The furrows with different materials (straw, plastic film, gravel-sand) (Liu et al. 2010; Wang et al. 2009; proposed and studied with regard to WUE and crop performance (Liu et al. 2010; Wang et al. 200 ; Yuan et al. 2009; Zhou et al. 2009). Although these techniques have been found to be more or less effective in reducing evaporation and runoff, improving infiltration and soil temperature, halting wind and water erosion, and enhancing biological activity and soil fertility (Li 2003), their use on wind and waterosions.

The Therefore, in large-scale agriculture under sem feasible and economically viable option to cover from cover crops, seem to be the only technically feasible and Conservation of the soil moisture and protect the soil, while improving the soil water and WUE. Conservation of the soil moisture is one of the major advantages of the mulch farming systems (Mulumba and Lal 2008; Baumhardt and Jones 2002). In semiarid environments with rainfall above the minimum threshold for a benefit and Jones 2002). In semiarid environments generally increases yields by enhancing the soil water in terms of water storage, straw; Monzon et al. 2006), but in poorly drained soils or in temperate storage (Bescansa et al. 2006; Monzon et al. 2006), butue retention may sometimes reduce yield climates with suboptimal springtime temperatures, residue retention mal 2008a; Fabrizzi et al. 2005; below optimal levels due to the decreases in the soil temperatu

Anken et al. 2004) and the soil nitrogen (Gao and Li 2005).

As already discussed, the impact of the residues on soil water conservation may depend on their composition, management, and amount (Leys et al. 2010, Ward et al. 2009; Blanco-Cancit no conp 07 b Sauer et al. 1996; Steiner 1989). Although the possible impacts of the crop residues on Lal 2007 ; the hydrophes surface deliver the highest benefit in terms of management systems that retain crop 2006. Burt et al. 2005), studies that relate long-term residue soil water availability (Coppens et al. 2006, Burt et al. 20 field conditions are scarce and are somecover to soil water availability and crop productivity under field conditions are scarce and are sover times inconclusive or contradictory (Blanco-Canqui et al. 2006) as the benefits of the residecontures in terms of soil fertility and water availability might be offset mainly by lower soil temperater The in tern the problems (Liu et al. 2004; Mann et al. 2002). The during the inger production (Graham et al. 2007; Wilhelm et al. 200-) increasing demand for reside benefits of longis raising concerns regarding excessive residu the crop residues (Dabney et al. 2004). Studying term NT management may be lost by removing the crep res on the different percentages of corn stover removal over 2 years on three long-term $N$ an increase in the Blanco-Canqui and Lal (2007b) found a decrease in the plant-available water with an ince site, weltpercentage of stover removal. However, this was reflected in higher crop yields only at one sice, vild percentage or stover rene. They concluded that soils with different characteristics might reveal period drained but erosion-prone. They contain threshold level was continued over a longer time perines effects if stover removal above a certain threshold levels was urgently needed. However, hing and that site-specific determination of these threshold levels was urgently neces provided by retainin thresholds should also be assessed with regard to other ecosystem services provilality (Lal 2005. crop residues, such as offsetting $\mathrm{CO}_{2}$ emissions and maintaining the overall soil qualit disadvat Cover crops are grown for multiple reasons and their use may present advantages and conditions tages, as comprehensively reviewed by Dabney et al. (2001). With regard to soil moisture con 1056 for through an increased residue cover, an increase in SOC, improved soil physical properties (Lu et al. 2000 ), or removal of the excess water from a wet soil to allow timely establishment of the next crop (Unger and Vigil 1998). However, the reduction in soil moisture is the main reason why cover crops are more suited to subhumid and humid regions, unless irrigation is available to compensate for the extra water consumption by the cover crop. The use and the choice of cover crop species are highly sie-specific and depend on the main objective to be achieved. Short-cycle and early maturing speies or a premature interruption of the cover crop cycle have been proposed to reduce competition cies o with the main cop (Whish et with summer or winter rainfall, normally a single cash or food crop is produced during the growing season, often followed by fallow. In some regions, more than one-third of the agricultural land may be under fallow. With the NT system of soil and crop management, it has been shown that introducing cover crops (for forage or grain) in rotation can reduce the fallow land and simultaneusly improve the soil cover, rainwater infiltration, soil water storage, biological nitrogen fixation (in case of legumes), and SOM and fertility (Goddard et al. 2008; Crabtree 2010), while reducing the soil evaporation as already indicated from crop residues (Jalota and Arora 2002). This has been shown to work in semiarid regions in many parts of the world, including North Africa (Mrabet 2008), Canada (Baig and Gamache 2009; Lindwall and Sonntag 2010), the United States (Ransom et al. 2007), Australia (Flower et al. 2008), and Eurasia (Gan et al. 2008). Similarly, with irrigated systems, off-season cover crops provide similar advantages.

\subsection{PRODUCTION SYSTEM MANAGEMENT}

\subsubsection{CROP MANAGEMENT}

This section focuses on the different ways that crops can be managed within production systems to improve the soil water availability, WUE, and WP, apart for cultural practices related to soil tillage, residue management, and soil cover, which were dealt with in the earlier sections. These constitute a large range and include crop and cultivar choice, crop establishment and yield response to water, crop genetic improvement, pest management, fertilization and nutrient management, crop phenopic expression, and crop rotation and intensification.

However, it must be stressed that individual practices that form a constituent part of good crop management and good production system management for optimizing the use of rainfall or irrigation water are often interrelated in terms of their effects on the final outcome. The interactions among practices can work synergistically to produce outcomes in terms of soil moisture availability, WUE, and WP, in which the "whole is larger than the sum of the parts." For example, for a given amount of rainfall, the soil moisture availability to plants depends on how the soil surface, the SOM, and the plant root ystems are being managed. Also, high water productivities under a good soil moisture supply are only possible when plant nutrition is adequate. Similarly, no amount of fertilizer application and use of modern varieties will improve the WUE and the WP if the soil has a $20-30 \mathrm{~cm}$ hard plough pan - $20 \mathrm{~cm}$ below the surface; and worse, if the soil has no organic matter and life in it to build and maintain a good soil structure and porosity for maximum moisture storage and root growth. Equally, Wo

Thus, soil evaporation, it is not possible to fully optimize and maximize water use and WP. possibility of making equal, soils that are maintained in good health and quality will offer the the possibility making the maximum amount of soil moisture available for crop production and manipulation of optimal water-use efficiencies and water productivities through good agronomic variable but or good crop management. However, good crop management is not an independen to sustain a function of how sustainably the production system as a whole is managed in order conceptin intensify production while harnessing the desired ecosystem services. It is with this sysert in nind that the following while hartions discuss some of the key clements of crop and producto system manage that the following sections discuss some of the key elements of crop and production avement in relation to soil water availability, WUE, and WP. 
10.4.1.1 Crop and Cultivar Choice

The choice of adapted crops and cultivars in irrigated or rainfed production systems, from a moisture viewpoint, is dictated primarily by the nature of the water supply (amount, frequency, and variability) and the type of production system deployed (tillage system or NT system; also generally known as the conservation agriculture [CA] system) (Friedrich et al. 2009; Kassam et al. 2009). Production system define the possible biological space-time relationships with the prevailing environment and resource use and have an overriding influence on crop agronomy or crop management and cultivar choice, whereas the economic and environmental objectives of the producer will dictate which adapted crops whereas the economic and environmental objectives of the producer will dictate which adapted crops
and their cultivars can best fit into the cropping system in space and time. For example, relatively early sowing is possible with NT production system, with improved WUE and WP, compared with tillage systems. The NT system can also offer the opportunity to introduce crop cultivars of longer maturity and higher yield potential or to include a shorter maturity relay crop variety for food or as cover crop.

The water relationships of crops depend on many attributes of the crop and the soil, but they depend, in the case of rainfed crops, even more on the seasonal climate and the weather conditions of the place where it is grown-which determine how much water the crop will receive and when, and how fast the water will be used, and how much of water can be stored in the root zone. It is therefore important that the environmental physiology of the crops and the crop cultivars fit appropriately into the time available for crop growth and phenological development and that the crops and their cultivars participating in the cropping system are able to adjust their life cycles to match the unpredictable year-to-year variations in the length of the growing period and in the soil moisture balance. The ability to withstand diurnal water deficits and to survive dry periods in a state of physibalance. The ability to withstand diurnal water deficits and to survive dry periods in a state of physi-
ological dormancy seems likely to be important during this stage under both rainfed and irrigated conditions (Blum 2009; Soriano et al. 2004; Bunting and Kassam 1988).

Within any irrigated or rainfed production system, only a portion of the soil-available water (between field capacity and wilting point) is readily available to crops, which is equal to the leve of the maximum depletion of the soil water that a crop can tolerate without a decrease in the plant growth rate. This varies with the type of crop as well as the cultivar. The value of readily available water for production depends in part on the crop cultivar, the quality of the soil, and the evaporative demand of the atmosphere. All these factors, including the crop and the cultivar environmenta adaptability requirements, and in combination with economic factors alongside the length of time that the water supply from irrigation or rainfall will be available and its reliability, will influence the choice of crops and cultivars that might be considered for the cropping system (Kassam et al. 2007; Gregory et al. 2000; Bunting and Kassam 1988; FAO 1978-1981; Doorenbos and Kassan 1979). Some crops, such as potato, onion, and strawberry, require the soil to be continuously mois if they are to produce good yields; others, such as cotton, wheat, sorghum, safflower, and olive, will tolerate drier soil conditions. However, the level of depletion that a crop will tolerate varies greatly with their stage of development; most grain crops are vulnerable at the time of germination or planting, particularly under rainfed conditions, and, once established, prefer a smaller depletion during changes from the vegetative to reproductive growth, or in the case of cereals, during the period of panicle initiation, heading, and flowering to fruit and seed setting.

Further, crops vary in the extent to which the leaf water potential can fall without interrupting transpiration or doing damage to the leaves or other parts of the plant. For a given soil type or quality and level of evaporative demand, differences in the root system properties, the leaf and tissue water relations, and the crop development characteristics are all important in determining the dif ferences between crops and among cultivars in the magnitude and time course of the readily available soil water. Doorenbos and Pruitt (1977) have reviewed the general information for differen crops on the rooting depth and on the readily available water for different soil types and evaporative demand. Such information together with the information on the yield response to water provides demasis for designing croping systems that can optimize the available water and offer best water productivities, including under deficit irrigation (FAO 1992; Doorenbos and Kassam 1979).
The WUE and WP of rainfed crops can be improved through crop and cultivar choice by ensuring a good fit between the crop growth cycle and the length of the prevailing rainfed growing period ross the different climatic zones and also ensuring that the chosen crop cultivars have access to adequate nutrients and pest control (including weeds) to offer best WUE and WP. For example, in the warm tropical climatic zones with rainfall between 400 and $600 \mathrm{~mm}$, annual grain crops of similar maturity are selected to fit the moisture regime, but there are specific component crops included in the crop association that allow for fuller use of the end of wet season moisture. In areas of higher rainfall up to $1000 \mathrm{~mm}$, crop mixtures of grain crops with some root and tuber crops, especially hose involving different maturities, are common. In areas with above $1000 \mathrm{~mm}$ of rainfall, crops and their cultivars are selected to fit into multiple cropping systems that are based on both the simultaneous (intercropping) and sequential (relay cropping) principles to maximize the use of the available soil water (Bunting and Kassam 1988; Kowal and Kassam 1978; Andrews and Kassam 1976).

In warmer regions with a long wet season as in the humid tropics, or a shorter wet season as in the seasonally dry tropics, with irrigation facilities, crops can be grown year round. Once crop cultivars of a certain duration have been selected to match the prevailing moisture regime, and barring othe ment is a function of good crop nutrition and protection, and ensuring minimum soil evaporation losses and the maximum proportion of available water consumed as transpiration (Passioura and Angus 2010), aspects that are discussed later in this section. Under drought-prone environments, WP can be improved or maintained by selecting cultivars that have an effective dehydration avoidance ability (Blum 2009) so that they can endure or withstand a dry period. Usually, this is based on the cultivars' ability to extract more stored water from the soil profile, by developing a bigger working range in the water potential in leaves and other plant parts through osmotic adjustment and by storing water in their tissues so that wilting is delayed (Chimenti et al. 2006; Blum 2009; Sellin 2001; Ali et al. 1999; Ludlow and Muchow 1988; Kassam et al. 1979).

\subsubsection{Crop Establishment and Yield Response to Water}

Good and timely crop establishment is essential for achieving high WUE and WP. However, crop establishment can be a precarious or a vulnerable stage in a crop's life, particularly if the crop must be established with soil moisture derived from rainfall. This is because not only must the soil moisture supply be adequate for the seed to germinate, but it must also continue to supply the seedling roots with water and nutrients for growth. Under rainfed conditions, in a seasonally dry climate, whether in the tropics, subtropics, or a temperate climate, every year the farmer and the crop must cope with the variability of the soil moisture supply around the onset of the rains, and therefore at the start of the growing period. Each year, the start of the growing period can be different. However, for the seasonally dry tropics, it has been shown that an adequate soil moisture supply for crop establishment is reached when the rainfall is around $0.5 \mathrm{ET}$, increasing subsequently to meet the actual crop water requirement of the growing crop as its leaf area increases (FAO 1978-1981; Kowal and Kassam 1978). The actual crop water requirement is dictated by the evaporative demand of the atmosphere and the crop growth stage, in particular the crop leaf area. Dry spells soon after germination can be harmful if the soil moisture supply drops below $0.5 \mathrm{ET}$.

It is possible to make practical estimates of actual evapotranspiration (ETa), and hence the crop water requirement, from computed ET using empirically derived crop coefficients $(\mathrm{kc})$, such as $\mathrm{Eta}=\mathrm{kc}$ ET. Values of $\mathrm{kc}$ for different crops at different growth stages are given in Doorenbos and Kassam (1979). As indicated, for many dryland crops, kc at the time of crop emergence and stablishment is $0.4-0.6$, increasing to a maximum of $1.0-1.3$ when the crop canopy covers most or all of the ground and is able to intercept most or all of the incoming radiation. This occurs in many crops and environments when the leaf area index (LAI) is around 3 (Stewart 1991; Bunting and Kassam 1988; Kowal and Kassam 1978). The relationship between relative ET (ETa/ET) for several field crops shows that at a given LAI, crops of markedly different canopy structures (e.g., 
sorghum, cotton, groundnut, pearl millet, and maize) use water at very similar rates (Kowal and Kassam 1978). Thus, factors that control the leaf area, particularly the nutrient fertility and the plan .

population, will dictate the the cultivar has its own

In general, the relationship between yield (Y) and ET is linear and that (Stewart 1991) and the ration of yield decline ET defici, provided water is the only limiting factor (Stewart 1991) and the required inputs of nutrients were used and weeds were controlled, etc. However, a water deficit of given magnitude may occur either continuously over the total growing period of the crop or it may occur during any one of the individual growth periods, that is, establishment, vegetative, flowering,

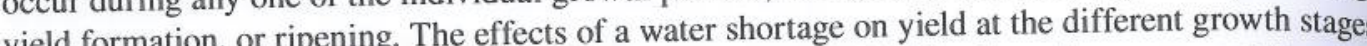
yield formation, or of a number of crops are $(\mathrm{ky})$, which relates the relto the water supply was quantified through tive yield decrease to the relative ET deficit. In the case of deficits occuring continuously over the total growing period, the effects of increasing water deficits on yield were less $(k y<1)$ for alfalfa, groundnut, safflower, and sugar beet than for banana, maize, and sugarcane $(k y>1)$. In the case of deficits occurring during the individual growth periods, the effect on yield is relatively small for the deficits occurring during theins and relatively large for the flowering and yield formation periods.

Thive and ripent limiting, an analysis of the crop water

This means that when we identify those crops an production functions when performed for a range of crops can serve to inter regime frops an cultivars that are best suited ecologically to the prevailing or expected water regime from rainfal or irrigation. They also help identify what crops and cultivars should be selected for the differen seasonal moisture expectations from rainfall or irrigation. When the effects of the managemen decisions (such as plant population and fertilizer application levels) are simulated in the analysi, decisions (such as plant populat for different types of rainfall and irrigated moisture regimes can be optimal identified. They can thus provide

duction capabilities (Stewart 1991). For irrigated conditions, crop management for the optimal use of water (i.e., to achicve bes
WUE and WP) can be simulated against particular objective functions, and actual crop management can follow the planned simulations. In the case of rainfed conditions, the rainfall probability ment can follow the planed soil water balance analysis are required to quantify the probabilities analysis and the associated soil we the rain different rainfall amounts in select the probability of dry (or wet) spells in specific time period. period may begin and end and reveals the risk, allowing refeThis provides a basis for broad-based planning, including an analysis ok the nuch, allowing to to ence crop and cultivar mix and cropping systems to be identified. Linking such an analysis to an additional analysis of rainfall predictions, as is done in the case of response farming, allows cro management decisions regarding crop and variety types, planting dates, plant densities, and fertimanagement decisions regar to be made in response to the upcoming season (Stewart 1991). Cro izer levels and application the notion the water managent is of the probabilitis just prior to the start of each season, it is possible (from the total range of probabilities) and have new probabins (1991), is the reduction of the effectiv principle of response farming, as elaborated by Stewart (1991), is the reduction of the cilctive variability through an improved rainfall prediction, which does not mean pinpointing what in occur, but, rather, identifying a portion of the range of recorded happenings that should not need ifferbe considered as possibilities in the current season. This concept is based on the findings in difitith be conside the rainfall season begins (date at which ent locations that amount and duration thereafter a particular soil moisture supply may be reached) and Kassam 1978).

(Stewart 1991; Stewart and Kashasha 1984; Kowal and Kassam 1978).

Thus, from the above, it is clear that the crop management strategy for improved or op have WUE and WP requires attention to a whole suite of elements. There are additional factors hed sow a significant impact on the overall water-related performance. For example, with tillage-based Also ing and crop establishment, time is required to prepare the seedbed at the start of the rains. ang a the seedbed dries loses its capillary contact to the deeper soil water. As a result, moisture and time are spent that can delay sowing and crop establishment, as well as expend energy that may be saved or spent on something more productive. Also, the effective rainfall is reduced, thereby decreasing the potential WP, as well as WUE or effective water use (Blum 2009; Soriano et al. 2004)

The key to the effective use of soil water under rainfed conditions is to be able to plant the crop as early as possible. Any delay in crop establishment usually leads to a loss in yield in the case of rainfed crops. Where the average length of the growing period is short, as in the case of the semiarid regions, early sowing reduces the chances of late season water deficit. Given the rainfall variability at the start of the rainy season, often it is not possible to take full advantage of early sowing with tillage-based approaches in which the soil moisture that is available at the beginning of the season is used unproductively in land preparation through tillage for subsequent sowing.

An alternate approach to sowing in tilled soil is the possibility of sowing early into dry soil or just the time of the onset of rain, if the soil has some moisture. This is only feasible under CA, which involves direct seeding into a soil with an organic mulch cover that allows, as seen earlier, maximum infiltration and therefore maximum effective rainfall. Where the rainfall climate is semiarid savannah with less than 90-120 days or it is a dryland type with no humid period during the rainy season, an adaptation such as dry sowing in mulch-covered microbasins or pits (called likoti, tassa, and zai) help achieve maximum infiltration and early sowing and crop establishment (Marongwe et al. 2011; Owenya et al. 2011; Silici 2010). In undisturbed dry soils, germination can occur on the basis of the available humidity in the soil pores from subsoil moisture, even when the bulk soil is below the permanent witling point. Similarly, in rainfall climates that are humid, a mulch-covered NT permanent bed system provides a good basis for crop establishment and for achieving higher WUE and WP (Govaerts et al. 2007). This is because the soil moisture in undisturbed mulchcovered soils is still at much higher levels and closer to the seeding soil horizons than in fully tilled soils.

Where the rainfall season is longer, it is possible to increase the WUE and the WP through an increase in the cropping intensity as well. Early sowing and crop establishment of the first crop allows a second crop to be fitted into the cropping system more optimally, and in certain cases, can even create time for a third short-season crop to be fitted into the cropping system. This has happened in Brazil in the Cerrados with the maize-soybean cropping system (Landers 2007) and in the Indo-Gangetic Plains with the wheat-rice cropping system (Hobbs et al. 2008; Hobbs 2007).

\subsubsection{Crop Genetic Improvement}

Physiologically, an improvement of the genetic yield potential, and therefore WP, with modern cultivars has been achieved through improving the HI by improving the sink capacity. At the same time, to achieve higher WUE and WP, the root system must be able to exploit the largest possible soil rooting volume for available water. Also, key phenological and physiological processes that determine sink size and yield formation, for example, panicle initiation, flowering and seed setting in cereals or tuber initiation in tuber crops, and yield components such as the number of head-bearing tillers, seeds per spikelet, or seeds per cob, etc., are protected against drought or extreme temperatures as much as possible. Thus, the selection of improved WUE and WP has tended to lead to a larger root system and a higher HI, but also to physiological resilience to drought and temperature stress. The $\mathrm{HI}$, WUE, and WP are indices and represent the outcomes of a series of crop ecophysiological procausing operating in the right way under normal circumstances as well as under situations of stress as expliciter deficits and under situations of heat stress. Outcome-related indices are not helpfu drought targets of breeding and genetic improvement programs. Instead, for water-limited and ance inone environments to target plant adaptive characteristics including dehydration avoida can (1) enable the crop to establish as early as possible and reach and exploit the desinum amount of soil-available water for tran conditions (Blum 2009). (Blum 2009). 
This is supported by the fact that in water-limited environments, the timing of flowering is perhaps the most important trait for breeders to select in order to achieve a good balance between the haps the most important trait for breent and the water used during seed setting and grain filling water used during canopy development and This is because the yield is correlated with the soil mois(Passioura and Angus 2010; Fischer 1979). This is because the yiale
ture available from the soil storage and is supplemented by the rainfall or irrigation during the yield formation period for all crops.

However, because of the yearly variation in the length of the rainfed growing period, the crop in which yield formation begins early may do better in one season whereas the crop with a later se of yield formation may do better in another season. Under water deficit or drought situations, many of yield formation may do better are less able to cope due to the lack of elasticity and, combined with short-duration modern cultivars are less a often fail completely to produce a yield. Local cultivars, the high-density close spacing approach, often fail completely to produce a yith a reduction in yield rather
on the other hand, often have a better ability to respond to drought with on the other hand, often
than complete failure.

The ability to withstand, tolerate, and recover from drought depends on the extent to which the crop can adjust its solute potential to maintain turgor in the roots and in the shoots and leave (Passioura and Angus 201; Blum 2009; Ali et al. 1999; Ludlow and Muchow 1988; Kassam et al. (Passioura and Angus 201, Blussible to produce cultivars that have a full complement of drought1979). Thus, it should be possible to produce cultivars that have a full comples tolerant and drought-resistant genes introgressed through marker-assisted breeding as well as through gene transformation including trait-specific genes from novel sources. Such drought tolerance would also impart salinity tolerance, making possible the more effective use of saline water. However, it must be emphasized that the best drought proofing cannot be achieved throug genetic improvement alone. In the final analysis, adaptability to drought is a production syste renetic improvent in which agronomic manipulation and the management of all the different comporesponsibility in which agrient-water system have an influence on the final outcome in terms of nents of the soil-plant-nutrient-water system hation and the soil management to improve the roo WUE and WP. Often, the agronomic manipulation and the soil man rice intensification (SRI) in formation and the rooting depth, as in the case of CA or the system of rice intensification (SRI) in uncompacted and well-structured soils with deep reaching biopores, is the best foundation layer of resilience against drought that can be deployed.

\subsubsection{Pest (Weeds, Insects, and Pathogens) Management}

Unhestestems tend to succumb to infestation by pests Unhealthy and weak plants in de reductions in WUE and WP can all kinds, thereby reducing both the WUE, or EUW, and W

occur mainly through a reduction in the photosynthesis and the growth of the crop plants,
the root system, due to competition from weeds or an attack by insect pests or pathogens. In the case of weeds, the decrease in WUE and WP occurs because water that would otherwise be available for crop growth is transpired by weeds. The loss of water through weeds can occur at be available for crop grow cycle, but this has to be balanced with evaporation loss from the bare sol any stage in the cropping cycle, but this has to butrients and light, thereby reducing their growth surfaces. Weeds also compete with crops for nutrients ast plant becomes stunted, thereby decreas In the case of semiparasitic weeds such as Striga, the host plant becomes stunted, thercby denironing both WUE and WP. Where cropping relies on stored water in the soil in water-limited enving ments, WUE and WP can be increased by keeping the land weed free through the entire croppittric season, as was shown by Anderson and Greb (1987) for proso millet grown in dryland agricultur in the Great Plains of the United States. Similarly, in the case of summer fallow periods to accumb in the Great Plains of the fallow period reduced or avoided by using herbicides.

reduced or avoided by using herbicides.

Herbicide technology eliminates the need for tillage in many cropping systems (ST, WUE an However, tillage is still common in many regions of the world, and where it is practiced, WP are lower as a result of the loss of soil moisture in land preparation and also due to the creatce sowing. Many weed seeds are relatively small and can only thrive because of tillage, which mulch sol improved seedling establishment conditions. Where crop residues are used to develop a muld st improved seedling establishadvantaged. Thus, integrated weed management involving the and mulch cover offers an important opportunity for weed suppression (Liebman and Mohler 2001), thereby increasing WUE and WP.

In situations where there is no alternative use of soil water, growing spontaneous vegetation can have a positive impact on the overall WUE and WP because the biomass generated can be used to develop mulch cover as well as protect the soil from erosion. Such vegetation can also include plants normally regarded as weeds, provided their further propagation is avoided by adequate measures.

Insect pest and diseases usually reduce the crop capacity to protect itself against unproductive water loss. This can occur because of a loss in the leaf surface area from attack by leaf-eating insects and by pathogens that cause leaf spots, leaf streaks, and crinkling, thereby reducing photosynthesis. The damage caused to the root systems by soil diseases and nematodes leads to a reduced ability to fully explore and utilise soil water, thereby reducing WUE and WP. Such damage can be greater under conditions of cereal monocropping. Losses can be reduced by using nonhost crops in rotation with cereals, as is occurring in southern Australia, Canada, and Eurasia (Baig and Gamache 2009; Flower et al. 2008; Gan et al. 2008; Goddard et al. 2008; Blackshaw et al. 2008).

\subsubsection{Fertilization and Nutrient Management}

Plant nutrients play an important role in determining the growth of roots and the yield (Rockstrom and Barron 2007) because the source of the substrate for root growth is photosynthesis, which depends on the unit leaf rate as well as on the leaf area, both of which are nutrient-dependent, as well as age-dependent. The leaf area directly affects the transpirational losses, and there is a linear relationship between the transpiration and the biomass that a crop produces, but the slope of the line depends on the nutrient availability. However, the portion of the biomass that is harvested as yield (HI) is a feature of the crop type or variety and of the moisture regime and the sensitivity of the crop growth stage to water deficit and nutrient stress (Doorenbos and Kassam 1979).

An adequate and balanced nutrient supply from a healthy soil is a prerequisite for good growth of the roots and the aboveground plant parts, for yields, and therefore for WUE and WP (Ali and Talukder 2008; Hatfield et al. 2001; Ryan 2000; Liu et al. 1998). For example, when the roots are not impaired by pathogens, the higher $\mathrm{N}$ status of the crop leads to a larger root system and to more soil water extraction (Deng et al. 2003; Angus and van Herwaarden 2001; Liu et al. 1998). However, as indicated earlier, under the variable rainfed conditions of the semiarid tropics and subtropics, both summer and winter rainfall, effective nutrient management for improved WUE and WP can be achieved through the practice of response farming in which risk can be minimized by delaying the decision to apply fertilizer, and how much, until later in the season when it becomes possible to predict what kind of moisture season it is most likely to be (Stewart 1991). In southern Australia, this tactic has also been shown to work and the advantage of delaying the decision to top dress is in the saving on the cost of fertilizer and avoiding yield loss by not applying fertilizer if the season is dry (Passioura and Angus 2010; Angus 2001; Angus and Fischer 1991). In practice, effective sutrient management must be seen in terms of the nutrient needs of the crops within the cropping systems in space and time so that the overall production system deployed is also conducive to Thent nutrient productivity alongside the aim of maintaining desirable levels of WUE and WP. difs, nutrient management under the CA system for improved WUE and WP is a fundamentally and Friedrient management strategy compared with that under a tillage-based system (Kassam often less mineral). Under the CA systems, the WP and the nutrient productivities are higher, and nutrient mineral fertilizer is needed because of greater biological nitrogen fixation and improved Goddard conservation within the cropping system (Baig and Gamache 2009; Friedrich et al. 2009; Verd et al. 2008).

Supply of sive growth has a direct relation to water use, as well as to the yield and WP for a given anthesis is roil water. In the case of cereals, this is because the vegetative biomass at the time of onset of flowering the number of grains per unit area. Similarly for legume crops, biomass at the of flowers, pods, and subsequent biomass growth during further flowering determine the numbers 
the time of tuber initiation and the subsequent growth of the crop determine the number of tubers per unit area, the number that actually bulk, and the extent of bulking. Assuming healthy crop roots, per unit area, the number the formation of reproductive- or yield-forming parts depend on the nutrien vegetative growth and the formation of reprode vetative growth, and therefore suboptimal WUE an status of the soil and of the plants. Too rients, late sowing, and suboptimal plant density. On the othe WP, can be caused by insuffict hand, early sowing, excessive nitrogen, and high plant density cause excessive vegetative growth. In areas that suffer from end-of-season drought, excessive growth can lead to the exhaustion of the soil water, leaving insufficient soil water for transpiration and grain filling (Passioura and Angus 2010). There is also evidence that excessive nitrogen can lead to greater structural carbohydrate rather than stored carbohydrate that can be translocated to the grain together with nitrogen during grain filling, thus reducing WP. Further, excessive nitrogen can lead to foliar diseases and insect attack (Kitchen thus reducing W. Fur

The above effects from an excessive nitrogen supply have been recorded when using mineral The above effects from an excessive nitrogen supply have been recorded when so that the soil
sources of nutrients under production systems involving tillage over many years so health is often in a suboptimal condition from compaction, poor infiltration, and low SOM. Results can also be in the opposite direction when organic sources of nutrients are used or when inorganic and organic sources are used in combination. For example, with maize, an increase in the WUE and WP was res sor $1: 2$ (Xiaobin WP was recorded when the rate is an organic source of nutrients and et al. 2001). Larger root systems are produced whe active and diverse (Uphoff where the SOM content is higher and the soil microorganisms are more active and diverse (Uphoff et al. 2006). In this regard, the behavior of the rice grown under mostly aerobic soil conditions, as is the case under the SRI methods, is of particular interest. Under the SRI approach, some 20\%-30\% less fertilizer is required compared with irrigated flooded rice grown under the best management less fertilizer is require compare, is required to produce a full crop. Because of the greater yields practice, and 40\% with SRI and the reduced water requirement, foth

ity is superior (see the SRI case description for more details). Examples of soil nutrient deficiencies affecting WUE and WP also relate to the zinc deficiency in
wheat in Turkey (Cakmak et al. 1996) and the sulfur deficiency in groundnuts in India (Patel et al. 2008). The role of calcium and magnesium in improving the $\mathrm{pH}$, the soil structure, and the waterholding capacity and, consequently, WUE and WP is well known. Similarly, several researchers (e. Cakmak 2005) have recorded the role of the potassium nutritional status in alleviating the detrimental effects of abiotic stresses through osmotic adjustment.

Evirals of $\mathrm{N}$ and $\mathrm{P}$, decrease in soils Evidence shows that mineral fertilization requirements, paticularly of that have been under the CA system for extended periods of time (Landers 2007), and the problem of low availability or immobilized $\mathrm{P}$ in soil is ameliorated, even when soil analyses do not show high quantities of soluble P (FAO 2008; Turner et al. 2006). Thus, combined water and nutrient productivity improved over time in CA systems, whereas with tillage-based production systems, nutrient and total productivity including WP remained at a suboptimal level.

10.4.1.6 Agronomic Manipulation for Best Phenotypic Expression Much of our scientific thinking about agronomic practices and crop production has been based on the assumptions that a crop can be best produced with soils that must be tilled year after year ant with increasing tillage intensity in many cases; that soil microorganisms and the SOM are not esscential to soil fertility or to the maintenance of soil health and ecosystem health; that plant root systems and their interactions with the soil microorganisms can be ignored in studies aimed at understant ing the ecophysiological basis of nutrient- and water-use efficiencies and productivity; that so ing the ecophantente of soil, crop, an mulch cover and crop rotation can be consider as opter and nutrients; that ecosystem health and in the optimization of the use of resources such as water and nutrienis aratit there is only one standard way of agronomically manipulating the crop-soil-nutrient-water pane eters; that the so-called undefined and unbridled quest for genetic improvement must override improvements that are possible through alternative crop production practices.
For example, the CA and SRI approaches to crop production show us a different way forward. CA and SRI are both works in progress and their concepts and methods are being extended to more crops and more agroecologies, for small-scale and large-scale production. These systems are harnessing an agronomic performance that cannot be predicted by current models or the scientific knowledge generated through the reductionist scientific research approaches that have characterized much of the agricultural research during the last century and still continue to do so. It would appear that there has been a "closure of the mind" in the last three to four decades, particularly the improving WUE and WP through agronomic manipulation of soil-plant-water-nutrient relationships as well as the manner in which the soil health and root systems are managed. Systems such as the CA, SRI, and CA-SRI have not been receiving the kind of attention they should from the scientific community. Given that such systems and agronomic manipulation can help small farmers to improve their overall and factor productivity and livelihood, this lack of attention is a serious gap in the current knowledge system.

While early planting with CA and SRI permits better WUE and WP because of improved soil moisture, upon which the nutrient productivity depends, optimal spacing appears to depend on the soil fertility conditions. Although, generally, a high seed rate and closer spacing have been the dominant approach with modern cultivars that are selected within such conditions, this may not always be optimal, as has been recently shown by the SRI approach for rice, as well as with other crops such as sugarcane, wheat, and finger millet (Uphoff and Kassam 2009). The high-density seed re appears to have been favored over the past three to four decades, but the SRI approach shows

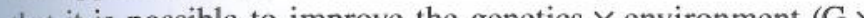
that it is possible to improve he WUE and WP through the integration and manipulation of a crop establishment strategy with crop nutrition and weed management. In fact, CA and SRI have revealed a whole new set of opportunities to improve WUE and WP based on alternative approaches to crop and water management (as elaborated in the CA and SRI case details elsewhere).

\subsubsection{Crop Rotation and Intensification}

Many advantages and benefits are associated with crop rotations, including the possibility of higher WUE and WP for the individual crops participating in the rotation and for the cropping system as a whole, when compared with monocropping. In environments of variable rainfall, crop rotations with crops of different maturity allow the reduction of climatic risk because in poor years, not al crops are affected equally and there are positive effects between crops in the rotation, involving cereal and legume crops, from the yield viewpoint, and therefore improved WUE and WP (Tanaka et al. 2005). Equally, rotations also reduce the risk of attack by insect pests and diseases (Chabossou 2004; Krupinsky et al. 2002), thus maintaining WP. Rotations involving high biomass legume crops also allow the in situ production of functional biomass in terms of crop residues and green manure crops and can help add organic matter to deeper layers in the soil as well as increase the soil biopores (Friedrich et al. 2009; Shaxson et al. 2008) Mixed sequences of crops, plus the presence of a permanent soil cover, tend to inhibit the buildup of specific weed species that would thrive under less varied or monocrop conditions and reduce WUE and WP.

The rotation of crops involves the rotation in sequence of several species of crops, including legumes as symbiotic (plant $\times$ rhizobia) sources of plant-fixed atmospheric $\mathrm{N}$, and other usable green manure cover crops, for maintaining the soil cover at all times, as well as the provision of labile organic residues both at and below the surface. It is important that the nutrient balances in when are maintained from one rotation cycle to the next. C accumulation only seems to occur otherwise is a legume in the system that fixes more $\mathrm{N}$ than is removed in the crop products or is Crop lost from the system (Boddey et al. 2006; Uphoff et al. 2006).

cycle by intensification involves making fuller use of the time available within the annual cropping the by introducing additional crops within and between seasons, thereby making fuller use of

the soil water while keeping the ground covered for longer periods. According to Gan et al. (2008), 
long-term studies in Kazakhstan have shown that reducing and gradually eliminating summer fallow improving WUE and WP. Similarly, studlow are fas conventional summer fallow can be replaced usin ies in the Canadian similarly in North Dakota in the annual grain legumes or green manure crops (Gan et al. 2008), and similarly in North Dakota in the United States (Ransom et al. 2006). Such replacement in the rotational system has been shown to improve the overall farm productivity as well as profitability and improving WUE and WP by $30 \%$
(Gan and Goddard 2008; Peterson and Westfall 2004).

The greater the range of plants grown, in mixtures or in sequence, the more varied will be the The greater roting depth, and the biodiversity of associations of greater the competition that can suppress those considered weeds or pests. A crop rotation will further help in interrupting the infection chain of diseases and might have other insect pest-repellent and insect pest-suppressing characteristics. Fo the alterations in cropping systems to be worthwhile to farmers, there need to be local uses and/or markets for additional outputs generated by improved crop sequences and mixtures.

\subsubsection{IrRigation Management}

Irigation plays and will continue to play an important role in global food security, and the need and the opportunities for expansion of irrigated cropland still exist (Oweis and Hachum 2003: Seckler et al. 2003). However, and in agreement with Rockstrom and Barron (2007), to minimize further blue water withdrawals and increase WP, a reduction in green water (water that is stored in further blue water withdrals an irrigated agriculture, the fundamental question still lingers: How the root zone) losses is critical. In irrigated agrount of water? The answer to this question is still, to produce more with the same or even less amount of water? undoubtedly, linked to the possibilities of minimizing unproductive water losses, namely, runof (tail water), evaporation, and deep percolation (Rockstrom et al. 2002). Sustainable managemen practices and technically feasible and cost-effective solutions to maximize crop transpiration an soil water storage and minimize runoff and evaporation, as well as irrigation systems to carry out such such er (Figure 10.1) and the parameters that influence the processes (Figure 10.2).

\subsubsection{Irrigation Performance}

Worldwide, irrigation schemes are often designed and managed to maximize irrigation efficiencie and minimize labor and capital requirements. For this multiobjective goal, one major challenge that confronts every designer and irrigator is that the soil that conveys the water over the field has that confronts evere highly variable both spatially and temporally, creating an engineering problen properties that are hestion, in which at least two of the primary must also be judged by the irrigator prior to the start of ever not only at the field layout stage, but must also be judged by : Walker and Skogerboe 1987). Recen irrigation event (Trout et al. 1992; Keller and Bliesner 2001; Walker and Skogerbices, have largely developments in surface irrigation technology, with its array of automating devices, have largly caught up with the irrigation efficiency advantages of the sprinkler and microirrigation systens (Duke et al. 1992; Heerman et al. 1992). Thus, while it is possible for the new generation of surface (Duke et al. 1992, the sprinkler and drip systems, their associated irrigation syche difficult to define and implement (de Sousa et a 1999;

1999; Clemmens et al. 1998, Clemmen system or its manage

Among the factors that are used to judge the performance of an irrigation system or is 20007 ment, the most common are efficiency and uniformity (Clemmens and Molden 2007 , Hubdivided an Santos 1996a, 1998; Heerman et al. 1992; FAO 1989). These parameters have been subdivides and defined in a multitude of ways and have been named in various manners (Hamdy 2007 , Bigation Nugteren 1990; ASCE 1978; ICID 1978). However, there are other factors influencing irriga field Nugteren efficiency, building chen 2007). In agriculture, farn

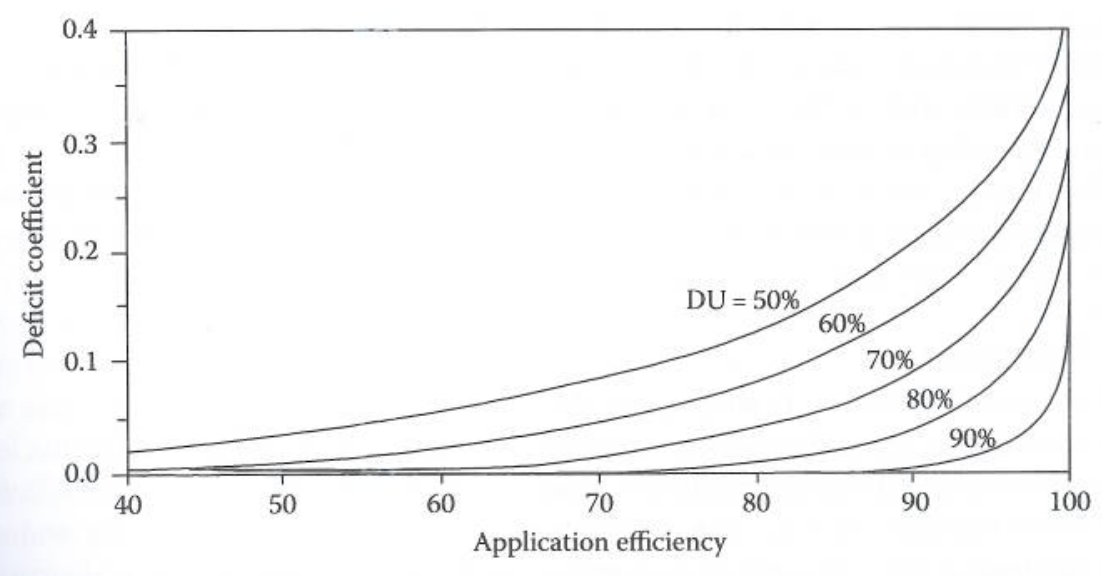

FIGURE 10.8 The relationship between the deficit coefficient, the application efficiency, and the distribuFGU uniformity (DU), assuming normal distribution of the infiltrated applied water. The deficit coefficient is the fraction of the root zone that has not undergone irrigation. (From Playan, E. and Mateos, L., Agr. Water Manage., 80, 100, 2006. With permission.)

ingation project managers, and river basin authorities may define WUE quite differently, consisting of various components and taking into account losses during storage, conveyance, and application to irrigation plots (Hamdy 2007; ICID 1978). More consensually, uniformity (distribution uniformity) is used to express the variation in the depths of application or supplied volumes (ICID 1978; Christiansen 1942). Conceptually, the adequacy of on-farm irrigation (field level) depends on how much water is stored within the crop root zone, the losses percolating below the root zone, the losses occurring as surface runoff or tail water, the uniformity of the applied water, and the remaining deficit or underirrigation within the soil profile following irrigation (Fereres and Soriano 2007; Hamdy 2007; Heerman et al. 1992; Bos and Nugteren 1990; Losada et al. 1990). Assuming that the statistical distribution of the infiltrated water follows a normal distribution (Santos 1996a,b, 1998; Losada et al. 1990; Till and Bos 1985), Figure 10.8 illustrates the relationships between uniformity, the water deficit, and the percolation (Playan and Mateos 2006). For a given target deficit coefficient, the lower the distribution uniformity, the lower is the application efficiency.

With proper and careful design and operation, high on-farm irrigation efficiency and uniformity can be achieved directly with systems such as sprinkler and microirrigation systems (Keller and Bliesner 2001; Solomon and Keller 1978; Hart and Heerman 1976) that do not depend on the soil surface for water distribution. The issue is more challenging for surface irrigation systems that depend on the soil to convey water and where the depth of water infiltrated (defining the distribution uniformity) is a function of the opportunity time, the length of time for which water is present on the soil surface to infiltrate (Heerman et al. 1992; FAO 1989). It is worthwhile remembering that the practice of surfoce irrigtion is thousuds of years od and, collectively, it still represents perips as much as $95 \%$ of the common irrigation activity of today (Oweis and Hachum 2003; FAO 1989; Walker and Skogerboe 1987).

With the two sources of surface irrigation system inefficiency in mind, deep percolation and surface runoff or tail water, a very large number of causes of poor on-farm irrigation performance They ren outlined in the technical literature (Hamdy 2007; Heerman et al. 1992; Trout et al. 1992). the range from inadequate design and management at the farm level to inadequate operation of (We water supply facilities (Walker and Skogerboe 1987). Nonetheless, since the depth of

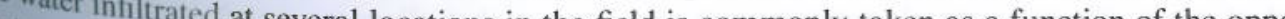
unity time for water to infitrese, in soil physical contithe sustainable conditions and characteristics, primarily the soil infiltration capacity, constrain the performance of irrigation and the economical production of irrigated crops (Tarboton 

and Wallender 1989). Management practices that can eliminate or at least mitigate these constraints are reviewed in Heerman management options include both cultural practices that alcr the undesirable soil condition an irrigation practices that minimize or avoid the constraints. The underpinning conclusion is that so must absorb adequate water during irrigation to meet the crop water requirements between irrigamust absorb adequate water during irrigation to soil infiltration characteristics, the irrigation system, and the system's management.

\subsubsection{Infiltration}

irigation (temporal variability), from soil to soil 列 (t) infiltration rate is an unknown variable in irrigation practice (Tarboton an manageable. Thus, the infiltration rerboe 1987). Soil infiltration varies both locally and with time, Wallender the former resulting from a nom age, and wheel traffic, and the latter from soil structure changes caused by som saction depletion, frost action, tillage, consolidation from wetting and drying, surface sealing due to dro impact and overland flow, soil animal and microorganism activity, and changes in the ionic so composition (Trout et al. 1992; Tarboton and Wallender 1989; Undersander and Regier 1988). Soi compositu (Tre ridly (excessive infiltration) or slowly (inadequate infiltration) or store only limthat absorite we costs and/or decrease the efficiency of irrigation.

decrease the efficiency of irrigation. Soils that slowly absorb water constrain the irrigation process by recation times or short irrigation to avoid water wastage (redistribution and runoff) and long application times or shor irrigation intervals to maintain adequate soil moisture in the root zone. Management strategies that increase infiltration require determining the location and the nature of the restricting layer and the proces infiltration redial actions that are required to improve the that created (1) formation and maintenance of biopores created by existing condition with surface residue retentio the macrofauna activity and the former root cha9; Miller et 19. 1987); (2) reduced or controlled traffic (Jordan et al. 2010; Tebrugge and During 1999; Miller et al. 1987), (2) tillage layer (Fornstrom et al to decrease the formation of dense tillage pans and compaction of the tillage layer (Fornstrom et an 1985; Eisenhauer et al. 1982); (3) deep, vertical, noninversion subsoiler to break tillage hard pan (4) increased organic matter content or a decrease in the proportion of sodium in the soil, to enhance (4) increare stabilizers such as polysoil aggregate acrylamide (PAM) of clay dispersion by calcium addition (Trout et al. 1992); and (7) use of plants and resides for the protection of the soil surface aggregates from water drop impact (pressurized systems) and hections, ther force of the overland flow (Silva 2010; Cary 1986). As already outlined in previous sections, are ways to approach agricultural production systems, whether rainfed or irrigated, to conditis that are close to those of natural ecosystems in terms of hydrophysical conditions, which per show the most favorable, site-specific behavior in terms of water infiltration. However, in tillage show the necessary rate, the irrigation syste based production systems whe low rate, to improve the existing conditions and the system's management must be adapted the cablegation) the with (1) use of long and frequent irrigations and systems (level-basin, surge finity times (de Sous allow for the rapid advance of surface flows and uniform intrat et al. 1999; Clemmens 1998; Shahidian et al. 1998; Clough and Clemmens 1985); (3) use of spras. 1987); (2) use of sprinkler spray heads on drop tubes (Thompson and James 1985); (3) : (4) conver (Solomon et al. 198), ( $\mathrm{f}$ smalle . sion of center pivots to lateral move irrigation frequency (Trout et al. 1992; Solomon et al. 198. ifte application depths with an increased irrigation fequen (T) and hold water until it can infilitrate (5) use of microbasin or reservoir (Garvin et al. 1986) to pond and hold water until il clication tith and (6) conversion to or use of microirrigation (drip irrigation), which allows low app omatch the low soil infiltrability (Keller and Bliesner 2001; Solomon and Keller 1978). Cablegation systems are automated surface irrigation gated-pipe systems (de Sousa et al. 1999; Shahidian et al. 1998; Kemper et al. 1987) that inherently provide for cutbacks in the furrow stream and the subsequent reduction in runoff, potentially increasing the irrigation efficiency in low infiltrating soils. Surge flow (surge irrigation) (de Sousa et al. 1999; Miller et al. 1987) is a process by which an irrigation is accomplished through a series of individual pulses of water onto the field such that the flow interruption is long enough to infiltrate all surface water

Soils with excessive infiltration are usually coarse-textured soils, freshly tilled soils that develop large voids between aggregates following tillage, and shrinking/swelling clays. Reducing their high infilration rate is difficult, with irrigation usually increasing the cost and/or decreasing the WUE (Trout et al. 1992). A mix of agronomic and irrigation management practices is needed to cope with the conditions of excessive infiltration: (1) compaction (Khalid and Smith 1978) and compact furrows with equipment and/or pacing wheels (Fornstrom et al. 1985; Musick et al. 1985); (2) NT or a reduction of the depth and disturbance of the tillage to improve the soil aggregation and to reduce the creation of interaggregates; (3) surge irrigation (de Sousa et al. 1999; Miller et al. 1987); (4) high surface irrigation applications, level basin systems (Clemmens 1998; Santos 1996b; Clough and Clemmens 1994), and a reduced field length to decrease the time required to spread the water across the field and thus improve the water distribution uniformity; and (5) conversion from surface to sprinkler or drip systems that do not depend on the soil surface for water distribution, therefore circumventing the problem.

All soils exhibit some degree of soil infiltration variability, locally (spatial) and with time (temporal). Spatial infiltration variability results from a nonuniform soil texture and structure (inherent variability), topography, tillage, and wheel traffic (Miller et al. 1987; Fornstrom et al. 1985; Trout and Kemper 1983), while temporal infiltration variation results from structural changes caused by distinct causes. Identifiable, large-scale spatial variability is best dealt with through (1) differential application of the residue and other organic matter that counteracts it and (2) subdivision of large fields into management subunits based on infiltration. Inherent soil variability is difficult to ameliorate. However, spatial variability resulting from tillage and wheel traffic can be ameliorated through (1) management of tillage and equipment traffic to reduce uneven soil compaction; (2) even traffic across all or alternate furrows; and (3) wheel compaction (better used with surge irrigation) to reduce the subsurface texture or structure of nonuniformity soils (Purkey and Walle (he means to deal with both the spatial and temporal variabilities in infiltration is to monitor the irrigation, to adjust the application rates, and to set times to obtain acceptable performances (Trout et al. 1992; Walker and Skogerboe 1987). Manual adjustments are critical, but costly. Feedback control systems that automatically adjust the irrigation application rates and times based on automatically sensed advance rates and tail water runoff have been effectively used (de Sousa et al. 1999; Purkey nd Wallender 1989). In such cases, according to Purkey and Wallender (1989), surge inigation (t) infiltration variability by as much as $50 \%$. Precision irrigation has also seen advocated (Sadler et al. 2005). Sprinkler and drip irrigation systems that do not depend on the sail surface infiltration rate for water distribution are the next best option to deal with the infiltration he absity. As long as their water application rates do not exceed the infiltration rates, water will Bliesnered into the soil, counteracting the infiltration variability problems (Silva 2010; Keller and Cor 2001; Solomon et al. 1985; Solomon and Keller 1978).

Control systems, water supply management, and precision irrigation certainly present real to cropities to handle the uncertainty associated with variable soil infiltration and to apply water hat in ands uniformly and efficiently (Heerman et al. 1992; FAO 1989). The literature suggests one or all cases where high levels of uniformity and efficiency were achieved, irrigators utilized tion scheduling (3) rowing practices: (1) precise and careful field preparation; (2) timely irrigaor reuse. Opng; (3) regulated inflow discharges; and (4) tail water runoff restrictions, reduction, managen (2005). 
10.4.2.3 Soil Water Storage

varies primarily with the texture, the SOM (Rawls et al. 2003), the 作 inherent restrictive layers, and the compacted sols layens for (Voorhees et al. 1986), limiting the maximum anount of water the can be efficienty appent the allowable interval between irrigations. The worse situation is when irigation mageme adapt to spat soil variations in infiltration alongside variations in the soil water storage capacity. adapt to spatial soil variations in infiltration alongsin one location than in the bulk of the field can Either or both of those characteristics being lower in one location the butimally designed for the bulk cause runoff from that location, despite the irrigation system being optimated area or leaving the fiel of the field (Sadler et al. 2005). Runoff water collecting within the irrigated

damages crops, wastes water, and moves sediments, nutrients, and biocides.

The frequent, light irrigation applications required on soils with a low-water-holding capacity increase the labor costs (except for mechanized irrigation systems) and decrease 1987). Managemen tion uniformity of the surface systems (Trout et al. practices, such as restricted traffic; lightweight tillage or been successfully used to slow the creatio ment; and the avoidance of traffic in moist soil, have been successt or frequent irrigation interval of compacted layers (Musick et al. 1985; Kaddah 1976). Since short or frequent irrioation to automated, require the systems to apply small amounts of irrigation water efficiently, conversion to automated, require the systers sole (Sadler et al. 2005; Buchleiter mechanized, or microirrigation satchelor et al. 1996; Duke et al. 1992).

10.4.2.4 Soil Crusts

. Soil crusts occur over a wide range of soils due the a high silt content (Ben-Hur and Lado 2008; more prevalent in soils with a low organic matter and a high silto and Serralheiro 2000; Miller and Lado et al. 2004; Bjorneberg et al. 2003; Ramos et al. 2003, Santos and flow break down the surface Gifford 1974). Created when the water-drop impact and the overland fow the crusts impede seedGifford structure and rearn impact the exchange of water, air, and heat between the soil and the atmosphere, ling emergence and thereby substantially lowering the infiltration (Trout et al with low infiltration soils (described above) management practices comparable to ones used to deal with low infiltration solls (dian NT systems that are advocated (Ben-Hur and Lado 2008; Lado et al. 2004). Reducedic matter at the surface provide leave enough crop residues and promote the accumulation of organic mat the first option to be the effect of shielding the soil surface from those destructive forces and are the 2003; Miller and the ensider in preventing soil sealing and crusting (Lado et al. 2004; Rawls ct al. 2003, Miller and conside 1974). Comparing different irrigation methods, sprinkler systems are the main culprit in Gifford 1974). Comparing sprinkler application-in amount, intensity, and kinetic energy causing surface crusts. Min socese the soil collapse and breakdown - with reduced sprinkler height and dros). Soil conditioners, such as PAM, also tend to crust formation (Silva 2010; Bjorneberg et al. 2003). Sor conc sprinkler irrigation systems' stabilize the soil aggregates from the destructive impact energy of and the surface irrigation shear water droplets (Bjorneberg et al. 2003; Sojka and Bjorneberg 2002) and the surface ine

Irrigation-Induced Soil Erosion

10.4.2.5 Irrigation-Induced An overview of water erosion from irrigation by Koluvek 20 t/ha with some fields exceeding 100 tha sediment yields from furrow-irrigated fields often exceed 20 t/ha with some field ith annual sedinteril Under the center pivot, sediment yields as high as 33 t/ha were measured, with an low lies shear yields as high as $4.5 \mathrm{t} /$ ha also reported from irrigation tracts. Typically, overland flow app Bjorneberg forces to the soil surface, which causes particle detachment and movement (Sojka and bjly exced 2002; Koluvek et al. 1993). As flow velocities increase, shear forces increase and eventuller urfiace the shear stress required to overcome the cohesive forces between the soil particles. Under a thin the shear stress required to overcom soil, the sediments deposit at the furrow surface to for h hallat irrigation, as the water infiltrates the soil, the sediments deibling 1993). The process is potentially if the depositional seal formation is slowed down and high infiltration is maintained through the use of known erosion control practices coupled with minimum soil disturbance and the selection of the appropriate cropping sequences (Lado et al. 2004; Koluvek et al. 1993; Trout et al. 1992). Furrow erosion has been reduced using various approaches, including straw placed in furrows (Brown 1985) and sodded furrows (Cary 1986). With a large percentage of the total seasonal furrow erosion occurring during the first irrigation following tillage (Lentz et al. 1992), PAM with an 18\% negative charge density injected in the irrigation furrow advance water has also been used to reduce furrow erosion (Orts et al. 2000; Lentz and Sojka 1994; Lentz et al. 1992). Santos and Serralheiro (2000) showed that PAM increased the cumulative infiltration by $15 \%-20 \%$ on furrow-irrigated Mediterranean soils. Permanent ridges for furrow irrigation systems and crop establishment under NT have been successfully applied (Cahoon et al. 1999) and could substantially reduce furrow erosion.

Silva (2010) has reviewed the factors affecting runoff and control practices under sprinkler irrigation that cause erosion only if the application rate exceeds the soil infiltration rate, resulting in gatior ponding and subsequent surface flow (Lyle and Bordovsky 1983). The soil and topographic variations, along with the water supply and economic constraints, often compromise system designs, and repeatedly, the application rates exceed soil infiltration rates, primarily under the outer spans of the center pivots irrigation system and with the use of low-pressure nozzles that have smaller wetted diameters (Silva 2010; Bjorneberg et al. 2003; Sojka and Bjorneberg 2002; Trout et al. 1992). With an improper average operating pressure as the most common cause for poor sprinkler system performance (Heerman et al. 1992), reducing the sprinkler application rate or increasing the soil infiltration capacity (described above) reduces or eliminates runoff. Tillage practices, such as basin or reservoir tillage, increase the surface storage to prevent overland flow (Garvin et al. 1986) and erosion. Sprinklers applying high molecular weight, water-soluble, anionic PAM were shown to improve the soil infiltration rate and reduce soil erosion (Santos et al. 2003; Aase et al. 1998). PAM applied to the soils through the irrigation water acted as a binding and settling agent to increase the soils aggregate stability and infiltration and reduce runoff and sediment losses (Santos et al. 2003; Bjorneberg and Aase 2000; Aase et al. 1998).

\subsubsection{Deficit Irrigation}

The inherent and management-induced nonuniformity of the irrigation systems implies that some water deficit and/or percolation must occur even with the best irrigation schedule. With volumes of irrigation less than the volume of water needed for ET (crop water requirement), under deficit irrigation, all of the applied water remains in the root zone and may be used in ET (Fereres and Soriano 2007). Evidently, the whole field will have some soil water deficit after irrigation and there will be areas with a level of deficit that may be detrimental for production (Fereres and Soriano 2007; Zwart and Bastiaanssen 2004), emphasizing the need for irrigation systems that can deliver high uniformity water applications (Figure 10.8). In the process, the WP (either taken as yield or net income per unit of water used in ET) of the applied irrigation water under deficit irrigation, that is, the applicahon of water below the full crop water requirements or ET, is higher than under full irrigation (water satisfying the full crop water requirement) (Fereres and Soriano 2007).

Broadly, two types of deficit irrigation, sustained (SDI) and regulated (RDI), are assumed (Ramos and Santos 2009, 2010; Fereres and Soriano 2007; Santos et al. 2007; Shatanawi 2007). In SDI, the irrigation is reduced during the whole season while RDI starts with normal irrigation and then the irrigation is gradually reduced. In RDI, the deficit irrigation strategy is based on limiting phenoloneficial water losses by reducing the amount of water for the crop during the noncritical product stages. The deficit irrigation is controlled during times when the adverse effects on Fereres and vines of to props. Globally, the potential ben fits of defit irigation derive from three fact W to production, greater irigation WUE, a de 
Accomplishments in the irrigation of fruit trees and vines with an innovative technique of imposing deficit irrigation by alternating drip irrigation on either side of the fruit tree and vine row (partial (2003), an (2007), the factors affecting WP in crop production and techniques to increase WP are analyzed.

10.4.2.7 Evaporation

Reducing evaporation while increasing productive transpiration can enhance WP if there is adequate plant nutrition. Evaporation varies with agricultural practices (Burt et al. 2005) and range quate (n) concern (Playan and Mateos 2006). The advere effects of an incre evaporation losses and sharply reduce irrigation uniformity. The amount of evaporation depend on the climate, the soils, and the extent of the mulch cover and of the crop canopy that shades the soil, with evaporation claiming a very high share of ET with low plant densities. As for the rainfe systems, evaporation losses under irrigation can be drastically reduced by both the tillage system

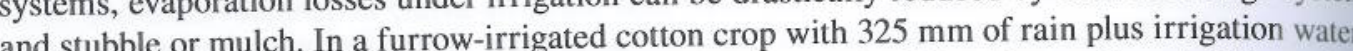
and stubble (1994) LT $160 \mathrm{~mm}$ under CT without residues. The importance of the surface mulch ras was reported by Hares and Novak (1992), who found 1-day evaporation losses of 1.9, 1.7, 0.6, and $0.3 \mathrm{~mm}$ with $0,907,9070$, and $18140 \mathrm{~kg} / \mathrm{ha}$ spread straw, respectively. Burt et al. (2005) report that drip an sprinkler irrigation systems do not necessarily result in less evaporation than good surface irriga tion systems. Nonetheless, the decreased area of surface wetting obtained with microirrigation is distinct advantage to minimize the evaporation from the soil surface (Pereira 2007; Batchelor et al. 1996) Bus center pivots can result in a high percentage of soil/plant surface evaporation.

\subsubsection{Case Studies on Improved Production System Management}

The following two case studies have been chosen to illustrate how changes in the production system The of water and improvements in the soil quality.

\subsubsection{Soil Tillage Systems in the Central Great Plains}

A field study was set up in 1989 by the Kansas State University near Tribune, a region with a semiari continental climate (mean annual precipitation $=425 \mathrm{~mm}$, mean annual air temperature $=11.2 \mathrm{C}$. on a deep and well-drained loess-derived silt loam, very characteristic of the west-central Gre. Plains. Three different tillage systems were established on a virgin, native grass prairie area wit Plains. The ditions. The CT system we a 3-year rotation of wheat-sorghum-fallow (Wallow period (thre based on a sweep plow, also used for the necessary weed control during the fallow period (hring fal to four operations). RT used a combination of tillage and herbicides to control weeds during fallow low, whereas in the NT system, weed control was entirely based on herbicides both during fallow and between crops. In all three systems, in-crop weed control was done by herbicides as recied Fertilization was identical for the three systems, as well as the maintenance of the crop residus in the field. The only difference between the tillage treatments was that the row spacing and he in the ficld. The fingle-dist drill system used in the wheat crop was $30.5 \mathrm{~cm}$ (h

ener drill) for NT (Stone and Schlegel 2010).

This study continues today and the effects of the tillage systems on the soil physical proprlege are described in several publications. Based on soil samples taken in 2000, Stone and setential. (2010) measured the bulk density, the total $\mathrm{N}$ and C, the water content at $-1.5 \mathrm{MPa}$ matric pol WA an and the aggregate stability, the latter through the determination of the concentration of the Whatle-ring the MWD. The ponded, steady-state infiltration rate was also measured in 2000 using doublc
TABLE 10.5

Some Soil Parameters after 10 Years under Different Tillage Systems

\begin{tabular}{|c|c|c|c|c|c|}
\hline \multirow[b]{2}{*}{ Parameter } & \multirow[b]{2}{*}{ Units } & \multicolumn{4}{|c|}{ Tillage System } \\
\hline & & NT & RT & CT & NP \\
\hline Total carbon & $\mathrm{g} / \mathrm{kg}$ & 19.3 & 18.1 & 17.5 & 20.1 \\
\hline $\begin{array}{l}\text { Water content at } \\
-1.5 \mathrm{Mpa}\end{array}$ & $\mathrm{kg} / \mathrm{kg}$ & 0.131 & 0.124 & 0.122 & 0.145 \\
\hline $\begin{array}{l}\text { Mean weight } \\
\text { diameter }\end{array}$ & $\mathrm{Mm}$ & 1.55 & 0.66 & 0.57 & 3.78 \\
\hline Ponded steady-state & $\mathrm{mm} / \mathrm{h}$ & 30.6 & 15.3 & 11.4 & 24.3 \\
\hline
\end{tabular}

infiltration

Source: Adapted from Stone, L.R. and Schlegel, A.J., Agron. J., 102, 483, 2010. Note: NT: no-till; RT: reduced tillage; CT: conventional tillage; NP: native prairie

infiltrometers. The results of these measurements are summarized in Table 10.5, and the respective yield data can be found in the Report of Progress 997 of Kansas State University Southwest Research-Extension Center (2008), available online through the Kansas State University library. More recent measurements regarding this experimental site and other long-term tillage studies in the central Great Plains have been published by Blanco-Canqui et al. (2009a,b). Those studies focus on the aggregate properties with regard to soil erodibility and $\mathrm{SOC}$, maximum bulk density $\left(\mathrm{BD}_{\max }\right)$, and critical water content (CWC).

The data presented by Stone and Schlegel (2010) on some soil parameters after 10 years of differentiated tillage treatments indicate that of the three tillage treatments, NT maintains soil conditions closest to those determined under native prairie. Although the water content at $-1.5 \mathrm{MPa}$ matric potential is not an indicator for plant-available water, the authors interpret its good correlation to SOC as a strong reason for the water-holding capacity of the soil. Together with the much higher infiltration rate under NT, which surpassed even the infiltration capacity of the native soil, there improves plant-available soil water. The concentration of WSA from samples taken in 2000 are clear indicator for better aggregate stability under NT when compared with the two tilled treatments. These results were confirmed 19 years after the start of the study by Blanco-Canqui et al. $(2009 \mathrm{a}, \mathrm{b})$, who found that $4.75-8 \mathrm{~mm}$ aggregates from the NT treatment required a significantly higher kinetic energy to be disintegrated than the aggregates from RT and CT. This behavior was corroborated by the water-drop penetration test and measurements of $\mathrm{BD}_{\max }$ and $\mathrm{CWC}$. Although Theas with even gentle slopes may lose part of the scarce precipitation through runoff.

The grain yields obtained in this study show a clear benefit of the conservation tillage systems $75 \%$ and $50 \%$ was more pronounced in grain sorghum. On average, over 17 years, CT produced of Figre $10 \%$ and RT $87 \%$ and $79 \%$ of NT yields, for wheat and sorghum, respectively. Both graphs Altho 10.9 also indicate a trend for the differences increasing with time.

Although no in-field soil moisture data are available from this study, Stone and Schlegel (2010) NT man from their results that the better conditions of aggregation and water infiltrability under efficiency summer. In fact, the considerable differences in yield between the tillage systems, especially in the sible factor for crop, corroborate the interpretation of water availability being the main responfactor for the differences in crop performance. 

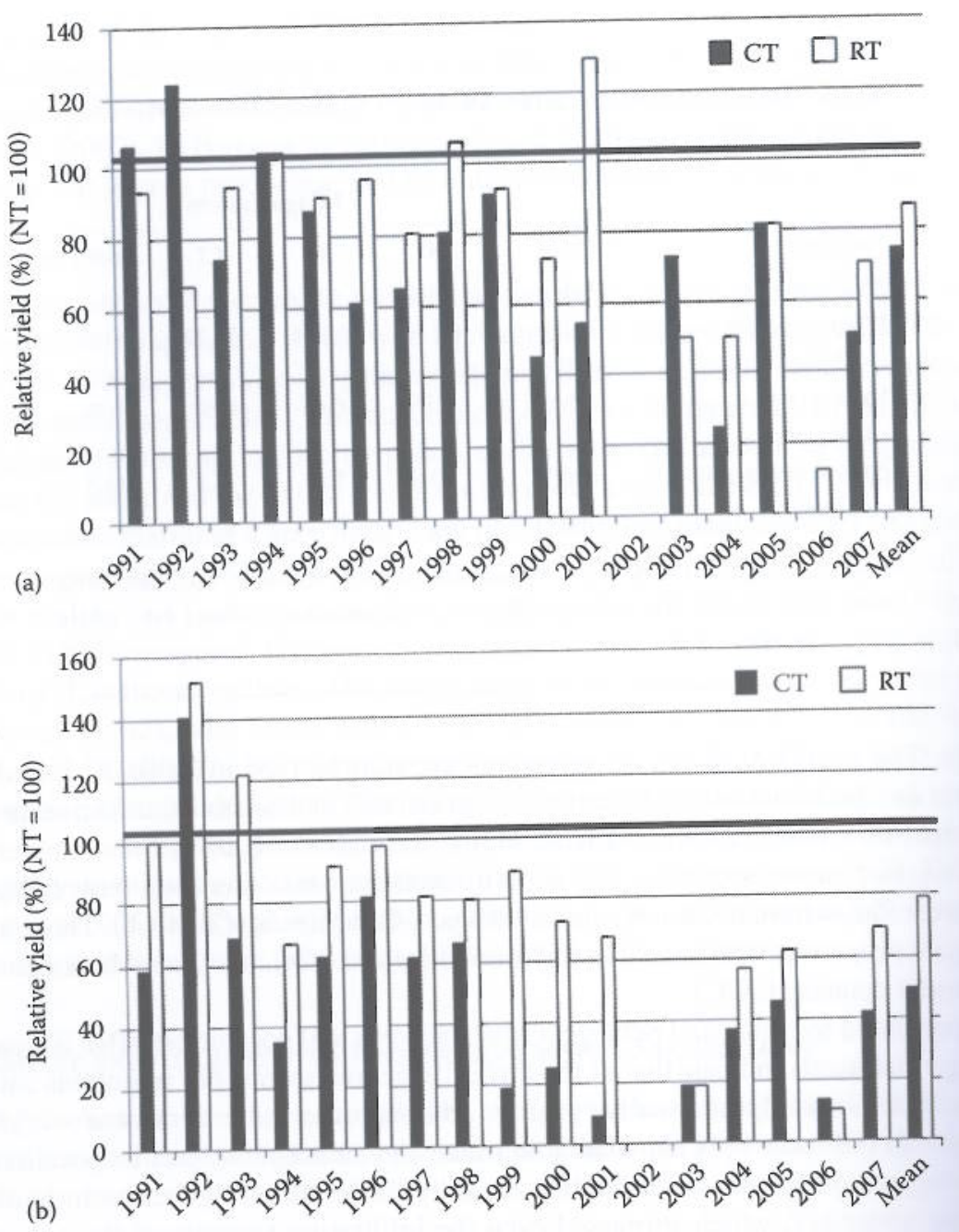

FIGURE 10.9 Relative grain yields of (a) wheat and (b) sorghum of conventional (CT) and reduced tillage (RT) as compared with no-till (NT). (From Kansas State University Southwest Research-Extension Center, 2008.)

10.4.3.2 The System of Rice Intensification

The SRI - a rice production system based on alternative ideas about crop and water managemen The

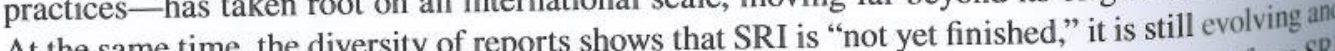
At the same time, the diversity of reports shows changing. The productivity gains, including WP and a decrease in the water requirement, from mor changes in the management of crops, soil, water, and nutrients have now been demonstrated in than 40 countries by farmers and a diverse group of stakeholders who support resource-linices as small-scale rice farmers in raising their output and incomes by using locally available resources productively as possible.

Over recent years, the merits of the SRI system as compared with the recommended anaer Over recent years, the meris bic (flooded) rice production systems have become been defined on the basis of six agronomic prac empirical data. The SRI production concept has been defined on the basis of six agro single trath tices: (1) the use of very young-about 10 days old - seedlings for transplanting; (2) single variely plant/hill; (3) wide spacing of transplants, from $20 \times 20 \mathrm{~cm}$ to $50 \times 50 \mathrm{~cm}$ depending on the througt and the soil fertility; (4) mainly moist (not saturated and flooded) soil water regimes kept t intermittent irrigation; (5) regular weeding through a rotary hoe to also facilitate soil aeration; and (6) liberal use of organic fertilizers. These practices were first described in detail some 30 years ago by Henri de Laulanié, a Jesuit priest, who recognized that small rice farmers in Madagascar simply lacked the resources to invest in intensifying their rice cultivation practices through the recommended "modern" technological package based on costly (and unavailable) external inputs and inadequate or nonexistent extension support.

de Laulanié paid little attention to the issue of genetically improved and input responsive modern varieties (the backbone of "modern" rice production and indeed of industrialized agriculture in general). Yet, by manipulating the other crop management factors, including their interactions, he recorded a large decrease in the water requirement and spectacular yield increases, for the local varieties. This corresponded to large water savings as well as greatly increased WP. In essence, SRI crop management and water management at the level of practice represents an "integrated" ggronomy. Through integrated management of its various crop-soil-soil biota-water-nutrientspace-time components, SRI seeks to capitalize on a number of basic agronomic principles aimed at optimizing the aboveground as well as the belowground plant growth and development and the performance of the crop as a whole.

Of particular interest here is the SRI recommendation of keeping the soil just moist but not continuously flooded, either by making minimum daily applications of water or by intermittent irrigation. SRI practices of single seedling per hill and wider spacing together with aerobic soil conditions are reported to increase the yields of irrigated rice by $25 \%-75 \%$ or even more with an even greater increase in WP and a reduction in the water requirement by $40 \%-50 \%$, in seeds by $80 \%-90 \%$, in the cost of production by $20 \%$, and in the use of fertilizer by some $50 \%$.

Thus, SRI offers an opportunity to reduce water demand while enhancing yields and WP. As has been shown in several studies, the most evident phenotypic difference with SRI is in the plant root growth. Direct measurements confirm that the SRI methods induce both greater and deeper root growth, which contributes to increased WUE and nutrient uptake throughout the crop cycle, compared with the shallower rooting and shorter duration of root functioning under continuous flooding. Rice plants grown with the SRI methods take up more macronutrients than the roots of conventionally managed plants.

Evidence is accumulating that making the changes in the rice-growing practices that constitute SRI can result in win-win outcomes-for farmers, consumers, and the environment-in terms of WP as well as water savings. These gains are possible across a wide range of agroecosystems and are not limited to smallholders. Although the greatest benefits come from using the full set of practices, and using them as recommended, there are demonstrable advantages from "partial SRI." Based on the results of large-scale factorial trials in Asia and Africa, one can predict that in most of the cases reported, there are opportunities to achieve still-greater benefits from SRI methods.

SRI methods, with appropriate adaptations, are effective in a wide variety of environments: tropical humid ecology (Panama), a semiarid region on the edge of the desert (Mali), midaltitude and tropical environment (Madagascar), sandy-marshy regions (southern Iraq), various dry as henvironments in Asia (India, Pakistan, and Indonesia), and even mountainous areas with ch of these environmen ciples, to create microenvirications of standard rice-growing practices, according to the SRI prinpotential. A crop mantenvironments that are favorable to a more beneficial expression of rice genetic getting and crop management and water management strategy such as SRI is not an alternative to the most ufing genotypes best suited to a given production situation; rather, it is a way to make The suf any given variety's production capability.

highest SRI y of SRI is not dependent on using more modern rice cultivars, although most of the Plant LRI yields have come from combining its practices with high-yielding varieties or hybrids. potentials. It is has been, and will continue to be, successful in improving yield and other crop es, and where these comever, that SRI methods can also raise the yields of most indigenous varietwhere these command a higher market price because of consumer preferences, farmers 
may find these "unimproved" varieties more profitable. This can help with the conservation of rice biodiversity.

Another important consideration is that SRI phenotypes are widely reported by farmers an observers to be less susceptible to pest and disease damage. In 2005-2006, a systematic evaluation was carried out in eight provinces in Vietnam, comparing SRI plots with neighboring farmerpractice plots. This found the prevalence of major rice diseases and pests (sheath blight, leaf blight,
small leaf-folder, and brown planthopper) to be 55\% less on SRI plants in the spring season and 70\% less in summer (National IPM Program, 2007). Farmers frequently say that with SRI management, their rice plants are resistant enough to crop damage that agrochemical protection is unnecessary or it gives them no net economic benefit. The SRI approach is an example of a paradigm shift, to more biologically driven, agroecological strategies for crop production, in contrast to chemically dependent ones.

With any agricultural strategy, we should be concerned about the genetic potentials, as thes are the starting points for all life. However, the SRI experience is showing that better optimizin management of the environment for growth can achieve a fuller expression of these potentials whilc using overall water use and maximizing crop WP.

\subsection{CONCLUSION}

At the end of the first decade of the twenty-first century, there is more awareness than ever before regarding the future need and the importance of producing more food, feed, fiber, and biofuel that must be attained through a $70 \%$ increase in total global output based on increased productivity per unit of land and production inputs rather than by extending agricultural production to so far untouched terrestrial ecosystems. The production inputs used to push forward the "Gree

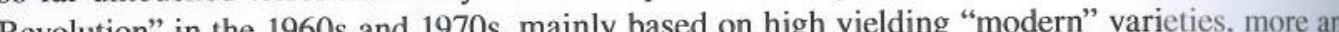
better use of fertilizers, plant protection products, and tillage, contributed decisively to production increases over the past few decades to keep pace with population growth. Today, there are many voices highlighting the fact that the potential productivity gains through increases in the $\mathrm{HI}$ and i the use of water, agrochemicals, and tillage have been met and that a new kind of Green Revolution is needed to match the increasing demand for agricultural commodities while conserving and encing as altered ecosystems and environmental quality. Additionally, such a poverty, water scarcity, land degradation, loss of biodiversity, and climate change.

poverty, water scarcity, land degradation, loss of biodiversity, and clime change.

In this context, two aspects are of fundamental importance for agricultural intensification: soil quality and the EUW. Within the ecosystem, both soil resources and water resources are inextricably linked, and so is their management for agricultural and nonagricultural uses. However, the expansion of irrigated land and the withdrawal of blue water for irrigation purposes are reaching their normal exploitable limits, thus making further improvements in WUE and WP a necessity their nor a rainfall tha in both ingated and rainfed agriculure. This ent infiltrates the soil and is accessible to plants, for use in transpiration in support of biomass grown and harvestable yields. The latter also applies to irrigated lands, because a larger green water share in the soil water balance effectively reduces the amount of supplementary irrigation.

The key message of this chapter, based on substantial empirical and scientific evidence, is that is perfectly possible to design and put into practice sustainable production systems, both rainfed ant irrigated, that are simultaneously productive, profitable, resource conserving, and environmentally irrigated, that are sil water balar of sustainprotective. In such production systens, the managenon able intensification and therefore the optimization of rainfall infiltration, soil water storage, the thre and WP, as well as all the ecosystem services required by society, can be achieved, provided the dis principles of CA are applied simultaneously: minimum soil disturbance, permanent organic sow cover, and diversified cropping system. Similarly, SRI agronomy and water management show betents. there is a large scope for improving WUE and WP in conventional irrigated or flooded rice syser
However, CA and SRI (or CA-SRI) systems are "works in progress" and their development has been led largely by farmers. These systems deserve much greater attention from the scientific research community and policy makers. Improved modern varieties and irrigation systems can be important in enhancing WUE and WP, but in themselves, they can only do so much. CA and SRI provide excellent examples of how to obtain "more output for less input" from most adapted culivars, traditional or modern. They show that when production systems pay attention to ecosystem ervices, it is possible to achieve sustainable intensification. While CA and SRI are not organic, they can be; they are probiotic and promote biodiversity in all parts of the production systems. They can maintain high overall farm productivity as well as individual factor productivities by promoting soil life and biodiversity, large root systems, organic matter as a substrate for soil micro-organisms and soil organic cover, and species diversification in the cropping systems. These attributes strongly sugest that the principles of the CA and CA-SRI systems need to be better understood and spread over ever-larger areas to meet the future global food security and ecosystem service needs. They embody the notion of sustainable soil water management.

\section{REFERENCES}

, J. K., D. L. Bjorneberg, and R. E. Sojka. 1998. Sprinkler irrigation runoff and erosion control with polyacrylamide-Laboratory tests. Soil Science Society of America Journal 62 (6):1681-1687.

M. and R. Lal. 2009. Tillage and drainage impact on soil quality: Il. Tensile strength of aggregates, moisture retention and water infiltration. Soil \& Tillage Research 103 (2):364-372.

Aboukeira, A. A. A. 2010. Deficit irrigation as an agricultural water management system for corn: A review. In Proceedings CIGR XVIIth World Congress. Quebec: CSBEI00254.

Abreu, S. L., J. M. Reichert, and D. J. Reinert. 2004. Mechanical and biological chiseling to reduce compaction of a sandy loam alfisol under no-tillage. Revista Brasileira De Ciencia Do Solo 28 (3):519-531.

Acock, D., A. M. McNeill, G. K. McDonald, and R. D. Armstrong. 2007. Subsoil constraints to crop production on neutral and alkaline soils in south-eastern Australia: A review of current knowledge and management strategies. Australian Journal of Experimental Agriculture 47 (11):1245-1261.

Adekalu, K. O. and D. A. Okunade. 2006. Effect of irrigation amount and tillage system on yield and water use efficiency of cowpea. Communications in Soil Science and Plant Analysis 37 (1-2):225-237.

Aiken, R. M., D. C. Nielsen, and L. R. Ahuja. 2003. Scaling effects of standing crop residues on the wind profile. Agronomy Journal 95 (4):1041-1046.

Ali, M., C. R. Jensen, V. O. Mogensen, M. N. Andersen, and I. E. Henson. 1999. Root signaling and osmotic adjustment during intermittent soil drying sustain grain yield of field grown wheat. Field Crops Research $62(1): 35-52$.

Ai, M. H. and M. S. U. Talukder. 2008. Increasing water productivity in crop production—A synthesis. Agricultural Water Management 95 (11):1201-1213.

Arez, R. and H. S. Steinbach. 2009. A review of the effects of tillage systems on some soil physical properties, water content, nitrate availability and crops yield in the Argentine Pampas. Soil \& Tillage Research $104(1): 1-15$

Muentes, J., J. Lampurlanes, and C. Cantero-Martinez. 2009. Alternative crop rotations under Mediterranean no-tillage conditions: Biomass, grain yield, and water-use efficiency. Agronomy Journa 101 (5):1227-1233.

. drews, D. J.). Crop Protection 6 (1):61-63.

s. D. J. and A. H. Kassam. 1976. The importance of multiple cropping in increasing world food supWl: In Multiple Cropping, edited by R. I. Papendick, A. Sanchez, and G. B. Triplett, pp. 1-10. Madison, Wus, J. F. 2001 . Society of Agronomy.

A Agriculture 41 (3):277-288

eart. An. A. Fscher. 1991. Grain and protein responses to nitrogen applied to wheat growing on a red Angus, J. F. and A A . F Journal of Agricultural Research 42 (5):735-746.

Agronomy. . van Herwaarden. 2001. Increasing water use and water use efficiency in dryland wheat. Agronomy Journal 93 (2):290-298 
Anken, T., P. Weisskopf, U. Zihlmann, H. Forrer, J. Jansa, and K. Perhacova. 2004. Long-term tillage system effects under moist cool conditions in Switzerland. Soil \& Tillage Research 78 (2):171-183.

Armand, R. C. Bockstaller, A. V. Auzet, and P. Van Dijk. 2009. Runoff generation related to intra-field soil surface

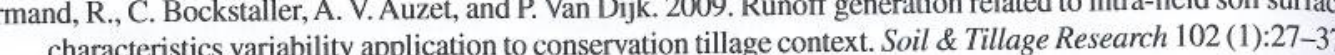
ASCE 1978. Descring irrigation and Drainase Division 104 (IR1):35-41.

Asgarzis. H. M. R. Mosadde hi, A. A. Mahboubi, A. Nosrati, and A. R. Dexter. 2010. Soil water availabil ity for plants as quantified by conventional available water, least limiting water range and integral water (1-2):229-244.

Asseng, S., F. X. Dunin, I. R. P. Fillery, D. Tennant, and B. A. Keating. 2001. Potential deep drainage under wheat crops in a Mediterranean climate. II. Management opportunities to control drainage. Australian Journal of Agricultural Research 52 (1):57-66.

Azooz. R. H. and conventional tillage systems. Canadian Journal of Soil Science 76 (2):143-152.

Baig, M. N. and P. M. Gamache. 2009. The economic, agronomic and environmental impact of no-till on the Canadian prairies. Alberta Reduced Tillage Linkages (http://www.reducedtillage.ca/docs Impactnotill rtlaug2009.pdf (accessed November 2, 2010))

Basch $G$. 1988 Alentejo/Portugal, unter besondere Berücksichtigung der Bodenbearbeitung, Göttinger Beiträge zur Land- und Forstwirtschaft in den Troper und Subtropen, 31, 1-188, Göttingen.

Basch, G., M. Carvalho, J. F. C. Barros, and J. M. G. Calado. 2010. The importance of crop residue manage ment for carbon sequestration under no-till. In Proceedings of the European Congress on Conservatio Agriculture-Towards Agro-environmental, Climate and Energetic Sustainability, edited by Ministerio de Medio Ambiente e Medio Rural e Marino, pp. 241-248, Madrid.

Batchelor, C., C. Lovell, and M. Murata. 1996. Simple microirrigation techniques for improving irrigation fficien on vetable ardens. Agricultural Water Management 32 (1):37-48.

Baumbardt R. L. and O. R. Jones. 2002. Residue management and paratillage effects on some soil properties and rain infiltration. Soil \& Tillage Research 65 (1):19-27.

Bell, M. J., B. J. Bridge, G. R. Harch, and D. N. Orange. 2005. Rapid internal drainage rates in Ferrosols. Australian Journal of Soil Research 43 (4):443-455.

Ben-Hur, M. and M. Lado. 2008. Effect of soil wetting conditions on seal formation, runoff, and soil loss in arid and semiarid soils-A review. Australian Journal of Soil Research 46 (3):191-202.

Benjamin, J. G., D. C. Nielsen, and M. F. Vigil. 2003. Quantifying effects of soil conditions on plant growth and crop production. Geoderma $116(1-2): 137-148$.

Bennett, J. 2003. Opportunities for increasing water productivity of CGIAR crops through plant breeding and molecular biology. Water Productivity in Agriculture: Limits and Opportunities for Improvement 1:103-126.

Bescansa, P., M. J. Imaz, I. Virto, A. Enrique, and W. B. Hoogmoed. 2006. Soil water retention as affected by tillage and residue management in semiarid Spain. Soil \& Tillage Research 87 (1):19-27.

Bhattacharyya, R., V. Prakash, S. Kundu, and H. S. Gupta. 2006. Effect of tillage and crop rotations on pore size distribution and soil hydraulic conductivity in sandy clay loam soil of the Indian Himalayas. Soil Tillage Research 86 (2):129-140.

Bjorneberg, D. L. and J. K. Aase. 2000. Multiple polyacrylamide applications for controlling sprinkler irrigation runoff and erosion. Applied Engineering in Agriculture 16 (5):501-504.

Bjorneberg, D. L., F. L. Santos, N. S. Castanheira, O. C. Martins, J. L. Reis, J. K. Aase, and R. E. Sojka 2003. Using polyacrylamide with sprinkler irrigation to improve infiltration. Journal of Soil and Water Conservation 58 (5):283-289.

Blackshaw, R. E., K. N. Harker, J. T. O'Donovan, H. J. Beckie, and E. G. Smith. 2008. Ongoing development of integrated weed management systems on the Canadian prairies. Weed Science 56 (1):146-150.

Blanco-Canqui, H., C. J. Gantzer, S. H. Anderson, E. E. Alberts, and A. L. Thompson. 2004. Grass barnic and vegetative filter strip effectiveness in reducing runoff, sediment, nitrogen, and phosphorus loss.
Science Society of America Journal 68 (5):1670-1678.

Blanco-Canqui, H. and R. Lal. 2007a. Impacts of long-term wheat straw management on soil hydraulic prope ties under no-tillage. Soil Science Society of America Journal 71 (4):1166-1173.

Blanco-Canqui, H. and R. Lal. 2007b. Soil and crop response to harvesting corn residues for biofuel produc tion. Geoderma 141 (3-4):355-362.

Blanco-Canqui, H. and R. Lal. 2009. Crop residue removal impacts on soil productivity and environmentis quality. Critical Reviews in Plant Sciences 28 (3):139-163.
Blanco-Canqui, H., R. Lal, W. M. Post, and L. B. Owens. 2006. Changes in long-term no-till corn growth and yield under different rates of stover mulch. Agronomy Journal 98 (4):1128-1136.

Blanco-Canqui, H., M. M. Mikha, J. G. Benjamin, L. R. Stone, A. J. Schlegel, D. J. Lyon, M. F. Vigil, and P. W. Stahlman. 2009a. Regional study of no-till impacts on near-surface aggregate properties that influence soil erodibility. Soil Science Society of America Journal 73 (4):1361-1368.

Blanco-Canqui, H., L. R. Stone, A. J. Schlegel, D. J. Lyon, M. F. Vigil, M. M. Mikha, P. W. Stahlman, and C. W. Rice. 2009b. No-till induced increase in organic carbon reduces maximum bulk density of soils. Soil Science Society of America Journal 73 (6):1871-1879.

Blevins, R. L. and W. W. Frye. 1993. Conservation tillage-An ecological approach to soil-management. Advances in Agronomy 51:33-78.

Bluemling, B., H. Yang, and C. Pahl-Wostl. 2007. Making water productivity operational-A concept of agricultural water productivity exemplified at a wheat-maize cropping pattern in the North China plain. Agricultural Water Management 91 (1-3):11-23.

Blum, A. 2009. Effective use of water (EUW) and not water-use efficiency (WUE) is the target of crop yield improvement under drought stress. Field Crops Research 112 (2-3):119-123.

Boddey, R. M., J. R. A. Bruno, and S. Irquiaga. 2006. Leguminous biological nitrogen fixation in sustainable tropical agroecosystems. In Biological Approaches to Sustainable Soil Systems, edited by N. Uphoff, A. S. Ball, E. Fernandes, et al. Boca Raton, FL: CRC Press, Taylor \& Francis Group.

B. A. S. B. J. Magid, T. J. C. Amado, F. S. Neto, M. D. D. Ribeiro, A. Calegari, R. Ralisch, and A. de Neergaard. 2006. Taking stock of the Brazilian "zero-till revolution": A review of landmark research and formers' practice. Advances in Agronomy 91:47-110.

Bos, M. G. and J. Nugteren. 1990. On Irrigation Efficiencies, 4th edition, ILRI Publication No. 19. Wageningen:

ILRI.
Bossio, D., W. Critchley, K. Geheb, G. van Lynden, and B. Mati. 2007. Conserving land-protecting water. In Water for Food, Water for Life: A Comprehensive Assessment of Water Management in Agriculture, edited by D. Molden, pp. 551-583. London, Colombo: Earthscan, International Water Management Institute.

Bossio, D., K. Geheb, and W. Critchley. 2010. Managing water by managing land: Addressing land degradation to improve water productivity and rural livelihoods. Agricultural Water Management 97 (4):536-542.

Bot, A. and J. Benites. 2005. Importance of soil organic matter. Key to drought-resistant soil and sustained food production. In Soils Bulletin No. 80, edited by FAO. Rome: FAO.

Bottinelli, N., T. Henry-des-Tureaux, V. Hallaire, J. Mathieu, Y. Benard, T. D. Tran, and P. Jouquet. 2010. Earthworms accelerate soil porosity turnover under watering conditions. Geoderma 156 (1-2):43-47.

Bouman, B. A. M. 2007. A conceptual framework for the improvement of crop water productivity at different spatial scales. Agricultural Systems 93 (1-3):43-60.

Brown, M. J. 1985. Effect of grain straw and furrow irrigation stream size on soil-erosion and infiltration. Journal of Soil and Water Conservation 40 (4):389-391.

Bruinsma, J. 2009. The resource outlook to 2050: By how much do land, water use and crop yields need to increase by 2050? Paper read at the Expert Meeting on "How to Feed the World in 2050," June 24-26. Rome: FAO.

Buchleiter, G. W., C. R. Camp, R. G. Evans, and B. A. King. 2000. Technologies for variable water application with sprinklers. In Proceedings 4th Decennial National Irrigation Symposium, edited by R. G. Evans, B. L. Benham, and T. P. Trooien, pp. 316-321. St. Joseph, MI: American Society of Agricultural Engineers.

Buczko, U., O. Bens, E. Hangen, J. Brunotte, and R. F. Huttl. 2003. Infiltration and macroporosity of a silt loam soil under two contrasting tillage systems. Landbauforschung Volkenrode 53 (2-3):181-190.

Bunting, A. H. and A. H. Kassam. 1988. Principles of crop water use, dry matter production and dry matter partitioning that govern choices of crops and systems. In Drought Research Priorities for the Dryland Tropics, edited by F. R. Bidinger and C. Johansen, pp. 43-61. Hyderabad: ICRISAT.

Bur, C. M., D. J. Howes, and A. Mutziger. 2001. Evaporation estimates for irrigated agriculture in California In Conference Proceedings of the Annual Irrigation Association Meeting, San Antonio, TX, pp. 103-110. Falls Church, VA: The Irrigation Association.

Bur, C. M., A. J. Mutziger, R. G. Allen, and T. A. Howell. 2005. Evaporation research: Review and interpretation. Journal of Irrigation and Drainage Engineering-ASCE 131 (1):37-58.

Buttar, G. S. M. S. Aujlat, H. S. Thi Drainage Engineering-ASCE 131 (1).37-58. gation on the yield and wer use ahoon, J. E., D. E. Eisent

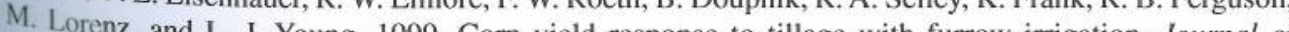
Production Agriculture 12 (2) 269-275, yield response to tillage with furrow irrigation. Journal of 
Cakmak, I 2005. The role of potassium in alleviating detrimental effects of abiotic stresses in plants. Journal Plant Nutrition and Soil Science-Zeitschrift Fur Pflanzenernahrung Und Bodenkunde 168 (4):521-530.

Cakmak. J. Yilmaz, M. Kalayci, H. Ekiz, B. Torun, B. Erenoglu, and H. J. Braun. 1996. Zinc deficiency as a critical problem in wheat production in Central Anatolia. Plant and Soil 180 (2):165-172.

Calegari, A., M. R. Darolt, and M. Ferro. 1998. Towards sustainable agriculture with a no-tillage system. Advances in GeoEcology 31:1205-1209.

Camp, C. R. E J. Sadler D. E. Evans, L. J. Usrey, and M. Omary. 1998. Modified center pivot system for precision management of water and nutrients. Applied Engineering in Agriculture 14 (1):23-31.

Carvalho, M. and G. Basch. 1995. Effects of traditional and no-tillage on physical and chemical properties of a Vertisol. In Experience with the Applicability of No-tillage Crop Production in the West-European Countries. Proceedings of the EC-Workshop II, edi

Cary, J. W. 1986. Irrigating row crops from sod furrows to reduce erosion. Soil Science Society of Americe Journal 50 (5):1299-1302.

Castro, O. M., A. C. R. Severo, and E. J. B. N. Cardoso. 1993. Avaliação da atividade de microorganismos do solo em diferentes sistemas de manejo da soja. Scientia Agricola 50 (2):212-219.

Chaboussou, F. 2004 (1985). Healthy Crops: A New Agricultural Revolution; Orig. Santé des Cultures: Une Révolution Agronomique. Charlbury, UK/Paris: Jon Carpenter Publications/Flammarion La Maison Rustique.

Chan, K. Y. 2001. An overview of some tillage impacts on earthworm population abundance and diversityImplications for functioning in soils. Soil \& Tillage Research 57 (4):179-191.

Chimenti, C. A., M. Marcantonio, and A. J. Hall. 2006. Divergent selection for osmotic adjustment results in improved drought tolerance in maize (Zea mays L.) in both early growth and flowering phases. Field Crops Research 95 (2-3):305-315.

Chiroma, A. M., A. B. Alhassan, and B. Khan. 2008. Yield and water use efficiency of millet as affected by land configuration treatments. Journal of Sustainable Agriculture 32 (2):321-333.

Christiansen, J. E. 1942. Irrigation by Sprinkling. Berkeley, CA: University of California.

Clemmens, A. J. 1998. Level-basin design based on cutoff criteria. Irrigation and Drainage Systems $12(2): 85-113$.

Clemmens, A. J. and A. R. Dedrick. 1982. Limits for practical level-basin design. Journal of the Irrigation and Drainage Division-ASCE 108 (2):127-141.

Clemmens, A. J. and D. J. Molden. 2007. Water uses and productivity of irrigation systems. Irrigation Science 25 (3): $247-261$

Clemmens, A. J. 1998. Level-basin design based on cutoff criteria. Irrigation and Drainage Systems 12 (2):85-113.

Clough, M. R. and A. J. Clemmens. 1994. Field evaluation of level-basin irrigation. In ASAE Annual Meeting Paper No. 94-2136, edited by ASAE. St. Joseph, MI: ASAE.

Coppens, F., P. Garnier, S. De Gryze, R. Merckx, and S. Recous. 2006. Soil moisture, carbon and nitrogen dynamics following incorporation and surface application of labelled crop residues in soil column European Journal of Soil Science 57 (6):894-905.

Crabtree, B. 2010. Search for Sustainability with No-Till Bill in Dryland Agriculture. Beckenham, WA: Crabree Agricultural Consulting.

Cullum, R. F. 2009. Macropore flow estimations under no-till and till systems. Catena 78 (1):87-91.

Cullum, R. F., G. V. Wilson, K. C. McGregor, and J. R. Johnson. 2007. Runoff and soil loss from ultra-narroy row cotton plots with and without stiff-grass hedges. Soil \& Tillage Research 93 (1):56-63.

da Silva, V. R., J. M. Reichert, and D. J. Reinert. 2006. Soil temperature variation in three different syser. soil management in

da Veiga, M., D. J. Reinert, J. M. Reichert, and D. R. Kaiser. 2008. Short and long-term effects of tillage sys tems and nutrient sources on soil physical properties of a southern Brazilian Hapludox. Revista Brasilein De Ciencia Do Solo 32 (4):1437-1446.

Dabney, S. M., J. A. Delgado, and D. W. Reeves. 2001. Using winter cover crops to improve soil and water quality. Communications in Soil Science and Plant Analysis 32 (7-8):1221-1250.

qualis. Communications in Soil Science and Plant Analysis 32 (7-8).1221-125. erosion of loessial soil. Transactions of the ASAE 47 (3):767-775.

Dang, Y. P. R. C. Dalal, S. R. Buck, et al. 2010. Diagnosis, extent, impacts, and management of subsoil constraints in the northern grains cropping region of Australia. Australian Journal of Soil Resean $48(2): 105-119$.
Dasilva, A. P., B. D. Kay, and E. Perfect. 1994. Characterization of the least limiting water range of soils. Soil Science Society of America Journal 58 (6):1775-1781

de Sousa, P. L., L. L. Silva, and R. P. Serralheiro. 1999. Comparative analysis of main on-farm irrigation systems in Portugal. Agricultural Water Management 40 (2-3):341-351.

Deng, X. P., L. Shan, S. Z. Kang, S. Inanaga, and M. E. K. Ali. 2003. Improvement of wheat water use efficiency in semiarid area of China. Agricultural Science in China 2 (1):35-44

Diaz-Ambrona, C. G. H., G. J. O'Leary, V. O. Sadras, M. G. O'Connell, and D. J. Connor. 2005. Environmental risk analysis of farming systems in a semi-arid environment: Effect of rotations and management practices on deep drainage. Field Crops Research 94 (2-3):257-271.

Doorenbos, J. and A. H. Kassam. 1979. Yield response to water. In FAO Irrigation and Drainage Paper 33 edited by FAO. Rome: FAO.

Doorenbos, J. and W. Pruitt. 1977. Guidelines for predicting crop water requirements. In Irrigation and Drainage Paper 24 (Rev.), edited by FAO. Rome: FAO.

dos Santos, T. P., C. M. Lopes, M. L. Rodrigues, C. R. de Souza, J. P. Maroco, J. S. Pereira, J. M. Ricardoda-Silva, and M. M. Chaves. 2003. Partial rootzone drying: Effects on growth and fruit quality of fieldgrown grapevines (Vitis vinifera). Functional Plant Biology 30:663-671.

Duke, H. R., L. E. Stetson, and N. C. Ciancaglini. 1992. Irrigation systems control. In Management of Farm Irrigation Systems, ASAE Monograph No. 9, edited by G. J. Hoffman, T. A. Howell, and K. H. Solomon. St. Joseph, MI: ASAE.

Ehlers, W. and M. Goss. 2003. Water Dynamics in Plant Production. Wallingford, UK: CABI Publishing.

Eisenhauer, D. E., E. C. Dickey, P. E. Fischbach, and K. D. Frank. 1982. Influence of reduced tillage on furrow irrigation infiltration. In ASAE Annual Paper No. 82-2587, edited by ASAE. St. Joseph, MI: ASAE.

Eriksen-Hamel, N. S., A. B. Speratti, J. K. Whalen, A. Legere, and C. A. Madramootoo. 2009. Earthworm populations and growth rates related to long-term crop residue and tillage management. Soil \& Tillage arch 104 (2):311-316.

Ernst, G., D. Felten, M. Vohland, and C. Emmerling. 2009. Impact of ecologically different earthworm species on soil water characteristics. European Journal of Soil Biology 45 (3):207-213.

Evans, R. G. and E. J. Sadler. 2008. Methods and technologies to improve efficiency of water use. Water Resources Research 44:15.

Fabrizzi, K. P., F. O. Garcia, J. L. Costa, and L. I. Picone. 2005. Soil water dynamics, physical properties and corn and wheat responses to minimum and no-tillage systems in the southern Pampas of Argentina. Soil (i):57-69.

Falkenmark, M. 2007. Shift in thinking to address the 21 st century hunger gap-Moving focus from blue to green water management. Water Resources Management 21 (1):3-18

Falkenmark, M. and J. Rockstrom. 2004. Balancing Water for Humans and Nature. London: Earthscan.

Fang, Q., L. Ma, Q. Yu, L. R. Ahuja, R. W. Malone, and G. Hoogenboom. 2010a. Irrigation strategies to improve the water use efficiency of wheat-maize double cropping systems in North China Plain. Agricultural Water Management 97 (8):1165-1174.

Fang, Q. X., L. Ma, T. R. Green, Q. Yu, T. D. Wang, and L. R. Ahuja. 2010b. Water resources and water use efficiency in the North China Plain: Current status and agronomic management options. Agricultural Water Management 97 (8):1102-1116.

FAO. 1978-1981. Agroecological Zones Project Report. Methodology and Results for Africa (Vol.1), West Asia (Vol.2), South and Central America (Vol.3), Southeast Asia (Vol.4). In World Soil Resources Report 48. Rome: FAO.

FAO. 1989. Guidelines for designing and evaluating surface irrigation systems. In Irrigation and Drainage

FAO. 1992 . CROPWAT FAO

CROPWAT-A computer program for irrigation planning and management. In Irrigation and Drainage Paper No. 26. Rome: FAO.

2008. Investing in sustainable crop intensification: The case for soil health. In Report of the International Technical Workshop, FAO, Rome, July. Integrated Crop Management Vol. 7. Rome: FAO.

Feres, E. and A. Kassam. 2003. Water and the CGIAR: A strategic framework. Water International 28 (1):122-129.

M. A. Soriano. 2007. Deficit irrigation for reducing agricultural water use. Journal of

Experimental Botany 58 (2): 147-159.

improvement, Irto, P. Bescansa, M. J. Imaz, A. Enrique, and D. L. Karlen. 2009. No-tillage improvement of soil physical quality in calcareous, degradation-prone, semiarid soils. Soil \& Tillage
Research $106(1) \cdot 29-35$ 
Fischer, A. 1979. Growth and water limitations to dryland wheat yield in Australia: A physiological framework Journal of the Australian Institute of Agricultural Science 45:83-94.

Flower, K., B. Crabtree, and G. Butler. 2008. No-till cropping systems in Australia. In No-Till Farming Systems Special Publication No. 3, edited by T. Goddard, M. Zoebisch, Y. Gan, W. Ellis, A. Watson, and S. Sombatpanit, pp. 457-467. Bangkok: World Association of Soil and Water Conservation (WASWAC).

Fornstrom, K. J., J. A. Michel, J. Borrelli, and G. D. Jackson. 1985. Furrow firming for control of irrigatio advance rates. Transactions of the ASAE 28 (2):519-531.

Fowler, R. and J. Rockstrom. 2001. Conservation tillage for sustainable agriculture-An agrarian revolution gathers momentum in Africa. Soil \& Tillage Research 61 (1-2):93-107.

Freese, R. C., D. K. Cassel, and H. P. Denton. 1993. Infiltration in a piedmont soil under 3 tillage systems Journal of Soil and Water Conservation 48 (3):214-218

Freitas, P. S. L., E. C. Mantovani, G. C. Sediyama, and L. C. Costa. 2006. Influência da cobertura de resíduos de culturas nas fases da evaporação direta da água do solo. Revista Brasileira de Engenharia Agrícola Ambiental 10 (1):104-111.

Friedrich, T., A. H. Kassam, and F. Shaxson. 2009. Conservation agriculture. In Agriculture for Developin Countries. Science and Technology Options Assessment (STOA) Project, edited by R. Meyer. Karlsruhe European Parliament, European Technology Assessment Group.

Furbank, R. T., S. von Caemmerer, J. Sheehy, and G. Edwards. 2009. C-4 rice: A challenge for plant phenomics Functional Plant Biology 36 (10-11):845-856.

Gan, Y. and T. Goddard. 2008. Roles of annual legumes in no-till farming systems. In No-Till Farming System. Special Publication No. 3, edited by T. Goddard, M. Zoebisch, Y. Gan, W. Ellis, A. Watson, and S. Sombatpanit, pp. 279-288. Bangkok: World Association of Soil and Water Conservation (WASWAC).

Gan, Y., K. N. Harker, B. McConkey, and M. Suleimanov. 2008. Moving towards no-till practices in northen Eurasia. In No-Till Farming Systems, Special Publication No. 3, edited by T. Goddard, M. Zoebisch. Y. Gan, W. Ellis, A. Watson, and S. Sombatpanit, pp. 179-195. Bangkok: World Association of Soil an Water Conservation (WASWAC).

Gao, Y. J. and S. X. Li. 2005. Cause and mechanism of crop yield reduction under straw mulch in dry land Transactions of the Chinese Society of Agricultural Engineers 21:15-19 (in Chinese with Englis abstract).

Garvin, P. C., J. R. Busch, and D. C. Kincaid. 1986. Reservoir tillage for reducing runoff and increasing production under sprinkler irrigation. In ASAE Annual Paper No. 86-2093, edited by ASAE. St. Joseph, M. ASAE.

Geerts, S. and D. Raes. 2009. Deficit irrigation as an on-farm strategy to maximize crop water productivity in dry areas. Agricultural Water Management 96 (9):1275-1284.

Ghassemi, F. and I. White. 2007. Inter-Basin Water Transfer: Case Studies from Australia, United States, Canada, China and India. Cambridge: Cambridge University Press.

Ghosh, P. K., D. Dayal, K. K. Bandyopadhyay, and K. Mohanty. 2006. Evaluation of straw and polythene mulch for enhancing productivity of irrigated summer groundnut. Field Crops Research 99 (2-3):76-86. Gill, B. S. and S. K. Jalota. 1996. Evaporation from soil in relation to residue rate, mixing depth, soil texture and evaporativity. Soil Technology 8 (4):293-301.

Gimenez, R. and G. Govers. 2008. Effects of freshly incorporated straw residue on rill erosion and hydraulics Catena 72 (2):214-223.

Gleick, P. H., E. L. Wolff, and R. R. Chalecki. 2002. The New Economy of Water: The Risks and Benefits of Globalization and Privatization of Freshwater. Oakland, CA: Pacific Institute for Studies in Development. Environment, and Security.

Goddard, T., M. Zoebisch, Y. Gan, W. Ellis, A. Watson, and S. Sombatpanit. 2008. No-Till Farmin Systems, Special Publication No. 3. Bangkok: World Association of Soil and Water Conservation (WASWAC).

Goldhamer, D. A., M. Salinas, C. Crisosto, K. R. Day, M. Soler, and A. Moriana. 2002. Effects of regulated deficit irrigation and partial root zone drying on late harvest peach tree performance. Acta Horticuluru 592:343-350.

Gomez, J. A. and M. A. Nearing. 2005. Runoff and sediment losses from rough and smooth soil surfaces in laboratory experiment. Catena 59 (3):253-266.

Gordon, L. J., C. M. Finlayson, and M. Falkenmark. 2010. Managing water in agriculture for food production and other ecosystem services. Agricultural Water Management 97 (4):512-519.

Govaerts, B., K. D. Sayre, K. Lichter, L. Dendooven, and J. Deckers. 2007. Influence of permanent raised bed planting and residue management on physical and chemical soil quality in rain fed maize/wheat systche Plant and Soil 291 (1-2):39-54.
Graham, R. L., R. Nelson, J. Sheehan, R. D. Perlack, and L. L. Wright. 2007. Current and potential U.S. corn stover supplies. Agronomy Journal 99 (1):1-11.

Gregory, P. J., L. P. Simmonds, and C. J. Pilbeam. 2000. Soil type, climatic regime, and the response of water use efficiency to crop management. Agronomy Journal 92 (5):814-820.

Groenevelt, P. H., C. D. Grant, and S. Semetsa. 2001. A new procedure to determine soil water availability. Australian Journal of Soil Research 39 (3):577-598.

Guzha, A. C. 2004. Effects of tillage on soil microrelief, surface depression storage and soil water storage. Soil \& Tillage Research 76 (2):105-114.

Hakala, K., M. Kontturi, and K. Pahkala. 2009. Field biomass as global energy source. Agricultural and Food Science $18(3-4): 347-365$

Hamdy, A. 2007. Water use efficiency in irrigated agriculture: An analytical review. Options Méditerranéennes Series B (57):9-19.

Hamza, M. A. and W. K. Anderson. 2003. Responses of soil properties and grain yields to deep ripping and gypsum application in a compacted loamy sand soil contrasted with a sandy clay loam soil in Western Australia. Australian Journal of Agricultural Research 54 (3):273-282.

Hamza, M. A. and W. K. Anderson. 2005. Soil compaction in cropping systems-A review of the nature, causes and possible solutions. Soil \& Tillage Research 82 (2):121-145

Hares, M. A. and M. D. Novak. 1992. Simulation of surface-energy balance and soil-temperature under strip tillage. 2. Field-test. Soil Science Society of America Journal 56 (1):29-36.

Hart, W. E. and D. F. Heerman. 1976. Evaluating water distribution of sprinkler irrigation systems. In Tech. Bulletin No. 128, edited by C. S. University. Fort Collins, CO: CSU Press.

Hartge, K. H. and H. Bohne. 1983. Effect of pore geometry on compressibility of soil and development of rye seedlings. Zeitschrift Fur Kulturtechnik Und Flurbereinigung 24 (1):5-10.

Hartmann, C., R. Poss, A. D. Noble, A. Jongskul, E. Bourdon, D. Brunet, and G. Lesturgez. 2008. Subsoil improvement in a tropical coarse textured soil: Effect of deep-ripping and slotting. Soil \& Tillage Research 99 (2):245-253

Hatfield, J. L., T. J. Sauer, and J. H. Prueger. 2001. Managing soils to achieve greater water use efficiency: A review. Agronomy Journal 93 (2):271-280

Haynes, R. J. 2000. Interactions between soil organic matter status, cropping history, method of quantification and sample pretreatment and their effects on measured aggregate stability. Biology and Fertility of Soils 30 (4):270-275.

Heerman, D. F., W. W. Wallender, and M. G. Bos. 1992. Irrigation efficiency and uniformity. In Management of Farm Irrigation Systems, ASAE Monograph No. 9, edited by G. J. Hoffman, T. A. Howell, and K. H. Solomon. St. Joseph, MI: ASAE.

Hibberd, J. M., J. E. Sheehy, and J. A. Langdale. 2008. Using C-4 photosynthesis to increase the yield of rice-rationale and feasibility. Current Opinion in Plant Biology 11 (2):228-231.

Hillel, D. 1980. Applications of Soil Physics. New York: Academic Press.

Hobbs, P. R. 2007. Conservation agriculture: What is it and why is it important for future sustainable food production? Journal of Agricultural Science 145:127-137.

Hobbs, P. R., K. Sayre, and R. Gupta. 2008. The role of conservation agriculture in sustainable agriculture. Philosophical Transactions of the Royal Society B-Biological Sciences 363 (1491):543-555.

Hoff, H. 2010. The global water challenge-Modeling green and blue water preface. Journal of Hydrology 384 (3-4):175-176.

loff, H., M. Falkenmark, D. Gerten, L. Gordon, L. Karlberg, and J. Rockstrom. 2010. Greening the global water system. Journal of Hydrology 384 (3-4):177-186.

1. K. and A. Smucker. 2005. Structure formation and its consequences for gas and water transport in unsaturated arable and forest soils. Soil \& Tillage Research 82 (1):5-14.

T. C., P. Steduto, and E. Fereres. 2007. A systematic and quantitative approach to improve water use eficiency in agriculture. Irrigation Science 25 (3):209-231.

49 B. D. 1994. Soil organic-matter and available water capacity. Journal of Soil and Water Conservation Hula, J., P. Kovaricek.

row . Kovaricek, and M. Kroulik. 2010. Water infiltration into the soil and surface water run-off in wideHussain, crops. Listy Cukrovarnicke a Reparske 126 (1):22-26.

soil. Soil R. Olson, and J. C. Siemens. 1998. Long-term tillage effects on physical properties of eroded CID. 1978 . Stance 163 (12):970-981.

Imboff, S... P. J Glars for the calculation of irrigation efficiencies. ICID Bulletin 27:91-101. manag. Ghiberto, A. Grioni, and J. P. Gay. 2010. Porosity characterization of Argiudolls under different anagement systems in the Argentine Flat Pampa. Geoderma 158 (3-4):268-274 
Jark of land use pattern and land configurations on surface run-off and soil erosion during south-west monsoon at Parbhani. Journal of Agrometeorology 10:38-41.

J..$K$. and V. K. A a, S. K. and V. K. Arora. 2002. Model-baseutural Water Management 57 (1):75-87.

ping systems in north-west India. Agric of atmospheric evaporativity, soil type and redistribution time on
Jalo, S. K. and S. S. Prihar. 1986. Effects of evaporation from bare soil. Australian Journal of Soil Research 24 (3):357-366.

Jensen, M. E. 2007. Beyond irrigation efficiency. Irrigation Science 25 (3):233-245. in, K., W. M. Cornelis, D. Gabriels, et al. 2009.

organic carbon losses. Catena
Jordan, A. L. M. Zavala, and J. Gil. 2010. Effects of mulching on soil physical properties and runoff under an, A., L. M. Zavala, and J. Gil. 2010. Effects of mulching on
semi-arid conditions in southern Spain. Catena 81 (1):77-85.

semi-arid conditions in southern spand slip plowing effects on soil properties and wheat grown on a stratidah, M. T. 1976. Subsoil chiseling and slip plowing eff:cts

fied fine sandy soil. Agronomy Journal climate change impacts on crop yield, crop water productivity and ,Y. H., S. Khan, and X. Y. Ma. 2009. C Natural Science 19 (12):1665-1674.

Kansas State University Southwest Research-Extension Center. 2008. Reducing tillage intensity in a when-

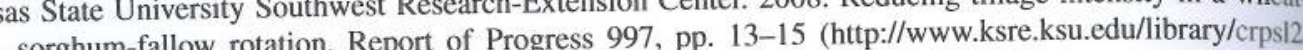
SRP997.pdf (accessed November 02, 2010))

Kassam, A., T. Friedrich, F. Shaxson, and J. Pretty. 2009. The spread of conservation agriculture: Justification, sustainability and uptake. International Journal of Agricultural Sustainability 7 (4):292-320.

Kassam, A. H., H. Doggett, and D. J. Andrews. 1979. Cereal physiology in relation to genetic improvemen at ICRISAT with some reference to drought endurance. In Proceedings of Physiology Programn Formulation Workshop, edited by K. J. Treharne, pp. 45-51. Ibadan: IITA.

Kassam, A. H. and T. Friedrich. 2009. Perspectives on nutrient management in conservation agriculture. Lead Papers of the IV World Congress on Conservation Agriculture, pp. 85-92. New Delh.

Kassam, A. H., D. Molden, E. Fereres, and J. Doorenbos. 2007. Water productivity: Science and practiceIntroduction. Irrigation Science 25 (3):185-188.

Katerji, N. and M. Mastrorilli. 2009. The effect of soil texture on the water use efficiency of irrigated crop Results of a multi-year experiment carried out in the Mediterranean region. European Journal Agronomy 30 (2): $95-100$.

Katerii, N., M. Mastrorilli, and H. E. Cherni. 2010. Effects of corn deficit irrigation and soil properties on water use efficiency. A 25-year analysis of a Mediterranean environment using the STICS model. Europea Journal of Agronomy 32 (2): 177-185.

Kaufmann, M., S. Tobias, and R. Schulin. 2010. Comparison of critical limits for crop plant growth based on different indicators for the state of soil compaction. Journal of Plant Nutrition and Soil Science 17 (4):573-583.

Kay, B. D. and D. A. Angers. 1999. Soil structure. In Handbook of Soil Science, edited by M. E. Sumner pp. 229-269. Boca Raton: CRC Press.

Kay, B. D. and A. J. VandenBygaart. 2002. Conservation tillage and depth stratification of porosity and sol organic matter. Soil \& Tillage Research 66 (2):107-118.

Kay, B. D. and D. A. Angers. 1999. Soil structure. In Handbook of Soil Science, edited by M. E. Sumner. pp. 229-269. Boca Raton: CRC Press.

Keller, J. and R. Bliesner. 2001. Sprinkler and Trickle Irrigation. London: The Blackburn Press. Kemper, W. D., T. J. Trout, and D. C. Kincaid. 1987. Cablegation: Automate supply for surface irrigation. Advances in Irrigation, edited by D. Hillel. Orlando, FL: Academic Press.

Khalid, M. and J. L. Smith. 1978. Control of furrow infiltration by compaction. Transactions of the ASAE 21 (4):655-657.

Khan, S., M. M. Hafeez, T. Rana, and S. Mushtaq. 2008. Enhancing water productivity at the irrigation systent level: A geospatial hydrology application in the Yellow River Basin. Journal of Arid Environments (6): 1046-1063.

Kirkegaard, J. A., J. M. Lilley, G. N. Howe, and J. M. Graham. 2007. Impact of subsoil water use on when yield. Australian Journal of Agricultural Research 58 (4):303-315.

Kitchen, N. R., K. W. T. Goulding, and J. F. Shanahan. 2008. Proven practices and innovative technologies for on-farm crop nitrogen management. In Nitrogen Environment: Sources, Problems, and Manage edited by J. L. Hatfield and T. R. F. Follet. Boston, MA: Academic Press.

Kladivko, E. J., N. M. Akhouri, and G. Weesies. 1997. Earthworm populations and species distributions wnde no-till and conventional tillage in Indiana and Illinois. Soil Biology \& Biochemistry 29
Klocke, N. L., R. S. Currie, and R. M. Aiken. 2009. Soil water evaporation and crop residues. Transactions of the ASABE 52 (1):103-110.

Koluvek, P. K., K. K. Tanji, and T. J. Trout. 1993. Overview of soil-erosion from irrigation. Journal of Irrigation and Drainage Engineering-ASCE 119 (6):929-946.

Kosgei, J. R., G. P. W. Jewitt, V. M. Kongo, and S. A. Lorentz. 2007. The influence of tillage on field scale water fluxes and maize yields in semi-arid environments: A case study of Potshini catchment, South Africa. .

Kowal, J. M. and A. H. Kassam. 1978. Agricultural Ecology of Savanna: A Study of West Africa. Oxford: Clarendon Press.

Krupinsky, J. M., K. L. Bailey, M. P. McMullen, B. D. Gossen, and T. K. Turkington. 2002. Managing plant disease risk in diversified cropping systems. Agronomy Journal 94 (4):198-209.

Lado, A. and A. Ben-Hur. 2004. Soil mineralogy effects on seal formation, runoff and soil loss. Applied Clay Science $24(3-4): 209-224$.

Lado, M., A. Paz, and M. Ben-Hur. 2004. Organic matter and aggregate size interactions in infiltration, seal formation, and soil loss. Soil Science Society of America Journal 68 (3):935-942.

Lal. R. 2005. World crop residues production and implications of its use as a biofuel. Environment International 31 (4):575-584.

Lal, R. 2008a. Crop residues as soil amendments and feedstock for bioethanol production. Waste Management 28 (4):747-758.

Lal, R. 2008b. Managing soil water to improve rainfed agriculture in India. Journal of Sustainable Agriculture $32(1): 51-75$.

Lal, R. 2009. Soil quality impacts of residue removal for bioethanol production. Soil \& Tillage Research 102 (2):233-241.

Lal, R. and M. K. Shukla. 2004. Principles of Soil Physics. New York: Marcel Dekker.

, F. R., R. M. Aiken, and A. A. Abou Kheira. 2009. Corn yield and water use characteristics as affected by tillage, plant density, and irrigation. Transactions of the ASABE 52 (1):133-143.

mpurlanes, J. and C. Cantero-Martinez. 2006. Hydraulic conductivity, residue cover and soil surface roughness under different tillage systems in semiarid conditions. Soil \& Tillage Research 85 (1-2):13-26.

Landers, J. 2007. Tropical crop-livestock systems in conservation agriculture: The Brazilian experience. In Mn

Lapen, D. R., G. C. Topp, E. G. Gregorich, and W. E. Curnoe. 2004. Least limiting water range indicators of soil quality and corn production, eastern Ontario, Canada. Soil \& Tillage Research 78 (2):151-170.

Kea, K. B., P. Pathak, and M. C. Klaij. 1991. Tillage systems and soils in the semiarid tropics. Soil \& Tillage

Research 20 (2-4):201-218.
ascano, R. J., R. L. Baumhardt, S. K. Hicks, and J. L. Heilman. 1994. Soil and plant water evaporation from strip-tilled cotton-Measurement and simulation. Agronomy Journal 86 (6):987-994

Leach, G. 1995. Global Land and Food in the 21 st Century: Trends \& Issues for Sustainability. Stockholm: Stockholm Environment Institute.

. Macedo, S. Imhoff, and V. P. B. Euclides. 2006. Least limiting water range: A potential indicator of changes in near-surface soil physical quality after the conversion of Brazilian

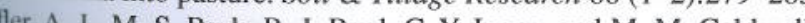

the r. M. S. Peck, R. J. Kyel, C. Y. Ivans, and M. M. Caldwell. 2005. Hydraulic redistribution through D. D. I. Shain of senesced plants. Eeology 86 (3).633-642.

. applications of polymers. Soil Science Society of America Journal 56 (6):1926-1932.

tion. Soil R. E. Sojka. 1994. Field results using polyacrylamide to manage furrow erosion and infiltraA. G. Govenc, K. Gill.27, E. Be,

Gillijns, E. Berckmoes, and I. Takken. 2010. Scale effects on runoff and erosion losses from arable land under conservation and conventional tillage: The role of residue cover. Journal L., X. Y. 2003 . Crogy 390 (3-4):143-154.

Chin. Gravel-sand mulch for soil and water conservation in the semiarid loess region of northwest Y. X. J. Catena 52 (2):105-127.

tration .

properties Soil Al-Kaisi. 2005. Strip-tillage effect on seedbed soil temperature and other soil physical W. M. and C. L. Mohler 2001. Weed 80 (1-2):233-249.

Weeds, edited by dited by M. Liebman, C. L. Mohler, and C. P. Staver. Cambridge: Cambridge University Press. 
Lindwall, C. W. and B. Sonntag (eds). 2010. Landscape Transformed: The History of Conservation Tillage and Direct Seeding. Knowledge Impact in Society. Saskatoon, SK: University of Saskatchewan.

Liu, C. A., S. L. Jin, L. M. Zhou, Y. Jia, F. M. Li, Y. C. Xiong, and X. G. Li. 2009. Effects of plastic film mulch and tillage on maize productivity and soil parameters. European Journal of Agronomy 31 (4):241-249.

Liu, W. D., M. Tollenaar, G. Stewart, and W. Deen. 2004. Response of corn grain yield to spatial and temporal variability in emergence. Crop Science 44 (3):847-854.

Liu, Y. S. Q. Li, F. Chen, S. J. Yang, and X. P. Chen. 2010. Soil water dynamics and water use efficiency in spring maize (Zea mays L.) fields subjected to different water management practices on the Loes Plateau, China. Agricultural Water Management 97 (5):769-775.

Liu, Z. M., L. Shan, X. P. Deng, S. Inanaga, W. Sunohara, and J. Harada. 1998. Effects of fertilizer and plant density on the yields of root system and water use of spring wheat. Research of Soil and Water Conservation 5 (1):70-75.

Lopez-Fando, C., J. Dorado, and M. T. Pardo. 2007. Effects of zone-tillage in rotation with no-tillage on soil properties and crop yields in a semi-arid soil from central Spain. Soil \& Tillage Research 95 (1-2):266-276.

Losada, A., L. Juana, and J. Roldan. 1990. Operation diagrams for irrigation management. Agricultural Water Management 18 (4):289-300.

Lu, Y. C., K. B. Watkins, J. R. Teasdale, and A. A. Abdul-Baki. 2000. Cover crops in sustainable food produc tion. Food Reviews International 16 (2):121-157.

Ludlow, M. M. and R. C. Muchow. 1988. Critical evaluation of the possibilities for modifying crops for high production per unit of precipitation. In Proceedings of Physiology Programme Formulation Workshop, edited by K. J. Treharne, pp. 45-51. Ibadan: IITA.

Lyle, W. M. and J. P. Bordovsky. 1983. Lepa irrigation system evaluation. Transactions of the ASAE 26 (3):776-781

MacEwan, R. J., D. M. Crawford, P. J. Newton, and T. S. Clune. 2010. High clay contents, dense soils, an spatial variability are the principal subsoil constraints to cropping the higher rainfall land in south-easter Australia. Australian Journal of Soil Research 48 (2): 150-166.

Makurira, H., H. H. G. Savenije, and S. Uhlenbrook. 2010. Modelling field scale water partitioning using on-site observations in sub-Saharan rainfed agriculture. Hydrology and Earth System Sciences 14 (4):627-638.

Makurira, H., H. H. G. Savenije, S. Uhlenbrook, J. Rockstrom, and A. Senzanje. 2009. Investigating the water balance of on-farm techniques for improved crop productivity in rainfed systems: A case study of Makanya catchment, Tanzania. Physics and Chemistry of the Earth 34 (1-2):93-98.

Mann, L., V. Tolbert, and J. Cushman. 2002. Potential environmental effects of corn (Zea mays L.) stover removal with emphasis on soil organic matter and erosion. Agriculture, Ecosystems \& Environment 89 (3): 149-166

Marongwe, L. S., K. Kwazira, M. Jenrich, C. Thierfelder, A. Kassam, and T. Friedrich. 2011. An African success: The case of conservation agriculture in Zimbabwe. International Journal of Agricultural Sustainability 9 (1):153-161.

Mary, G. R. and J. Changying. 2008. Influence of agricultural machinery traffic on soil compaction patterns, root development, and plant growth, overview. American-Eurasian Journal of Agricultural and Environmental Science 3 (1):49-62.

McGarry, D., B. J. Bridge, and B. J. Radford. 2000. Contrasting soil physical properties after zero and traditional tillage of an alluvial soil in the semi-arid subtropics. Soil \& Tillage Research 53 (2):105-115.

Miller, D. E., J. S. Aarstad, and R. G. Evans. 1987. Control of furrow erosion with crop residues and surge flow irrigation. Soil Science Society of America Journal 51 (2):421-425.

Miller, D. E. and R. O Gifford. 1974. Modification of soil crusts for plant growth. In Soil Crusts, edited by D. D. E. Cary. J.W. Tucson, AZ: University of Arizona Technical Bulletin No. 214

Mohammad, A. G. and M. A. Adam. 2010. The impact of vegetative cover type on runoff and soil erosion under different land uses. Catena 81 (2):97-103.

Molden, D. (ed.) 2007. Water for Food, Water for Life: A Comprehensive Assessment of Water Management in Agriculture. London, Colombo: Earthscan, International Water Management Institute.

Molden, D., D. Bin, R. Loeve, R. Barker, and T. P. Tuong. 2007. Agricultural water productivity and savings: Policy lessons from two diverse sites in China. Water Policy 9:29-44

Molden, D., T. Oweis, P. Steduto, P. Bindraban, M. A. Hanjra, and J. Kijne. 2010. Improving agricultural walc productivity: Between optimism and caution. Agricultural Water Management 97 (4):528-5.5.

Monzon, J. P., V. O. Sadras, and F. H. Andrade. 2006. Fallow soil evaporation and water storage as affecticd by stubble in sub-humid (Argentina) and semi-arid (Australia) environments. Field Crops Research $(2-3): 83-90$.
Moret, D. J. L. Arrue, M. V. Lopez, and R. Gracia. 2006. Influence of fallowing practices on soil water and precipitation storage efficiency in semiarid Aragon (NE Spain). Agricultural Water Management 82 ): $161-176$

Moret. D. I. Braud, and J. L. Arrue. 2007. Water balance simulation of a dryland soil during fallow under conventional and conservation tillage in semiarid Aragon, northeast Spain. Soil \& Tillage Research 92 (1-2):251-263.

Morocco. In No-Till Farming Systems, Special Publication No. 3, edited by T. Goddard, M. Zoebisch, Y. Gan, W. Ellis, A. Watson, and S. Sombatpanit, pp. 393-412. Bangkok: World Association (WASWAC).

Met, R. N. Saber, A. El-Brahli, S. Lahlou, and F. Bessam. 2001. Total, particulate organic matter and structural stability of a Calcixeroll soil under different wheat rotations and tillage systems in a semiarid area or Morco. Soil \& Tillage Research 57 (4):225-235.

Mulumba, L. N. and R. Lal. 2008. Mulching effects on selected soil physical properties. Soil \& Tillage Research 98 (1):106-111.

Musick, J. T., F. B. Pringle, and P. N. Johnson. 1985. Furrow compaction for controlling excessive irrigation water-intake. Transactions of the ASAE 28 (2):502-506.

Northern Ecological Areas of Vietnam. Report to the Council of Science and Technology, Ministry of Agriculture and Rural Development, Hanoi, Vietnam.

Ndiaye, B., J. Molenat, V. Hallaire, C. Gascuel, and Y. Hamon. 2007. Effects of agricultural practices on hydraulic properties and water movement in soils in Brittany (France). Soil \& Tillage Research 93 (2):251-263.

Noigi, S. N., J. Rockstrom, and H. H. G. Savenije. 2006. Assessment of rainwater retention in agricultural land and crop yield increase due to conservation tillage in Ewaso Ng'iro river basin, Kenya. Physics and Chemistry of the Earth 31 (15-16):910-918.

Nuttall, J. G. and R. D. Armstrong. 2010. Impact of subsoil physicochemical constraints on crops grown in the Wimmera and Mallee is reduced during dry seasonal conditions. Australian Journal of Soil Research 48 (2): $125-139$.

guntunde, P. G., A. E. Ajayi, and N. van de Giesen. 2006. Tillage and surface moisture effects on bare-soil albedo of a tropical loamy sand. Soil \& Tillage Research 85 (1-2):107-114.

W. W. J., R. E. Sojka, and G. M. Glenn. 2000. Biopolymer additives to reduce erosion-induced soil losses during irrigation. Industrial Crops and Products 11 (1):19-29.

weis, T. Y. and A. Y. Hachum. 2003. Improving water areas of west Asia productivity in the dry and North Africa. Water Productivity in Agriculture: Limits and Opportunities for Improvement 1:179-198.

wenya, M. Z., W. L. Mariki, J. Kienzle, T. Friedrich, and A. Kassam. 2011. Conservation Agriculture (CA) in Tanzania: The case of the Mwangaza CA farmer field school (FFS). International Journal of Agricultural Sustainability 9 (1): $145-152$.

assioura, J. 2006. Increasing crop productivity when water is scarce-From breeding to field management. Agricultural Water Management 80 (1-3):176-196.

Passioura, J. B. and J. F. Angus. 2010. Improving productivity of crops in water-limited environments. Advances in Agronomy 106:37-75.

Patel, G. N., P. T. Patel, and P. H. Patel. 2008. Yield, water use efficiency and moisture extraction pattern of summer groundnut as influenced by irrigation schedules, sulfur levels and sources. Journal of SAT Agricultural Research 6:1-4.

Percira, L. S. 2007. Relating water productivity and crop evapotranspiration. Options Méditerranéennes Series $B(57): 31-49$.

Perry, C., P. Steduto, R. G. Allen, and C. M. Burt. 2009. Increasing productivity in irrigated agriculture Agronomic constraints and hydrological realities. Agricultural Water Management 96 (11):1517-1524. (1) A. A. and D. G. Westfall. 2004. Managing precipitation use in sustainable dryland agroecosystems. Annals of Applied Biology 144 (2):127-138.

Ficre, F. J., W. E. Larson, R. H. Dowdy, and W. A. P. Graham. 1983. Productivity of soils-Assessing long ineres changes due erosion. Journal of Soil and Water Conservation 38 (1):39-44.

. and S. Nandagopal. 2004. Water resources: Agricultural and environmental issues. Bioscience 54

Pimentel, D., C. Harvey, P. Resosudarmo, et al. 1995. Environmental and economic costs of soil erosion and Playan, E, and Lon benefits. Science 267 (5201):1117-1123.

ductivity . Mateos. 2006. Modernization and optimization of irrigation systems to increase water productivity. Agricultural Water Management 80 (1-3):100-116. 
Podwojewski, P. D. Orange, P. Jouquet, C. Valentin, V. T. Nguyen, J. L. Janeau, and D. T. Tran. 2008. Landuse impacts on surface runoff and soil detachment within agricultural sloping lands in northern Vietnan. Catena 74 (2): 109-118

Postel, S. L. 1998. Water for food production: Will there be enough in 2025? Bioscience 48 (8):629-637.

Prihar, S. S. S. K. Jalota, and J. L. Steiner. 1996. Residue management for reducing evaporation in relation to

soil type and evaporativity. Soil Use and Management 12 (3):150-157.
. Purkey, D.R. an . W. T. Tam, S. P. Wani, and T. D. Long. 2006. Effect of mulch on soil temperature, moisture, 作 weed infestation and yile of grouna and J. A. Foley. 2008. Farming the planet: 1. Geographic distribution Ramankutty, N.,A. T. Evan, C.Ms in the year 2000. Global Biogeochemical Cycles 22 (1):19.

of global agricultural lands in the Ramos, A. F. and F. L. Santos

grown in orchards in southern Portugal. Biosystems Engineering 102 (3):321-333. Ramos, A. F. and F. L. Santos. 2010. Yield and olive oil characteristics of a low-density orchard (c).

subjected to different irrigation regimes. Agricultural water and its relationship with aggregate stability to different disaggregation forces. Catena 53 (4):365-376.

to different disaggregation for . Schatz. 2007. Sustainable improvement of wheat yield potential: The role of crop management. Journal of Agricultural Science 145:55-61.

role of crop management. Jounal of As illa \&

( carbon on soil water retention. Geoderma 116 (1-2):61-76.

Reichert, J M. J A. Albuquerque. D. R. Kaiser, D. J. Reinert, F. L. Urach, and R. Carlesso. 2009a. Estimation f war Je Revista Brasileira De Ciencia Do Solo $33(6): 1547-1560$.

Reichert, J. M. Leas Suzuki, D. J. Reinert, R. Horn, and I. Hakansson. 2009b. Reference bulk density an critical de soils. Soil \& Tillage Research 102 (2):242-254.

Rho . chards, R. A. 2006. Physiological traits used in the breeding of new cultivars for water-scarce environments. Agricultural Water Management 80 (1-3):197-211.

id the 2001. Lucerne in crop rola A A Astralian Journal of Agricultural Research 52 (2):263-277.

Ritchie, J. T. and J. E Adams. 1974. Field measurement of evaporation from soil shrinkage cracks. Soil Science Society of America Journal 38 (1):131-134.

Sot constant when crop water supply is adequate of fixed: The role of agronomic management. European Journal of Agronomy 28 (3):273-281.

fixed: The role of agronomic managenent ckstrom, J. 2000. Water resources management in smallholder farms in eastern and southere 25 (3):275-283. view. Physics and Chemistry of the Earth Part $B$-Hydrology Oceans and Atmosphere $25(3) .275-283$. Rockstrom, J. and J. Barron. 2007. Water productivity in rainfed systems: Overview of chall. of opportunities in water scarcity prone sation Rockstrom, J., J. Barron, and P. Fox. 2002. Rainwater management for increased productivity among smas holder farmers in drought prone environments. Physics and Chemistry of the Earth 27 (11-22) avalability Rockstrom, J., M. Falkenmark, L. Karlberg, H. Hoff, S. Rost, and D. Gerten. 2009a. Future water anall Wate for global food production:

Reckstrom, J., P. Kaurnbutho, J. Mwalley, A. W. Nzabi, M. Temesgen, L. Mawenya, J. Barron, J. Muttua, and S. D., P. Kaurnbutho, J. Mwalley, A. W. Nar, S. Damgaard-Larsen. 2009b. Conservation farming strategies in east and soun 103 (1):23-32. rainwater productivity from on-farm action research. Soll d The Reser challenge of a new gren revolu-

Rockstrom, J., M. Lannerstad, and M. Falkenmark. 2007. Assessing the water Challenge of the United States tion in developing countries. P

Rodrigueric D. J. Nuttall, V. O. Sadras, H. van Rees, and R. Armstrong. 2006. Impact of subsoil constraints on whez, D., J. Natull, V. O. Sadras, H. van Rees, wheat yield and gross margin on fine-tex
Rosegrant, M. W., X. Cai, and S. A. Cline. 2002. World Water and Food to 2025: Dealing with Scarcity. Washington, DC, London: IFPRI, International Water Management Institute.

Rosegrant, M. W., C. Ringler, and T. J. Zhu. 2009. Water for agriculture: Maintaining food security under growing scarcity. Annual Review of Environment and Resources 34:205-222.

ost, S., D. Gerten, A. Bondeau, W. Lucht, J. Rohwer, and S. Schaphoff. 2008. Agricultural green and blue water consumption and its influence on the global water system. Water Resources Research 44 (9):17.

Roth, C. H. 1985. Infiltrabilität von Latossolo-Roxo-Böden in Nordparaná, Brasilien, in Feldversuche zur Erosionskontrolle mit verschiedenen Bodenbearbeitungssystemen und Rotationen. Göttinge Bodenkundliche Berichte 83, pp. 1-104, Göttingen.

Ryan, J. 2000. Plant nutrient management under pressured irrigation syst by in the Mediterranean region. In Proceedings of the IMPHOS International Workshop Organized by the World Phosphate Institute. Aleppo: ICARDA.

sadler, E. J., R. G. Evans, K. C. Stone, and C. R. Camp. 2005. Opportunities for conservation with precision irrigation. Journal of Soil and Water Conservation 60 (6):371-379.

as, V. O. and J. F. Angus. 2006. Benchmarking water-use efficiency of rainfed wheat in dry environments. Australian Journal of Agricultural Research 57 (8):847-856.

ras, V. O., G. J. O'Leary, and D. K. Roget. 2005. Crop responses to compacted soil: Capture and efficiency in the use of water and radiation. Field Crops Research 91 (2-3):131-148.

ko, F. K. and G. Tian. 2003. Soil water depletion under various leguminous cover crops in the derived savanna of West Africa. Agriculture, Ecosystems \& Environment 100 (2-3):173-180.

s, F. L. 1996a. Evaluation and adoption of irrigation technologies. 1. Management-design curves for furrow and level basin systems. Agricultural Systems 52 (2-3):317-329.

tos, F. L. 1996b. Quality and maximum profit of industrial tomato as affected by distribution uniformity of drip irrigation system. Irrigation and Drainage Systems 10:281-294.

tos. F. L. 1998. Evaluation of alternative irrigation technologies based upon applied water and simulated vields. Journal of Agricultural Engineering Research 69 (1):73-83.

antos, F. L., J. L. Reis, O. C. Martins, N. L. Castanheira, and R. P. Serralheiro. 2003. Comparative assessment of infiltration, runoff and erosion of sprinkler irrigated soils. Biosystems Engineering 86 (3):355-364.

sntos, F. L. and R. P. Serralheiro. 2000. Improving infiltration of irrigated Mediterranean soils with polyacrylamide. Journal of Agricultural Engineering Research 76 (1):83-90.

nntos, F. L., P. C. Valverde, A. F. Ramos, J. L. Reis, and N. L. Castanheira. 2007. Water use and response of a dry-farmed olive orchard recently converted to irrigation. Biosystems Engineering 98:102-114.

sasal, M. C., A. E. Andriulo, and M. A. Taboada. 2006. Soil porosity characteristics and water movement under zero tillage in silty soils in Argentinian Pampas. Soil \& Tillage Research 87 (1):9-18.

Sauer, T. J., J. L. Hatfield, and J. H. Prueger. 1996. Corn residue age and placement effects on evaporation an soil thermal regime. Soil Science Society of America Journal 60 (5):1558-1564

Svenije. H. H. G. 1997. Determination of evaporation from a catchment water balance at a monthly time scale. Hydrology and Earth System Sciences 1:93-100.

nije, H. H. G. 2004. The importance of interception and why we should delete the term evapotranspiration from our vocabulary. Hydrological Processes 18 (8):1507-1511.

scckler, D., D. Molden, and R. Sakthivadivel. 2003. The concept of efficiency in water-resources management and policy. Water Productivity in Agriculture: Limits and Opportunities for Improvement 1:37-51.

Mer, M. 2007. Uncertainty of factors determining runoff and erosion processes as quantified by rainfal simulations. Catena 71 (1):56-67.

A. A. 2001. Hydraulic and stomatal adjustment of Norway spruce trees to environmental stress. Tree Physiology 21 (12-13):879-888.

, T., J. Burke, and K. Villholth. 2007. Groundwater: A global assessment of scale and significance. In Water for Food, Water for Life: A Comprehensive Assessment of Water Management in Agriculture, edited by D. Molden, pp. 396-432. London, Colombo: Earthscan, International Water Management Institute.

ments M. A. Naeem, G. Jilani, and M. Shafiq. 2010. Integrated soil management in eroded land augments the crop yield and water-use efficiency. Acta Agriculturae Scandinavica Section B-Soil and Plant Shahidiance 60 (3): 274-282.

. Serralheiro, and L. L. Silva. 1998. Real time management of furrow irrigation with a cableS. system. In Water and the Environment: Innovation Issues in Irrigation and Drainage, edited by Sharma, P. K.

tillage and C. L. Acharya. 2000. Carry-over of residual soil moisture with mulching and conservation Rese practices for sowing of rainfed wheat (Triticum aestivum L.) in north-west India. Soil \& Tillage Rearch $57(1-2): 43-52$. 
Sharratt, B. S. 2002. Corn stubble height and residue placement in the northern U.S. Corn Belt Part I. Soil physical environment during winter. Soil \& Tillage Research 64 (3-4):243-252.

Shatanawi, M. R. 2007. Future options and research needs of water uses for sustainable agriculture. Options Méditerranéennes Series B (57):21-29.

Shaxson, F, A. H. Kassam, T. Friedrich, B. Boddey, and A. Adekunle. 2008. Underpinning the benefits of conservation agriculture: Sustaining the fundamental of soil health and function. In Workshop on Investing in Sustainable Crop Intensification: The Case of Soil Health. Rome: FAO

Shear, G. M. 1985. Introduction and history of limited tillage. In Weed Control in Limited-Tillage Systems, edited by A. F. Wiese. Champaign, IL: Weed Science Society of America.

Sheehy, J. E. 2000. Limits to yield for C-3 and C-4 rice: An agronomist's view. Redesigning Rice Photosynthesis to Increase Yield 7:39-52.

Shiklomanov, I. A. 1993. World freshwater resources. In Water in Crisis: A Guide to the World's Freshwater Resources, edited by P. Gleick, pp. 13-24. New York: Oxford University Press.

Shiklomanov, I. A. and J. C. Rodda. 2003. World Water Resources at the Beginning of the Twenty-First Centur. New York: Cambridge Univiversity Press.

Shinners, K. J., W. S. Nelson, and R. Wang. 1994. Effects of residue-free band-width on soil-temperature an water-content. Transactions of the ASAE 37 (1):39-49.

Shipitalo, M. J., W. A. Dick, and W. M. Edwards. 2000. Conservation tillage and macropore factors that affect water movement and the fate of chemicals. Soil \& Tillage Research 53 (3-4):167-183.

Silici, L. 2010. Conservation agriculture and sustainable crop intensification in lesotho. In Integrated Crop Management Vol. 10, edited by Plant Production and Protection Division. Rome: FAO.

Sillon, J. F., G. Richard, and I. Cousin. 2003. Tillage and traffic effects on soil hydraulic properties and evapor tion. Geoderma 116 (1-2):29-46.

Silva, L. L. 2010. Runoff under Sprinkler Irrigation: Affecting Factors and Control Practices. New York: Nove Science Publishers.

Singh, B. and S. S. Malhi. 2006. Response of soil physical properties to tillage and residue management on two soils in a cool temperate environment. Soil \& Tillage Research 85 (1-2):143-153.

Singh, G., S. K. Jalota, and B. S. Sidhu. 2005. Soil physical and hydraulic properties in a rice-wheat croppin ystem in India: Effects of rice-straw management. Soil Use and Management 21 (1):17-21.

Singh, R., J. C. van Dam, and R. A. Feddes. 2006. Water productivity analysis of irrigated crops in Sirsa districh India. Agricultural Water Management 82 (3):253-278

Six, J., C. Feller, K. Denef, S. M. Ogle, J. C. D. Sa, and A. Albrecht. 2002. Soil organic matter, biota and aggregation in temperate and tropical soils-Effects of no-tillage. Agronomie 22 (7-8):755-775.

So, H. B., A. Grabski, and P. Desborough. 2009. The impact of 14 years of conventional and no-till cultivtion on the physical properties and crop yields of a loam soil at Grafton NSW, Australia. Soil \& Tillage Research 104 (1): 180-18

Sojka, R. E. and D. L. Bjorneberg. 2002. Erosion, controlling irrigation-induced. In Encyclopedia of Soil Science, edited by R. Lal. New York: Marcel Dekker, Inc.

Solomon, K. and J. Keller. 1978. Trickle irrigation uniformity and efficiency. ASCE Journal of the Irrigation and Drainage Division 104 (IR3):293-306.

Solomon, K. H., D. C. Kincaid, and J. C. Bezdek. 1985. Drop size distributions for irrigation spray nozzles Transactions of the ASAE 28 (6):1966-1974.

Soriano, M. A., F. Orgaz, F. J. Villalobos, and E. Fereres. 2004. Efficiency of water use of early plantings of sunflower. European Journal of Agronomy 21 (4):465-476.

Steduto, P., T. C. Hsiao, and E. Fereres. 2007. On the conservative behavior of biomass water productivity Irrigation Science 25 (3):189-207

Steiner, J. L. 1989. Tillage and surface residue effects on evaporation from soils. Soil Science Society of Americ Journal 53 (3):911-916.

Stewart, J. L. 1991. Principles and Performance of Response Farming. Wallingford, CT: CAB International. Stewart, J. L. and D. A. R. Kashasha. 1984. Rainfall criteria to enable response farming through crop-based climate analysis. East African Agricultural and Forestry Journal 44:58-79.

Stone, L. F. and P. M. da Silveira. 1999. Effects of soil tillage on soil compaction, available soil water, and development of common bean. Pesquisa Agropecuaria Brasileira 34 (1):83-91.

Stone, L. R. and A. J. Schlegel. 2010. Tillage and crop rotation phase effects on soil physical properties in the West-Central Great Plains. Agronomy Journal 102 (2):483-491.

Strudley, M. W., T. R. Green, and J. C. Ascough. 2008. Tillage effects on soil hydraulic properties in space and time: State of the science. Soil \& Tillage Research 99 (1):4-48
Suleimenov, M. and K. Akshalov. 2007. Eliminating summer fallow in black soils of northern Kazakhstan. In Climate Change and Terrestrial Carbon Sequestration in Central Asia, edited by R. Lal, M. Suleimenov, B. A. Stewart, D. O. Hansen, and P. Doraiswamy. New York: Taylor and Francis Group.

Suyker, A. E. and S. B. Verma. 2009. Evapotranspiration of irrigated and rainfed maize-soybean cropping systems. Agricultural and Forest Meteorology 149 (3-4):443-452.

Tanaka, D. L., R. L. Anderson, and S. C. Rao. 2005. Crop sequencing to improve use of precipitation and synergize crop growth. Agronomy Journal 97 (2):385-390.

To, H. B. H. Brueck, K. Dittert, C. Kreye, S. Lin, and B. Sattelmacher. 2006. Growth and yield formation of rice (Oryza sativa L.) in the water-saving ground cover rice production system (GCRPS). Field Crops (1):1-12.

Tarboton, K. C. and W. W. Wallender. 1989. Field-wide furrow infiltration variability. Transactions of the ASAE

32 (3): $913-918$.
. and on unsaturated infiltration capacity of soils. Landtechnik 54 (1):13-15.

Tebrugge, F. and R. A. During. 1999. Reducing tillage intensity-A review of results from a long-term study in Germany. Soil \& Tillage Research 53 (1):15-28.

verira, F., G. Basch, and M. J. Carvalho. 2000. Tillage effects on splash detachment, overland flow and interril erosion. In Proceedings of the 4th International Conference on Soil Dynamics, edited by Agricultural Machinery Research and Design Centre, pp. Adelaide, SA.

Tennakoon, S. B. and N. R. Hulugalle. 2006. Impact of crop rotation and minimum tillage on water use efficiency of irrigated cotton in a Vertisol. Irrigation Science 25 (1):45-52.

Teuling, A. J., R. Uijlenhoet, F. Hupet, and P. A. Troch. 2006. Impact of plant water uptake strategy on soil moisture and evapotranspiration dynamics during drydown. Geophysical Research Letters 33 (3): L03401, 5 pp.

Thierfelder, C. and P. C. Wall. 2009. Effects of conservation agriculture techniques on infiltration and soil water content in Zambia and Zimbabwe. Soil \& Tillage Research 105 (2):217-227.

Thompson, A. L. and L. G. James. 1985. Water droplet impact and its effect on infiltration. Transactions of the ASAE 28 (5):1506-1510.

Thompson, R. L. 2007. Sustainability in the food \& agricultural sector: The role of the private sector and government. In Proceedings from the 40th IPC Seminar, Stratford-upon-Avon, UK (http://www.agritrade. orgevents/documents/2007SustainabilitySeminar_002.pdf (accessed Novenber 2, 2010).

Till, M. R. and M. G. Bos. 1985. The influence of uniformity and leaching on the field application efficiency. ICID Bulletin 34 (1):32-36.

evisan, R., F. G. Herter, and I. S. Pereira. 2002. Variação da amplitude térmica do solo em pomar de pessegueiro cultivado com aveia preta (Avena sp.) e em sistema convencional. Revista Brasileira de Agrociencia 8:155-157

out, T. J. and W. D. Kemper. 1983. Factors which affect furrow intake rates. In Proceedings ASAE on Advances in Infiltration, edited by American Society of Agricultural Engineers, pp. 302-312. St. Joseph, MI: ASCE

rout, T. J. and W. H. Neibling. 1993. Erosion and sedimentation processes on irrigated fields. Journal of Irrigation and Drainage Engineering-ASCE 119 (6):947-963.

Tut, T. J., R. E. Sojka, and L. I. Okafor. 1992. Soil management. In Management of Farm Irrigation Systems, ASAE Monograph No. 9, edited by G. J. Hoffman, T. A. Howell, and K. H. Solomon. St. Joseph, MI:

Turner, B. L.

Ar, B. L., E. Frossard, and A. Oberson. 2006. Enhancing phosphorus availability in low-fertility soils. In Biological Approaches to Sustainable Soil Systems, edited by N. Uphoff, A. S. Ball, E. Fernandes, et al. Boca Raton, FL: CRC Press.

indersander. D. J. and C. Regier. 1988. Effect of tillage and furrow irrigation timing on efficiency of preplant irigation Science 9 (1):57-67.

C. W. and M. F. Vigil. 1998. Cover crop effects on soil water relationships. Journal of Soil and Water Conservation 53 (3):200-207.

Boca Rat S. Ball, E. Fernandes, et al. (eds). 2006. Biological Approaches to Sustainable Soil Systems. phoff, $N$ aton, FL: CRC Press

Countries. Science Kassam. 2009. System of rice intensification (SRI). In Agriculture for Developing European. Sarience and Technology Options Assessment (STOA) Project, edited by R. Meyer. Karlsruhe: European Parliament, European Technology Assessment Group. 
Verhulst, N. B. Govaerts, E. Verachtert, A. Castellanos-Navarrete, M. Mezzalama, P. Wall, J. Deckers, and K. D. Sayre 2010. Conservation agriculture, improving soil quality for sustainable production systems? K. D. Sayre. 2010. Conservation agricures Security and Soil Quality, edited by R. Lal and B. A. Stewart, In Advances in Soil Science: CRC Press.

pp.
. W B. W. W. Nelson, and G. W. Randall. 1986. Extent and persistence of subsoil compaction caused by $W$. B., Woil Science Society of America Journal 50 (2):428-433.

by heavy axle loads. Soil Science Socieng. 2005. Fresh water, in ecosystems and human well-being: rösmarty, C. J., C. Lee Current states and trens.

E. M. Douglas, M. Mubck, and conventional and conserva-

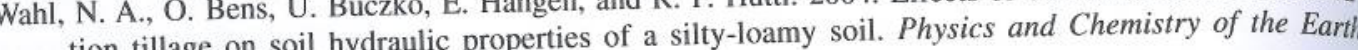
tion tillage on soil $11-12): 821-829$.

Walker. W. R. The V. Skr Irrigation: Theory and Practice. New York: Prentice-Hall Press.

Wang, Y. J., Z. K. Xie, S. S. Malhi, C. L. Vera, Y. B. Zhang, and J. N. Wang. 2009. Effects of rainfall harvesting and mulching technologies on water use efficiency

Agricultural Water Management 96 (3):374-382. Ward, P. R., K. Whisson, S. F. Micin, D. Zeelenberg, and S. P. Milroy. 20097

evaporation from a sandy soil. Crop \& Pasture Science 60 (8):730-737. hish, J. P. M., L. Price, and P. A. Castor. 20t5. Do spring \& Pasture Science 60 (6):517-525.

the northern grain zone of eastern Australia? Crop \& Pasture Scien. Linden. 2004. Crop and soil producilhelm, W. W., J. M. F. Johnson, J. L. Hatfield, W. B. Wure review. Agronomy Journal 96 (1):1-17.

tivity response to corn residue removal. A 2008. Residue impacts on runoff and soil erosion for different Wilson, G. V., K. C. McGregor, and D. Boykin. 200r. Res (2):300-307.

corn plant populations. Soil \& Wong, M. T. F. and S. Asseng. 2007. Yield and environt. Plant and Soil 297 (1-2):29-42.

variable rainfall in a Mediterranean envirat residue effects on water-stable aggregates. Soil \& Tillage Research 96:124-130.

Research 96:124-130.

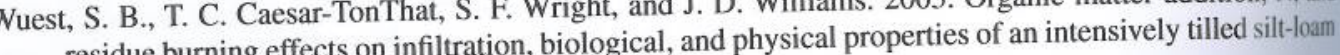
soil. Soil \& Tillage Research 84 (2):154-167.

soil. Soil \& Tillage Research 84 (2).1 2001. Land application of organic and inorganic fertilizer for corn Xiaobin, W., C. Dianxiong, and Z. Jingqing. China. In Sustaining the Global Farm, edited by D. E. Scott, R. H. in dryland farming region of North China Mohtar, and G.C. Steinhardt, Selected Papers from Ine University and the USDA-ARS National Soil Committee Meeting Held May 24-29, Erosion Research Laboratory. West Lafayette,

Yuan, C. P., T. W. Lei, L. L. Mao, H. Liu, and Y. Wh. 20

of different sized gravel. Catena 78 (2):117-121. Yunusa, I. A. M. and P.J. Newton. 2lant and Soil 257 (2):261-281.

The primer-plant concept. Plant and Soil 257 (2).261-281. W Wang. 2009. Effects of mulching and calch Zhang, S. L., L. Lovdahl, H. Grip, Y. N. Tong, X. Y. Yang, and Q. J. Wang. 20ess Plateau of China. Soil \& Tillay cropping on soil tempera
Research $102(1): 78-86$.

Zhang, X. Y., S. Y. Chen, M. Y. Liu, D. Pei, and H. Y. Sun. 2005. Improved water use efficiency as500isiald with cultivars and agronomic management in the North China Plain. Agronomy Journal with plastic film

Zhou, L. M., F. M. Li, S. L. Jin, and Y. J. Song. 2009. How two ridges and the furrow mulched with plast chere affect soil water, soil tem

Zu, R. H. J. S. Wu, D. Y. Huang, Q. H. Zhu, S. L. Liu, Y. R. Su, W. X. Wei, J. K. Syers, and Y. Li. 201 H. H., J. S. Wu, D. Y. Huang, Q. H. Zhu, S. L. Liu, Y. R. Su, W. X. Wil in subtropical China by incorf Improving fertility and productivity of a highly-weath

Thu rating rerts. 1991. Water-use evaluation u, J. C., C. J. Gantzer, S. H. Anderson, P. R. Beuselinck, and E. E. Alcenservation 46 (6):446-449. winter cover crops for no-till soybeans. Joumal of Soll and Warer Coter management? Agriculturat the Zoebl, D. 2006. Is water productivity a useful concept in agricultural water management? Ag
Management 84 (3):265-273.

Zwart, S. J. and W. G. M. Bastiaanssen. 2004. Review of measured crop w (2):115-133.

\section{Sustainable Management of Brackish Water Agriculture}

Paramjit Singh Minhas

\section{CONTENTS}

11.1 Introduction ......

1.2 Salinity/Alkalinity Hazards

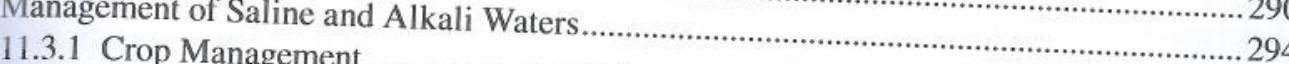

11.3.1.1 Selection of Crops

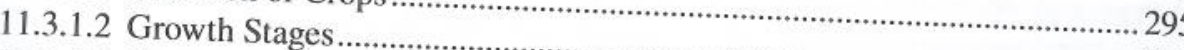

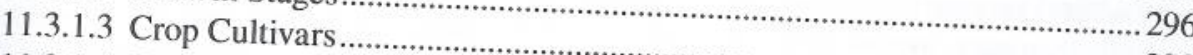

11.3.1.4 Environmental Factors .

11.3.1.5 Soil Texture

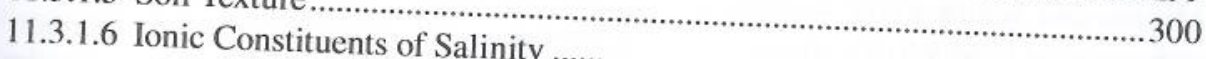

11.3.2 Water Manic Constituents of Salinity ……………….......................................... 300

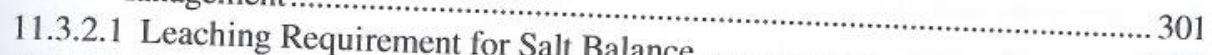

11.3.2.2 Farm Irrigation Management Balance ……………………...................... 301

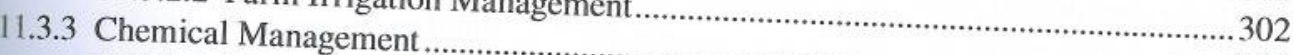

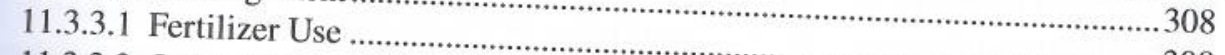

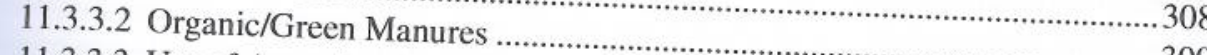

11.3.3.3 Use of Amendments

11.3.4 Cultural Practices

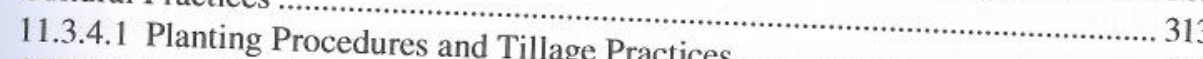

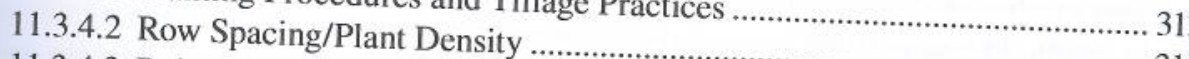

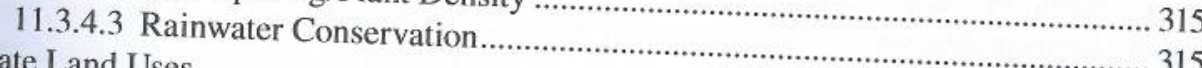

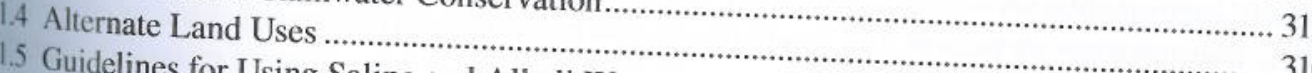

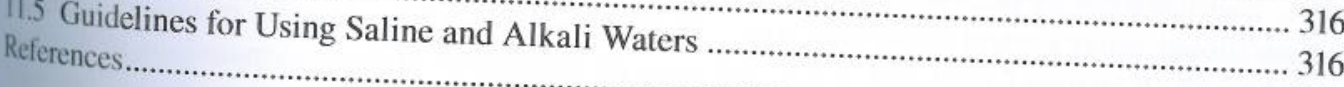

\subsection{INTRODUCTION}

Land irrigation is playing a major role in enhancing food and livelihood security the world over the

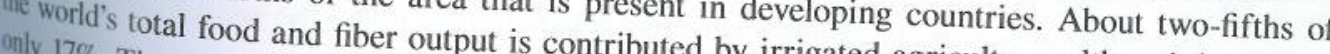
only 17\%. The FAO (2003) quifers $\left(-820 \times 10^{7} \mathrm{~m}^{3} / \mathrm{day}\right)$ is used for irrigativer withes, and and and semiarid regions largely depends upotion. In fact, the productivity of irrigated areas in increaser management and/or development of the ability to enlarge this resource base by better the shed manifold during the second half of groundwater. Globally, the aquifer withdrawal has the of groundwater used fecond half of the last century. For example, in the United States 2000 . an subcontinent, groum . $\mathrm{km}^{3}$ in 1950 to $240-260 \mathrm{~km}^{3}$ din , a typical scenario in the groundwater-irrigated regions $240-260 \mathrm{~km}^{3}$ during 